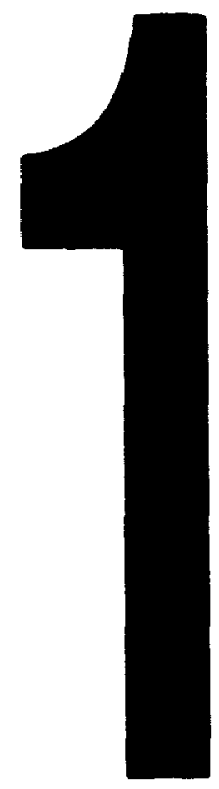

PM-1 31/2"14" PHOTOGRAPHIC MICROCOPY TARGET MES 1010 ANSI/ISO "2 EQUIVALENT

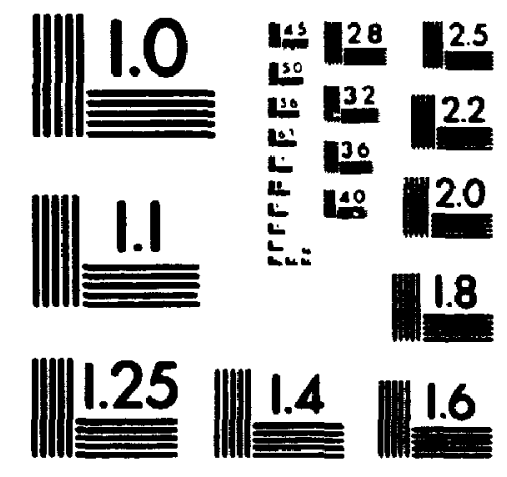

PRECISION 
Intertextuelle Anleihen volkstïmlicher Formeln in der Werbesprache: Sprichwörter und Redensarten in Anzeigen der Illustriertenwerbung

\author{
by \\ Biljana Veljovic
}

A Thesis submitted to the Faculty of Graduate Studies and Research in partial fulfilment of the requirements for the degree of

Master of Arts

Department of German

Carleton University

Ottawa, Ontario

01996

Biljana Veljovic 
National Lorary

of Canada

Acquisitions and

Bibliographic Services Branch

395 Wetungton Street

Otawa. Ontars

K1AONA
Bihliothéque nationale

du Canada

Direction des acquisitions et des senvices bibliographiques

395, ne Welington

Ontawa (Ontario)

KIA ONA

rout the vorre reterence

Ou tis motre reterence

The author has granted an irrevocable non-exclusive licence allowing the National Library of Canada to reproduce, loan, distribute or sell copies of his/her thesis by any means and in any form or format, making this thesis available to interested persons.
L'auteur a accordé une licence irrévocable et non exclusive permettant à la Bibliothéque nationale du Canada de reproduire, prêter, distribuer ou vendre des copies de sa thèse de quelque manière et sous quelque forme que ce soit pour mettre des exemplaires de cette these à la disposition des personnes intéressées.

L'auteur conserve la propriété du droit d'auteur qui protège sa thèse. Ni la thèse ni des extraits substantiels de celle-ci ne doivent être imprimés ou autrement reproduits sans son autorisation.

ISBN $\quad 0-612-13823-2$ 
Nome Biljana Veljović

Dissertation Absthacts Internotional is arranged by brood, general subject colegories. Floose selact the one subject which most neorty describes the content of your dissertation. Enter the corresponding four-digit cade in the spaces provided.

LANGUAGE - GeneraL $\frac{0161719}{\operatorname{sinteccos}} \mathrm{U} \cdot \mathrm{M} \cdot \mathbf{I}$

\section{Subipat Cotegories}

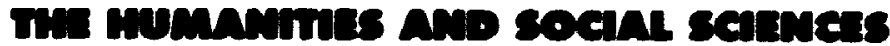

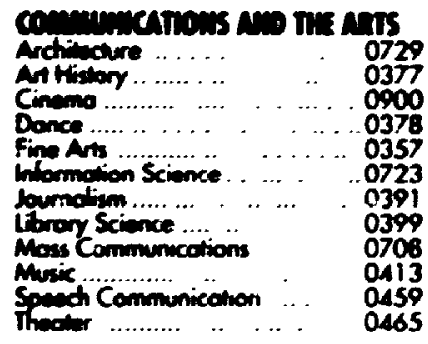

\section{Eucanom}

Generd ................ , 0515

Advil and Continuing $\quad 0516$

Agreutural ..... $\quad 0517$

Ant … ingud und Muliniculiurd. 0273

Eusiness

Communaty Colloge

Curricutum and imstruction

Eorty Childiood

Enmentory

Fincence

Gidence and Coumeling

Hoint

thish

Heme Economics

Home Eccingen

Industrial . and ineroture

Moiremolies

Music

Thilosophy of

Physicel?

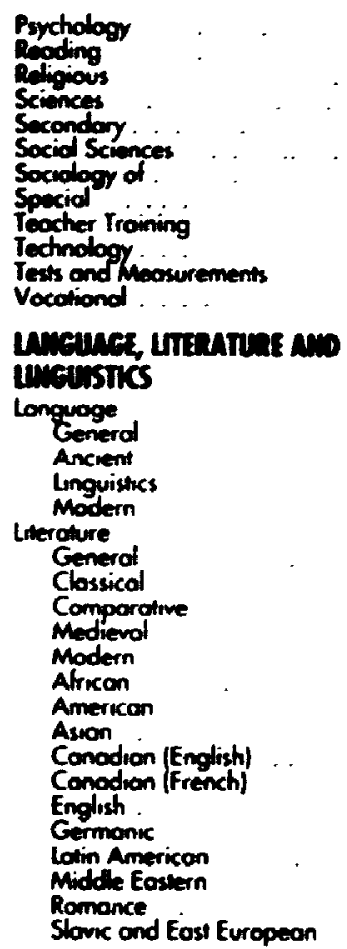

0525

0535

0527

0714

0536

0340

0530

0710

0268

0747

0679

0289

029

029

0401

0294

0297

0298

0316

0591

0305

0352

0593

0311

0312

315

0313 rimosamr, marem am

\section{Tianes}

Philosophy

Bublicel Studes

Clergy

Philorescity

Theology

\section{socun scarass}

Amerkon Sudies

Anthropology

Archoeology

Cuturd

Business Admurnstratron

Generd

Accounting

Bonking

Manogement

Comodion Strides

Economess

Geiverol

Agricultural

Commerce Business

Finonce

Mhislory

Theory

fottlore

Geogrophy

Gerontology

Histony

General

0422
0318
0321
0319
0320
0322
0469

0323

0324

0326

0327

0310

0272

0770

0338

0385

0501

0503

0.505

0508

0510

0358

0366

0351

0578

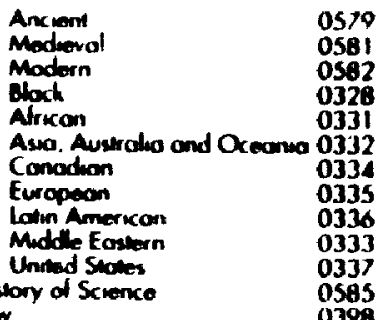

Low

Polfical Scuence

Generd

Inwornotional low and

Relotions

Public Adnunustrotion

Rocrection

Sacial Work

Soc rology

0626

Crmminatogy and Penology 0027

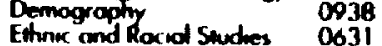

Irdrudual onus fanity

Studves

tndustrinal and tabor

Retatrons

Public and Sornd wollone 0650

Socroil Structure and

Developmont

Theory and Methods

Tromsporiction

0099

Womeri's Studies

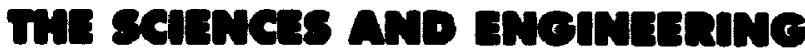

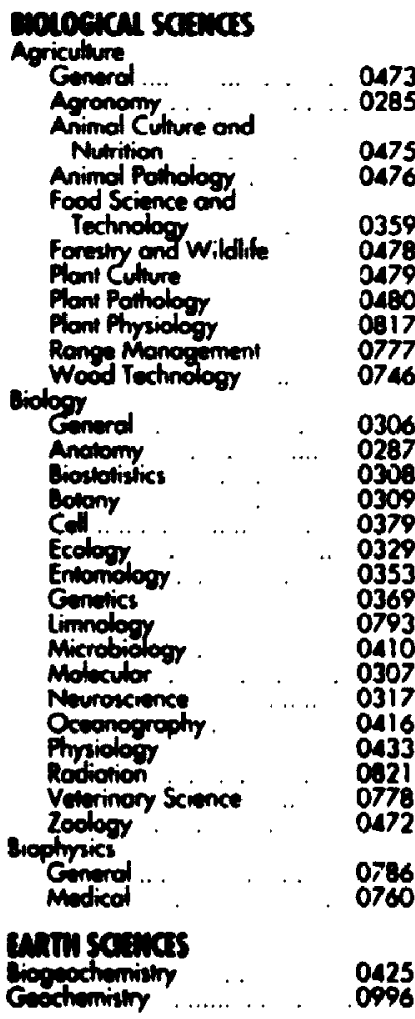

\begin{tabular}{|c|}
\hline 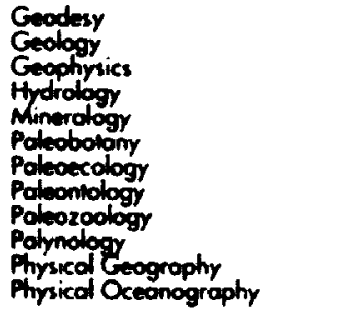 \\
\hline 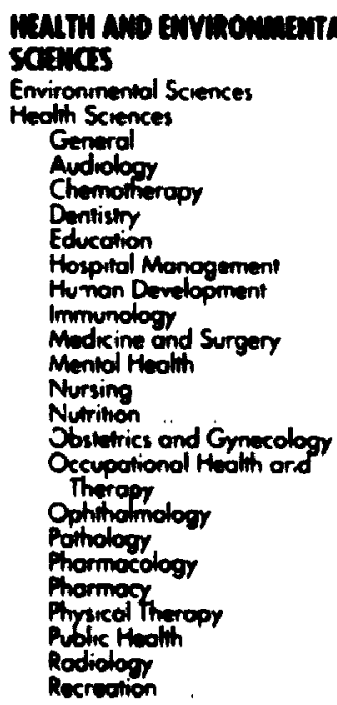 \\
\hline
\end{tabular}

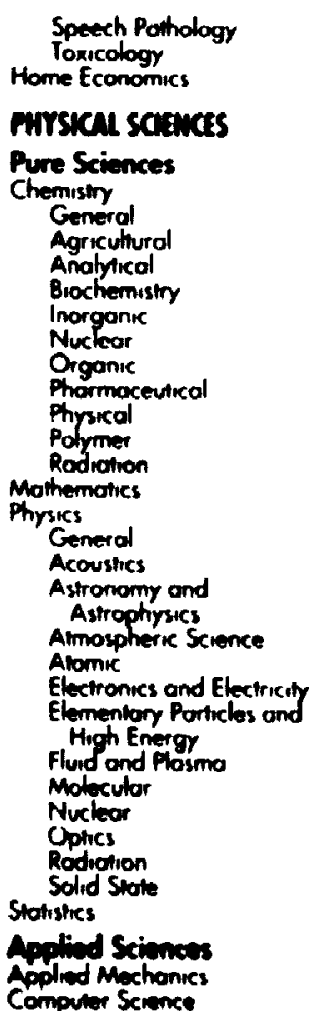

0460 0386

(1)

0485
0749
0486
0487
0489
0736
0490
049
049
0495
075
0405
0605
0986
0606
0606
0746
0607
0796
0759
0609
0610
0752
0756
0611
0463
0346
098
04

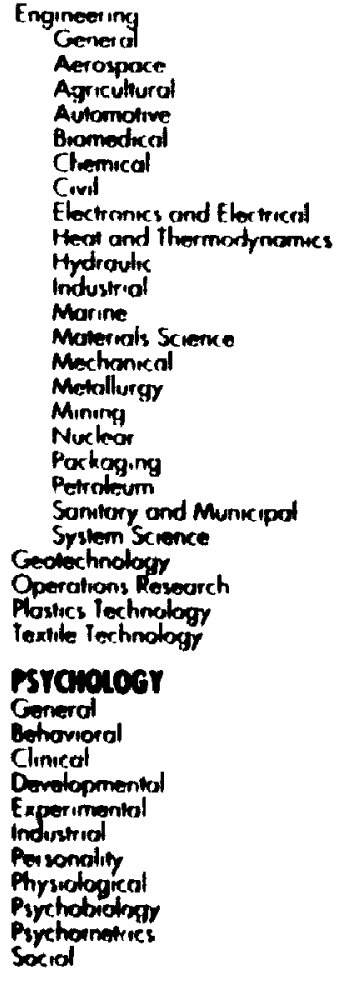

0537 0538 0535 0SA1 0542 OSA3 0544 0348
0545 0546 0547 0794 0743 0551 0552 0549 0765 0554 0428 0796 0795 0094 
The undersigned recommend to the Faculty of Graduate Studies and Research acceptance of the thesis

Intertextuelle Anleihen volkstümlicher Formeln in der Werbesprache: Sprichwörter und Redensarten in Anzeigen der Illustriertenwerbung

submitted by Biljana Veljovic, B.A.

in partial fulfilment of the requirements for

the degree of Master of Arts

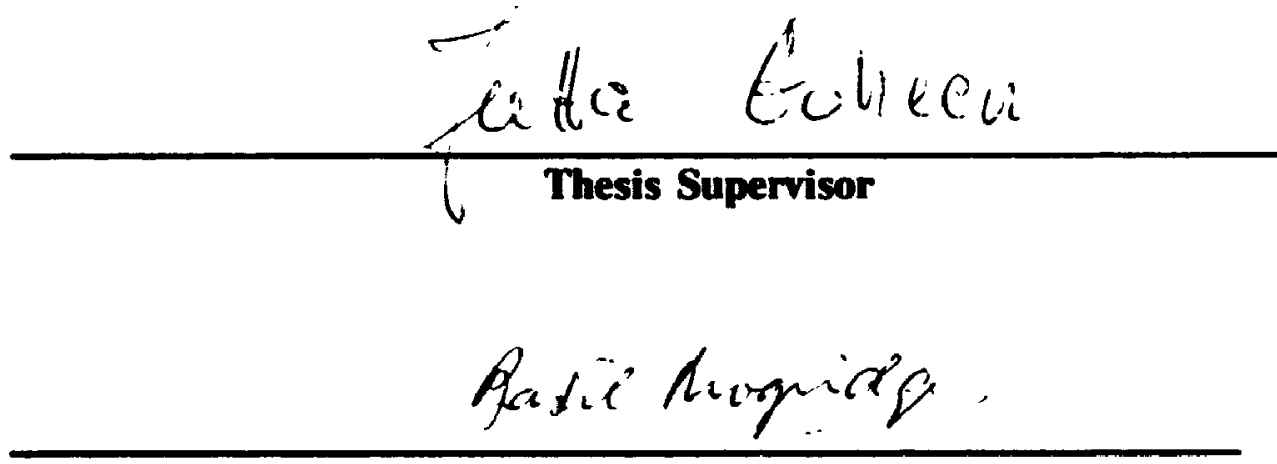

Chair, Department of German

Carleton University

May 15, 1996 
Prof. Dr. Jutta Goheen, die diese Arbeit betreut hat, verdanke ich eine Vielfalt von wertvollen Kommentaren und eine anteilnahmsvolle und durchgehende Unterstützung.

Für Dragan

In Nepean, den 17. April 1996 


\begin{abstract}
Diese Arbeit untersucht die Dynamik der intertextuellen Anleihen aus den Textsorten 'Sprichwort' und 'Redensart' in die Textsorte 'Werbeanzeige'. In der Ausgangshypothese habe ich angenommen, daß Sprichwörter und Redensarten innerhalb des Werbetextes seine epideiktische Absicht begünstigen. Diese Ansicht ist in theoretischen Untersuchungen zu diesem Thema stark vertreten. Um diese Hypothese zu bestätigen habe ich ein repräsentatives Korpus von Beispielen aus Illustriertenanzeigen zusammengestellt. Die Interessantesten Beispiele habe ich einzeln Analysien. Die Analyse des Korpus hat erwiesen, daß Sprichwörter und Redensarten in Illustriertenanzeigen relativ häufig vorkommen. Dieses Resultat weist darauf hin, daß Sprichwörter im Sprachbewußtsein der modemen Sprecher noch präsent sind, denn die Werbeanzeige verläßt sich auf ihre Wiedererkennbarkeit. Die Präsenz der Redensarten wurde nie in Fragegestellt. Daß beide Textsorten die Werbewirksamkeit fördern, hat sich sowohl aus dem theoretischen Hintergrund, als auch aus der Analyse der Beispiele ergeben.
\end{abstract}




\section{INHALTSVERZEICHNIS}

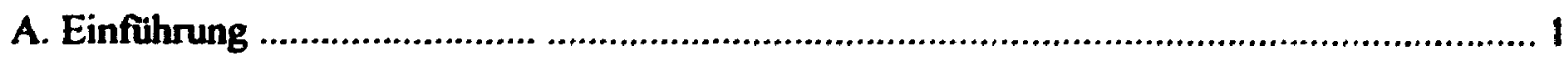

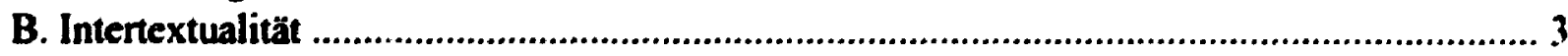

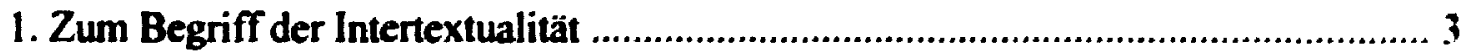

2. Fallstudie: Redensarten und Sprichwörter in der Werbung. ................................ 6

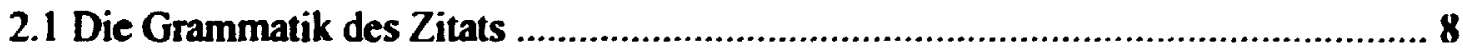

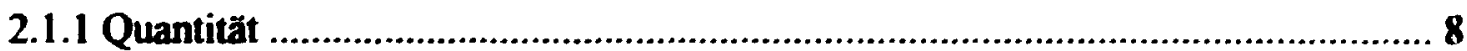

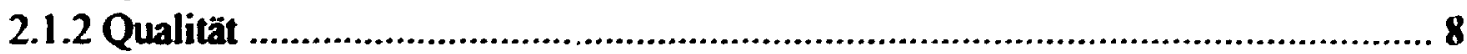

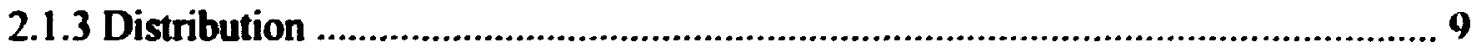

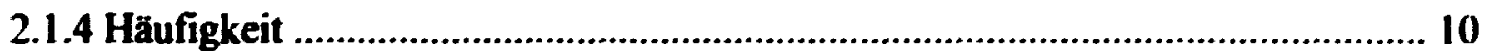

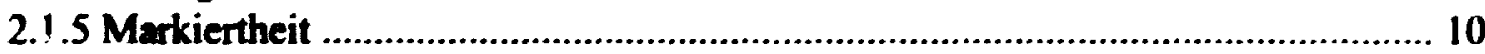

2.2 Die Pragmatik des Zitats .................................................................................... 10

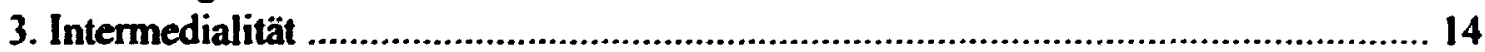

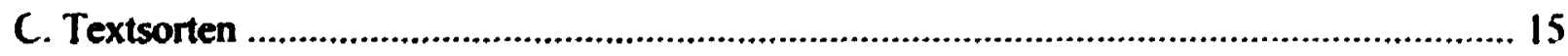

1. Volkstümliche Formeln: Sprichwort und Redensart .......................................... 15

1.1 Das Sprichwort ................................................................................................... 15

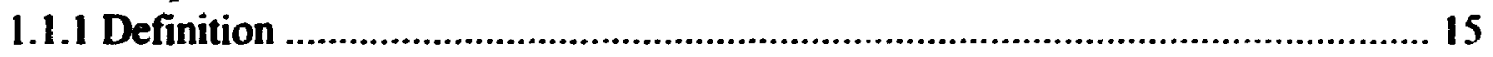

1.1.2 Herkunft des Sprichworts ............................................................................ 18

1.1.3 Stilistische Merkmale des Sprichworts ............................................................. 20

1.1.4 Inhaltliche Merkmale und Bedeutung des Sprichworts .................................. 25

1.1.5 Funktion, Gebrauchsweise und Wirkung des Sprichworts.. .............................. 26

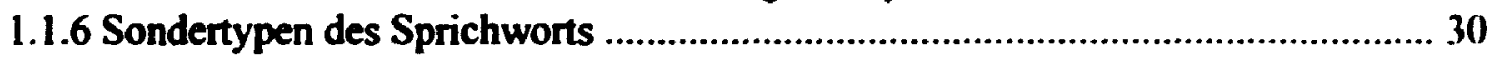

1.1.7 Verhältnis des Sprichworts zu ähnlichen Formen ........................................ 32

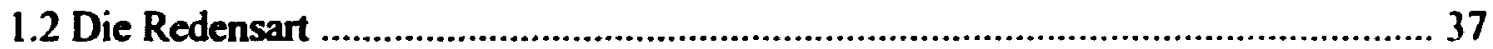

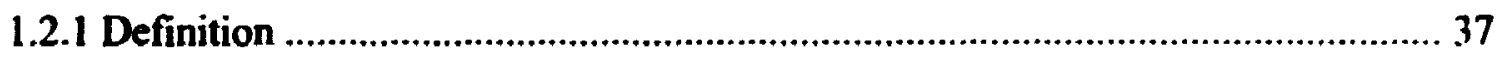

1.2.2 Abgrenzung der Redensart gegenüber anderen Wendungen ............................. 38

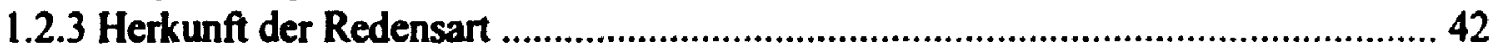

1.2.4 Stilistische Merkmale der Redensart ............................................................ 44

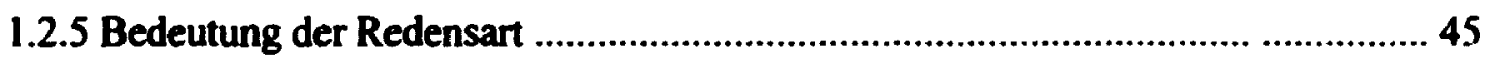

1.2.6 Funktion, Gebrauchsweise und Wirkung der Redensart .................................... 45

1.2.7 Gemeinsamkeiten und Unterschiede zwischen Sprichwort und Redensart .......... 46

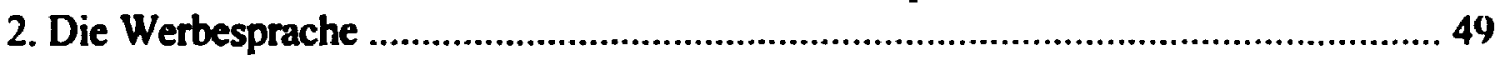

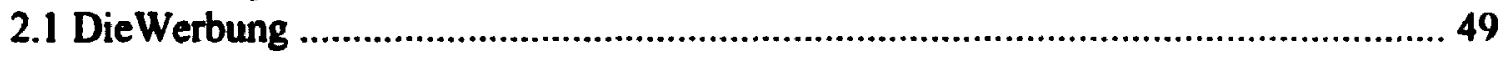

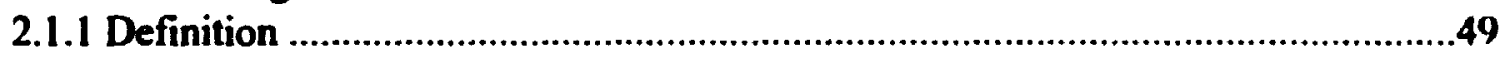

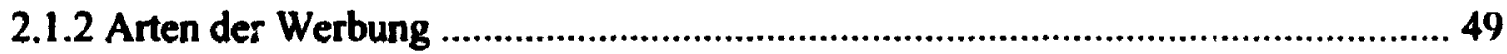

2.1.3 Verhältnis von Bild und Sprache in der Werbung .............................................5 50

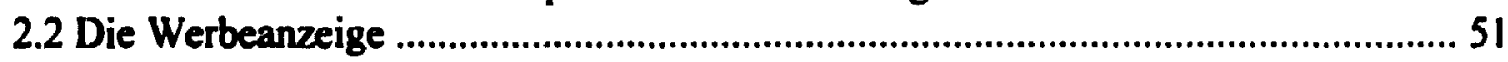

2.2.1 Definition der Werbesprache ............................................................................ 51

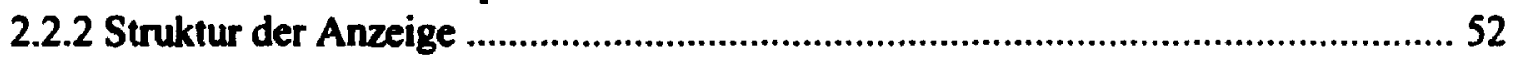

2.2.3 Merkmale der Werbesprache ............................................................................55

2.3 Pragmatik der Werbeanzeige: der Einfluß des Rezipienten auf die Werbe-

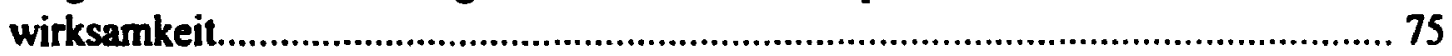

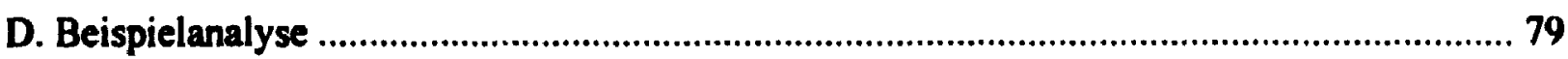

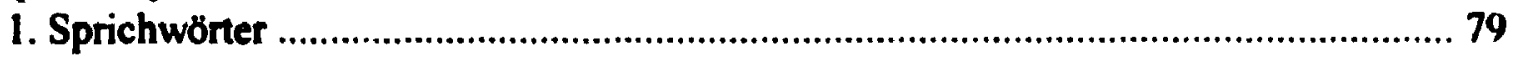


1.I Intertextulle Anleihe der Sprichwörter in der Form des Zitats ...................... 79

1.1.1 Wörtliche Übernahme der Sprichwörter ...................................................... 79

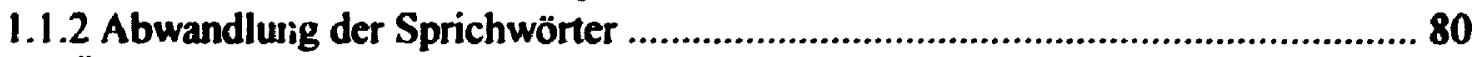

1.2 Übernahme oder Nachahrnung sprichwörtlicher Strukturen ............................. 83

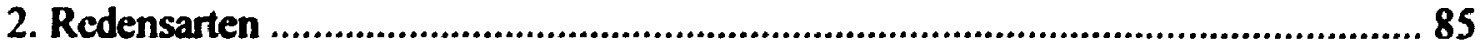

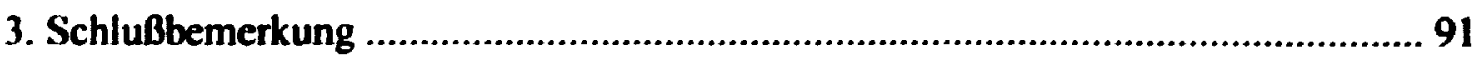

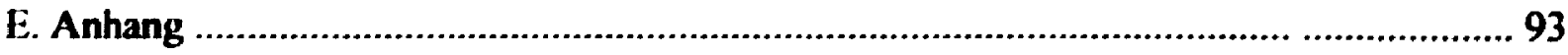

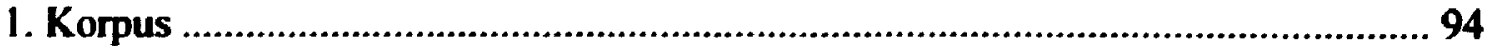

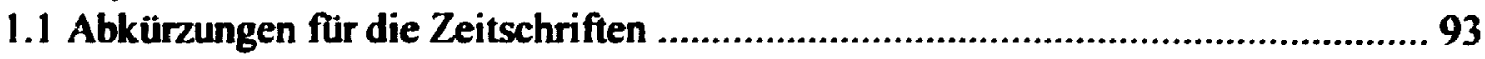

1.2 Beispiele von Sprichwörtern in der Werbung ..................................................... 95

1.2.1 Unveränderte Übernahme von Sprichwörtern ................................................... 95

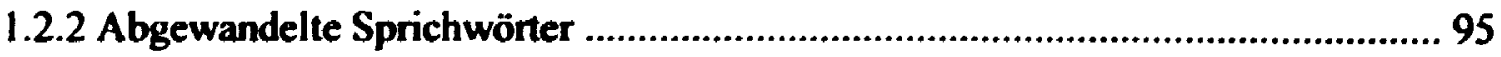

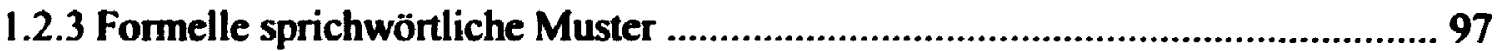

1.2.4 Inhaltliche sprichwörtliche Muster ................................................................ 99

1.3 Beispiele von sprichwörtlichen Redensarten und anderen phraseologischen Verbindungen in der Werbung ...........................................................................99

1.3.1 Sprichwörtliche Redensarten .............................................................................99

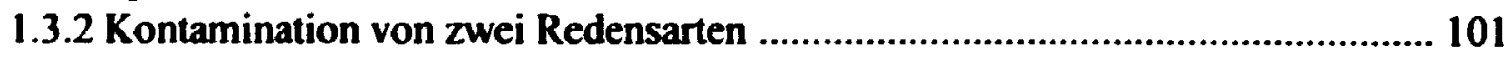

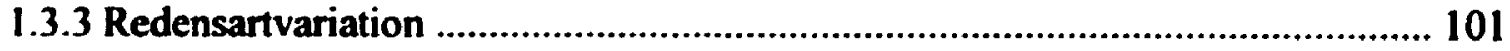

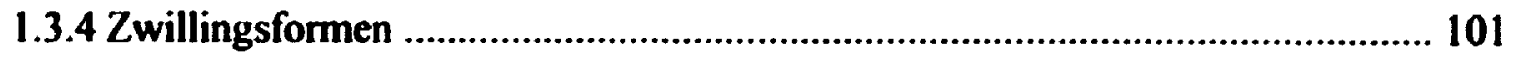

1.3.5 Nachahmung der Zwillingsformen ............................................................. 101

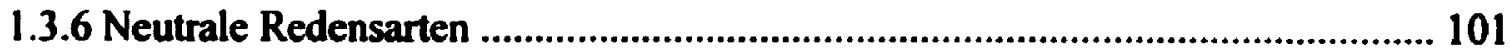

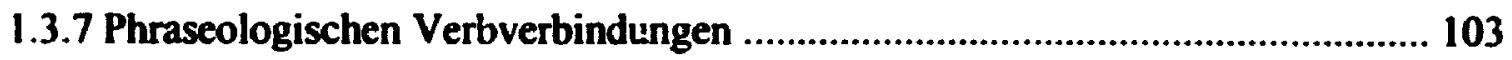

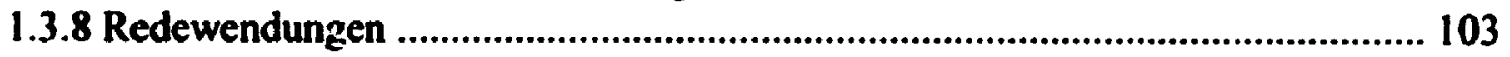

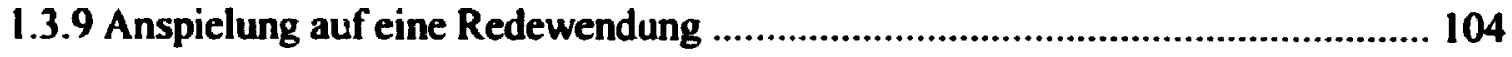

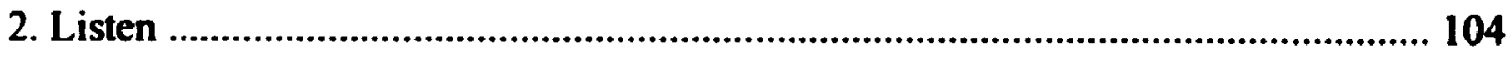

2.1 Liste der Sprichwörter nach dem Stichwort und der Numerierung von Wilhelm

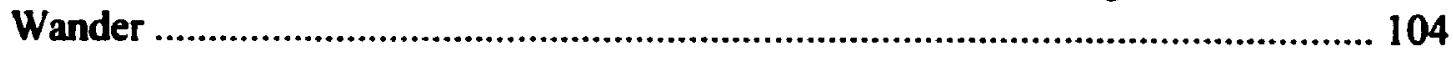

2.2 Liste der Sprichwörter nach Mustern mit dem Stichwort und der Numerierung von

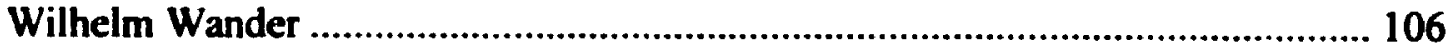

2.3 Liste der Sprichwörter nach dem Sprichwörterbuch von Beyer .......................... 104

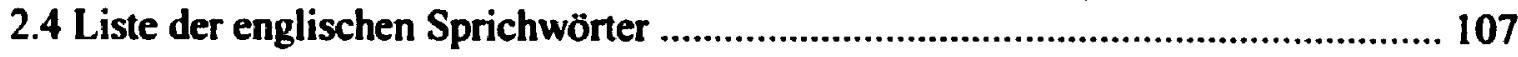

2.5 Liste der sprichwörtlichen Redensarten ................................................................ 107

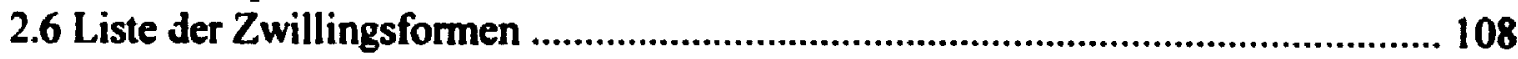

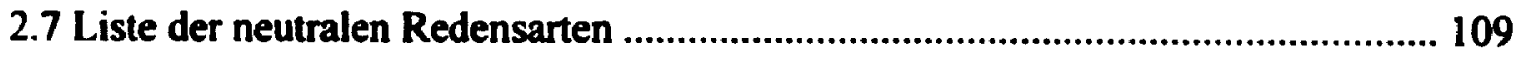

2.8 Liste der phraseilogischen Verbverbindungen ....................................................... 110

2.9 Liste der Redewendungen ............................................................................ 110

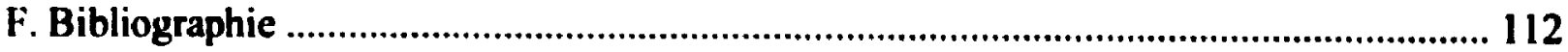




\section{A. EINFUHRUNG}

Die folgende Arbeit versucht, das Vorkommen von Sprichwörtern und Redensarten in Anzeigen der Illustriertenwerbung unter dem Aspekt der Intertextualität zu untersuchen. So stellt der Einsatz dieser volkstümlichen Formeln in einer Werbeanzeige einen Fall des intertextuellen Anleihens dar. Die Kategorisierung des Sprichworts als eigene Textsorte ist unproblematisch. Strittig könnte dagegen die Aufstellung der Redensart als Textsorte sein. Ihrer Bedeutung nach wird die Redensart als Teil des Lexikons einer Sprache bewertet. Bei dieser Überlegung jedoch habe ich die Form der Redensart, die aus mehreren Lexemen in fester Fügung besteht, als ausschlaggebend angesetzt. Damit stellt die Redensart eine dem Sprichwort ähnliche Textsorte dar. Ich bin von der Hypothese ausgegangen, daß die Dynamik der intertextuellen Anleihen sich als günstig für die Werbung erweist. In der bisherigen Forschung gab es schon Ansätze, die diese Hypothese bekräftigten. Mein origineller Beitrag sollte darin bestehen, diese theoretischen Ansätze, sowie meine eigent Hypothese, anhand von einem Beispielkorpus zu beweisen. Dabei habe ich mich für Werbeanzeigen aus den Illustrierten entschieden, erstens weil hier Anzeigen gedruckt vorliegen (im Gegensatz zum Radio oder Fernsehen), und zweitens wcil in dieser Form der Presse Anzeigen häufiger vorkommen als z.B. in Zeitungen. Die Auswahl der Zeitschriften sollte möglichst repräsentativ sein, doch diese Vorgabe kann im Ausland nur schwer erfullt werden, da wenige deutsprachige Zeitschriften zugängig sind. Um das Korpus zusammenzustellen, mußte ich die möglichen Beispiele zuerst identifizieren. Es hat sich eine Reihe interessanter Fälle der intertextucllen Mischung von 
Textsorten finden 'Werbeanzeige' und 'Sprichwort', bzw. 'Redensart' lassen. Es hat sich herausgestellt, daß Sprichwörter und Redensarten in Werbeanzeigen nicht nur direkt übernommen, sondern daß sie auch mehr oder weniger abgewandelt werden, oder daß nur ihre Muster in Anspruch genommen werden. Daher mußte das resultierende Korpus anschließend nach diesen Kategorien eingeordnet werden. Ich habe auf die statistische Bearbeitung der Daten verzichtet und deshalb kann ich nur aufgrund meines persönlichen Eindrucks Behauptungen über die Häufigkeit des Vorkommens betimmter Formen machen. Das Ergebnis der Analyse hat meiner Meinung nach die Ausgangshypothese bestätigt, indem sie gezeigt hat, wie die übernommenen Textosorten, nämlich die Sprichwörter und die Redensarten, als Teil des Werbetextes die Werbebotschaft auffallender, einprägsamer und 'aufnehmbarer' machen. 


\section{B. INTERTEXTUALITÄT}

\section{Zum Begriff der 'Intertextualitat'}

Intertextualität ist ein umstrittener Begriff, der vielfăltig interpretiert und gedeutet wird. In der Forschung gibt es keinen Konsensus darüber, was unter 'Intertextualität' eigentlich zu verstehen ist. Nach Pfister ist die Theorie der Intertextualität die Theorie der Beziehungen zwischen Texten (S.11). Darüber sind sich die Theoretiker einig. Umstritten jedoch ist, welche Arten von Beziehungen darunter subsumiert werden sollen. Und je nachdem, wieviel man darunter subsumiert, erscheint Intertextualität entweder als eine Eigenschaft von Texten allgemein oder als eine spezifische Eigenschaft bestimmter Texte oder Textklas.en. H.-P. Mai faßt die Lage zusammen, indem er, ăhnlich zu Pfister, awei widersprüchliche Definitionen der Intertextualität in der heutigen Forschung findet: "A poststructuralist approach uses the concept as a springboard for associative speculations about semiotic and cultural matters in general. On the other hand, traditional literary studies have seized upon the term to integrate their investigative interests in structures and interrelations of literary texts under a comprehensive, and fashionably sounding, catch-all term. These divergent interpretative interests cannot be reconciled theoretically." (S.51)

Beide Autoren unterscheiden also zwei Richtungen der intertextuellen Theorie. Man kann sagen, daß es beiden Gesichtspunkten um Bezüge zwischen Texten geht. Der poststrukturalistische Ansatz, den beide Forscher als ersten anfuhren, entwickelte sich 
zuerst unter progressiven französischen Intellektuellen und wurde dann von Gelehrten in den USA übernommen und weiterentwickelt. Die poststrukturalistische Schule ist als Reaktion auf den Positivismus und den schon als klassisch empfundenen Modernismus zu verstehen. Der Terminus 'Intertextualität' selbst wurde von Julia Kristeva geprägt und bezog sich in diesem Zusammenhang auf das, was sie, in Anlehnung an Bachtin, die Dialogizilät der Texte bezeichnete.' Jeder Text steht in gewissen Beziehungen zu Texten, die ihm vorausgehviı, und wird selber Stütze für zukünftige Texte. Es geht hier um den ganzen kulturellen Zusammenhang, nicht nur um literarische Texte. So Pfister: "Text ist hier also nicht nur die Aktualisierung eines Zeichensystems, sondern auch dieses selbst und ist darüber hinaus auch nicht mehr an das Zeichensystem der Sprache gebunden." (S.7-8) Eine solche Ausweitung des Textbegriffs fuhrt dazu, daß kein Text mehr nicht intertextuell ist. Somit ist Intertextualităt kein besonderes Merkmal bestimmter Texte oder Textklassen mehr, sondern mit der Textualität bereits gegeben. Damit ist jeder Text in jedem seiner Teile und Aspekte intertextuell. (ebenda)

Eine konservative Literaturwissenschaft lehnte die revolutionäre Wende in der Kultur ab und engte den Begriff der Intertextualităt wieder ein auf das, was schon immer als literarische Anleiheoder literarische Übernahme bekannt gewesen war, jetzt aber aus einem modernen Blickwinkel beobachtet wurde. Hier sahen die Literaturhistoriker und

I Julia Kristeva. "Bakhtine, le mot, le dialogue et le roman". In: Critique. Bd. 23 (1967): 438-465. 
Theoretiker eine Möglichkeit der besseren Systematisierung der Textsorten / Galtungen und des gewissenhaften Einsammelns der Fälle vom intertextuellen Anleihen. Pfister sieht die Intertextualität als "Oberbegriff für jene Verfahren eines mehr oder weniger bewußten und im Text selbst auch in irgendeiner Weise konkret greifbaren Bezugs auf einzelne Prătexte ${ }^{2}$, Gruppen von Prätexten oder diesen zugrundeliegenden Codes und Sinnsystemen, wie sie die Literaturwissenschaft unter Begriffen wie Quellen und Einfluß. Zitat und Anspielung, Parodie und Travestie, Imitation, Ütersetzung und Adaption bisher schon behandelt hat und wie sie nun innerhalb des neuen systematischen Rahmens prägnanter und stringenter definiert und kategorisiert werden sollen." (S.15) Diese Lage wird in vielen Beiträgen, die ich untersucht habe, zwar bedauert, aber die Autoren reduzieren ihren Ansatz ebenfalls auf die Untersuchung verschiedener Arten der Anleihc. ausgehend von der Klassifikation der Quellen- und Zieltexte nach Gattung, wie z.B. Dramen, Gedichte, usw., zur Betrachtung dessen, was eigentlich übernommen wird, wie z.B. literarische Figuren, Titeln, usw.), bis zu der Frage, ob es als direktes Zitat oder als Anspielung übernommen wird, und ähnliches. Die Forschung befaßt sich hauptsächlich mit literarischen Texten, selten werden die anderen Medien miteinbezogen. Pfister macht die gleiche Beobachtung: "Es ist dies das Konzept von Intertextualität, das den meisten der detaillierteren Studien zur Intertextualität zugrundeliegt." (S.15) Er meint das Konzept der Intertextualität, wo das Interesse den literarischen Quellen gilt. Pfister findet diese Lage in der Literaturwissenschaft nicht überraschend, "denn ein Konzept, das so

Prätext ist der Quellentext, d.h. der Text aus dem Material geschð̈ft wird. 
universal ist, daß zu ihm keine Alternative und nicht einmal dessen Negation mehr denkbar ist, ist notwendigerweise von geringem heuristischem Potential für die Analyse und Interpretation." (ebenda) Ich habe in dieser Arbeit ebenfalls den zweiten Ansatz als theoretischen Ausgangspunkt gewählt, denn letzten Endes ist für diese Arbeit die 'konkrete Anwendung' der Intertextualităt von Belang, da es hier um das Anleihen einer bestimmten Textsorte seitens einer anderen geht.

\section{Fallstudie: Redensarten und Sprichwörter in der Werbung}

Wenn Sprichwörter und Redensarten in Werbetexten eingesetzt werden, stellt es einen Fall des intertextuellen Anleihens dar: eine Textsorte wird in eine andere inkorporiert. Dabei sind bestimmte Wirkungen sowohl auf den Prätext wie auch auf den eigentlichen Text zu beobachten. Überhaupt läßt sich sagen, daßß Werbetexte gern zu anderen Textsorten greifen. Erstens kann eine bestimmte Textsorte, z.B. Comics, eine Anzeige dynamisieren, auffalliger und interessanter machen. Zweitens läßt sich dadurch die persuasive Illokution umen, wenn z.B. ein Dialog vorgetäuscht wird, in dem der eine Partner den anderen zum Kauf einer Ware überzeugen will.

Fleischer sieht Sprichwörter als "eigene Mikrotexte". (S.80) Im Vergleich zu den Redensarten sind sie "nicht im Lexikon einer Sprache als Benennungseinheiten gespeichert und werden dem zufolge nicht wie lexikalische Einheiten 'reproduziert', sondern wie andere Mikrotexte und Teiltexte (Gedichte und dgl.) 'zitiert'. " (ebenda) Da es sich also um die Transposition ganzer Texte handelt, scheint es besonders fruchtbar, 
die in Werbetexten übernommenen Sprichwörter als Zitate zu behandeln. Dabei stutze ich mich auf Pletts intertextuelle Untersuchung des Zitats. Er nennt seinen Versuch 'an intertextual case study'. Er meint: "This indicates that the quotation represents a material kind of intertextuality. Nut a structural rule. but a textual sign is being reproduced. The material quality of this textual sign can be verbal as well as non-verbal. As can be seen from these few remarks the quotation is obviously made up of a rather specific cluster of features, which makes it an almost ideal object for an intertextual case study ... ." (Plett, S.8) In seiner 'Grammatik des Zitats' unterscheidet Plett die folgenden Elemente:

i) den 'Zitattext', d.h. den Text, in dem das Zitat vorkommt (=Zieltext):

ii) den 'Prätext, d.h. den Text aus dem das Zitat genommen wird (=Quellentext);

iii) das Zitat selbst.

Er definiert das Zitat wie folgt: "A quotation repeats a segment derived from a pre-text within a subsequent text, where it replaces a proprie-segment." (S.9) Hier muß jedoch beachet werden, daß sowohl die Texte der Anzeigenwerbung als auch die Sprichwörter einige textsortenspezifische Merkmale aufweisen, die es nicht erlauben, diesc Systematisierung streng durchzuführen. Die Werbetexte sind in Einheiten aufgeteilt, wobei der prominenteste Teil, der Slogan, oft getrennt vom restlichen Text steht. Soll ein Sprichwort als Slogan vorkommen, steht es dann auch allein. Das bedeutet, daß in solchen Făllen das Zitat nicht in einen Zitattext eingebettet wird, wie es in der Literatur der Fall wäre. Es sei denn, der Slogan besteht aus mehr Text als nur einem Sprichwortzitat, was dann doch eine Einbettung darstellen würde. Das Sprichwort als Zitatmaterial weicht auch von üblichen literarischen Quellen ab. Um die Worte Fleischers 
zu wiederholen, stellt ein Sprichwort einen 'Mikrotext' dar, d.h. einen vollstăndigen Text. Aus einem Quellentext wird nicht ein Teil in Form des Zitats angeliehen, sondern ein ganzer Text. Zusammenfassend läßt sich sagen, daß ein Sprichwort als vollständiger Text intertextuell zu einem vollständigen Text anderer Sorte, d.h. Slogan werden kann. In anderen Fällen wird das Sprichwort in den Körper des Werbetextes eingebettet.

Plett befaßt sich im einzelnen mit den verschiedenen Merkmalen des Zitats (S.9-17).

\subsection{Die Grammatik des Zitats}

Die Grammatik des Zitats bezieht sich auf die formellen Eigenschaften des Zitats. Plett unterscheidet zwischen der Quantität, der Qualität, der Distribution, der Häufigkeit und der Markiertheit des Zitats.

\subsubsection{Quantität}

In der Regel bestehen Zitate aus morphologischen oder syntaktischen Einheiten. Seltener schließen sie größere Textausschnitte ein, und ausnahmsweise wird der ganze Prätext zitiert. Im Falle des Sprichworts haben wir eine syntaktische Einheit, die gleichzeitig den ganzen Prätext darstellt.

\subsubsection{Qualităt}

Das Zitat wird nicht immer ohne Änderungen in den Zitattext eingesetzt. Im Gegensatz zu den wissenschaftlichen Texten oder juristischen Texten, die so treu wie möglich zitieren sollen, zeigen poctisce Texte ihre spezifische Natur darin, daß sie textuelle 
Elemente nicht ohne Änderungen inkorporieren. sondern diese Elemente umformen, um sie mit neuer Bedeutung zu erfüllen: "intertextual deviations, like intratextual deviations, can be described in a secondary grammar." (S.9) Plett unterscheidet zwei Ebenen. auf denen das Zitat Abweichungen aufweisen kann. Diese wären dann die Ebene des Ausdrucks und die Ebene des Inhalts. Um eine andere Terminologie heranzuziehen. entsprechen diese Ebenen der Oberflächen- und Tiefenstruktur. Auf der Oberfläche können Zitate denselben Transformationen ausgesetzt werden, die die rhetorische Analyse unterscheidet, nämlich der Adjunktion, Detraktion. Substitution, Permutation und Wiederholung. Plett stellt noch einen Vergleich zur Rhetorik auf: "An approach to the aspects of the intertextual deep structure of quotations allows a comparison to rhetoric as well. The p:ocedure of quoting resembles that of tropification, since the resulting text always lends itself to two interpretations, namely a literal and a non-literal one. ..." (ebenda)

Hier ist zu merken, daß dieselben rhetcrischen und stilistischen Verfahren, dic als Merkmale der Sprichwörter und Redensarten im Vergleich zur 'Standardsprache' festgestellt wurden, wieder auf den ursprünglichen Wortlaut der Sprichwörter und Redensarten angewandt werden können, um eine sozusagen 'doppelte/zweifache Stilisiertheit' dieser Formen im Werbetext zu erreichen.

\subsubsection{Distribution}

Ein Zitat kann entweder am Anfang, in der Mitte oder am Ende eines Textes vorkommen. 
Dies trifft auch für den Werbetext zu, denn er ist ebnfalls dreifach gegliedert. In den meisten Fällen steht das Zitat entweder im Slogan oder am Anfang des Werbetextes, wo es ins Auge fallt.

\subsubsection{Häufigkeit}

Dieses Kriterium ist mit dem der Distribution verwandt und bezieht sich auf die Häufigkeit von Zitaten in einem Text. Da ein Werbetext aus werbepsychologischen Gründen nicht zu lang sein darf, findet man nie mehr als ein Zitat einer Textsorte, d.h. ein Sprichwortzitat und ein Redensartzitat. Beide Textsorten können aber in einer Anzeige zusammen vorkommen.

\subsubsection{Markiertheit}

Zitate können markiert oder unmarkiert eingesetzt werden. Dazu können die markierten Zitate entweder explizit oder implizit markiert werden. Explizit markiert werden Zitate, die mit einem performativen Verb eingefüht werden, z.B. "Ich zitiere: ...", oder bei denen die Quelle angeführt wird. Zitate werden implizit markiert durch Anführungszeichen, durch Kursivschreibung und weitere graphemische Mittel. Für die hier untersuchten Textsorten der Redensarten und Sprichwörter gilt, daß sie nie markiert werden, denn ihr Einsatz beruht auf der Annahme, daß sie als volkstümliches Sprachgut so wohl bekannt sind, daß sie sofort erkannt werden. Als markiert können sie nur innerhalb der direkten Rede vorkommen, d.h. wenn sie jemandem in den Mund gelegt werden. 


\subsection{Die Pragmatik des Zitats}

Von der Grammatik der Zitate unterscheidet Plett auch eine Pragmatik der Zitate. Dic Pragmatik würde solche Faktoren wie Sender, Empfänger, Kode, On. Zeit, Medium. Funktion, usw. beruicksichtigen. Der Sender bestimmt die Intention oder Funktion des Zitats. In Anlehnung an Morawski (Morawski, S.692-695) unterscheidet Plett vier 'functional modes', d.h. Intentionen, mit denen der Sprecher/Autor ein Zitat gebraucht. Bei den ersten zwei, dem autoritativen (authoritative) und dem gelehrten (erudite) Zitat. ist der Sprecher gezwungen oder verpflichtet, aus einer autoritativen oder gelehrten Quelle zu zitieren. Dagegen sind das ornamentale (ornamental) und das poetische (poetic) Zitat nicht den normativen Kräften der kommunikativen Situation unterworfen. Das ornamentale Zitat wird in aller Art des Gelegenheitsdiskurses (occasional discourse) angewandt: in Briefen, in der Anzeigenwerbung, in feierlichen Reden, Feuilletons, usw. Über das poetische Zitat sagt er: "As compared to the non-poetic types of quotation, the poetic quotation is characterized by its lack of an immediate prictical purpose. Such a purpose can, however, be achieved, when a politician, a journalist or a salesman employs a poetic quotation in a non-poetic text. In this case the poetic quotation is depoeticized, i.e. divested of its autotelic function and invested with the practical function of the respective quotation context." (S.14) Innnerhalb dieser Systematisierung stellen Sprichwörter und Redensarten im Werbetext Fälle des ornamentalen und 'depoetisierten' Zitats dar. Die Zwecke und Wirkungen der Redensarten und Sprichwörter in Werbeanzeigen werden im Abschnitt über die Werbesprache behandelt. Von den intertextuellen Aspekten wird in der Beispielanalyse die Rede sein. 
Um eine Wirkung auszulösen muß das Zitat vom Leser erkannt und identifiziert werden. "The receiver, i.e. the listener or reader, who comes across a quotation text, may either notice the quotations or he may not. If he overlooks them, the text misses its purpose which consists in opening up dialogues between pre-texts and quotation texts." Plett meint, daß deshalb beide, der Autor und der Leser, über genug Hintergrundwissen verfügen müssen. (ebenda) Meiner Meinung nach ist die Frage des Hintergrundwissens nur bei ornamentalen und poetischen Zitaten von Belang. Das autoritative und das gelehrte Zitat brauchen nicht vorher bekannt zu sein, denn sie dienen ja zur Vergrößerung und Unterstützung des Wissens. Ob das ornamentale oder poetische Zitat richtig 'ankommt', liegt außer der Kontrolle des Autors, denn er kann das Vorwissen des Lesers nur vermuten, aber nie wirklich kennen. Er kann nur hoffen, daß seine intendierte Botschaft empfangen wird. Nur im Leser existiert der Text. Der Text versälbstständigt sich gegenüber der Autorenintention. Dadurch wird der Intertext, der in der Rezeption des Lesers entsteht, ein dynamisches Konstrukt. Bleiben die intertextuellen Verweise und Anspielungen unerkannt, ist die Intention des Autors auch nicht erfüllt. Auch der Leser kann nur vermuten, welche Intention des Autors sich hinter dem Zitat verbirgt, aber kann es nie richtig wissen. Dazu Pfister: "Poststrukturalistische Konzepte der Intertextualität gehen, hierin im Einklang mit der Rezeptionsästhetik, vom Leser eher als vom Autor aus." (S.20) Darüber hinaus werden "im Rahmen der poststrukturalistischen Theoriebildung" die Unterscheidung zwischen Autor, Text und Leser "bewußt dekonstruiert". (S.21) Weiter argumentiert Pfister gegen pedantisches Suchen nach Autorintention oder Leserrezeption: "Innerhalb solcher umfassender Funktionsmodelle 
für den universalen Intertext ... spielen Erwägungen. ob ein Autor einen bestimmten Text gekannt hat und sich bewußt und intentional auf ihn bezieht und ob der Rezipient uber das gleiche Textrepertoire verfügt wie der Autor, keine oder eine nur untergeordnete Rolle." (S.22-23) Fragen nach dem Wissen und den Intentionen des Autors, nach der Textintentionalităt und nach den Informationsvorgaben beim Rezipienten und der Rezeptionssteuerung durch den Text selbst, wie sie konkreten Aktualisierungen des intertextuellen Beziehungspotentials zugrundeliegen, bleiben angesichts der Dezentrierung der Subjekte und der Entgrenzung der Texte belanglos, und stellen einen Rückfall in bürgerlich-humanistische Mythen dar. Gerade auf solche Fragen lenken jedoch die strukturalistisch oder hermeneutisch orientierten approaches zur Theorie und Erforschung der Intertextualität zurück. Diese prinzipiellen Überlegungen mögen uns als überflüssig vorkommen, denn Redensarten und Sprichwörter, wie oben schon erwähnt, stellen wohl bekanntes Sprachgut dar, und können vom Leser meist sofort erkannt werden.

Außer der Frage nach den Merkmalen des Zitats und der Rezeption des L esers ergibt sich die Frage nach der Integration des Zitats in den Text. Für Lindner gibt es cine Skala von 'Integrations' - Möglichkeiten, die von nahtloser Einordnung, bis zur Entstehung von kontextuellen Inkompatibilităten reicht. (S.118) Die Werbeanzeige sucht keinen Bruch im kommunikativen Akt. Sie strebt nach völliger Integration der Sprichwort- und Redensartzitate in den restlichen Werbetext. Die Tatsache, daß Sprichwörter und Redensarten im Slogan graphisch isoliert und hervorgehoben werden, andert nichts an 
diesem Streben. Nur durch völlige Integration läßt sich die Epideixis, d.h. die persuasive intention tarnen.

\section{Intermedialităt: Illustration der Sprichwörter und Redensarten}

Es war bisher von 'Intertextualität' die Rede. Der Versuch, Sprichwörter und Redensarten zu illustrieren, stellt einen Fall der sogn. 'Intermedialităt' dar: Formen, die zum sprachlichen Medium gehören. werden in das bildliche Medium übersetzt. Die Bildhaftigkeit der Sprichwörter und Redensarten hat die Maler und Graphiker immer wieder veranlaßt, das sprachliche Bild ins visuelle Bild zu übertragen.(Röhrich/Mieder, S.98) In früheren Zeiten woliten die Künstler die Narrheit und Bosheit der Menschheit auf eine lehrhafte Weise darstellen, im Einklang mit dem damaligen Einsatz der Sprichwörter und Redensarten in der Literatur. (Beyer, S.11) Heutzutage wird die sprichwörtliche und redensartliche lllustration in der politischen Karikatur satirischkritisch eingesetzt. Röhrich/ Mieder meinen, daß das "Surreale, von der Wirklichkeit abweichende ... in hohem Maße die Aufmerksainkeit auf sich [lenkt]. Und dies soll und will die Sprache der industriellen Werbung ebenso wie die der politischen Propaganda." (S.98) In dieser Untersuchung wird die Beziehung von Bild und Text in einzelnen Werbeanzeigen im Abschnitt D. BEISPIELANALYSE besprochen. 


\section{DIE TEXTSORTEN}

\section{Volkstümliche Formeln: Sprichwort und Redensart}

\subsection{Das Sprichwort}

\subsubsection{DEFINITION}

"Eine endgültige Definition des Sprichworts liegt immer noch nicht vor", stellen Röhrich/Mieder fest. (S.1) Sie versuchen aber unter den vielen Definitionen, die vorliegen, einige aufschlußreiche hervorzuheben. Zuerst zitieren sie Friedrich Seiler. der in seinem m. gebenden Werk Deutsche Sprichwörlerkunde (S.2) unter Sprichwörtern "im Volksmund umlaufende, in sich geschlossene Sprüche von lehrhafter Tendenz und gehobener Form" versteht. Hier wird also die 'Volkläufigkeit' als eines der Merkmale der Sprichwörter hervorgehoben. Die neuere Forschung teilt diese Ansicht, aber die lehrhafte Tendenz, die bei Seiler als zweites definierendes Merkmal betont wird, ist umstritten. So sagt Jolles dazu: "Der Spruch [d.h. Sprichwort - B.V.] ist nicht lehrhaft, er hat keinen lehrhaften Charakter, er hat selbst keine lehrhafte Tendenz." (S.158) Er qualifiziert diese Aussage, indem er hinzufügt, daß wir aus der Erfahrung lernen können, aber daß in der Welt, von der wir reden, die Erfahrung nicht als etwas aufgefaßt wird, woraus wir lernen sollen. Alles Lehrhafte ist ein Anfang, etwas, worauf weiter aufgebaut werden soll - die Erfahrung in der Form, in der sie der Spruch [das Sprichwort] faßt, ist ein Schluß. Ihre Tendenz ist rückschauend, ihr Charakter ist resignierend. Eine lehrhafte Tendenz wird 
aber von einigen Forschern bestätigt. So hat Mathilde Hain zwischen 1938 und 1943 in einem hessischen Dorf die 'Volkssprache' untersucht, wobei sie ihr "Augenmerk auf die geformten Bausteine, ... auf Sprichwort, Bild und Eormel" richtet. (S.10) Sie polemisiert gegen die statischen Auffassungen von Jolles, indem sie auf der Notwendigkeit einer dynamischen Betrachtungsweise besteht. Nur wenn eine sprachliche Gestalt im Gewebe von sozialen Beziehungen innerhalb einer Gruppe untersucht wird, kann die Problematik ihrer moralischen Funktion richtig gesehen werden. (S.42) Sie betont, daß jedesmal die Situation, nicht die Sprachform als solche, dem Sprichwort einen lehrhaften Charakter gibt. (S.43) Weiter führen die oben genannten Autoren auch Lutz Röhrich (S.9) ein, der das Sprichwort definiert als "einen festgeprägten Satz, der eine unser Verhalten betreffende Einsicht oder eine Aufforderung zu einem bestimmten Verhalten ausspricht". Über das genannte syntaktische Merkmal hinaus beschließen Röhrich/Mieder, daß in den Definitionen der letzten Jahre betont wird, wie "es sich beim Sprichwort um einen vollständigen und festen Satz handelt". (S.2) Zum Schluß bieten sie eine eigene Definition, die sie 'Arbeitsdefinition' nennen: "Sprichwörter sind allgemein bekannte, festgeprägte Sätze, die eine Lebensregel oder Weisheit in prägnanter, kurzer Form ausdrücken." (S.3) Im Reallexikon der deutschen Literaturgeschichte spiegelt Gustav Bebermeyer die Feststellung von Rörich/Mieder wider, in dem er die Vielfalt der Sprichwortdefinitionen betont: "Das Sprichwort hat im Laufe der Zeit eine große Zahl

Volkswort zu sein, nicht im ganzen Volke gangbar sein muß. Viele Sprichwörter sind nur in einem bestimmten geographischen Gebiet oder in einer sozialen Gruppe im Gebrauch. 
meist unvollständiger, einseitiger Definitionen erfahren. Lehrhafte Tendenz und Wirkung, sowie Volkstümlichkeit fordern nahezu alle; übereinstimmend gilt das Sprichwort als Ergebnis praktischer Lebenserfahrung wie Ausdruck der Volksmoral."

(S.133) Für Jolles ist das Sprichwort keine selbständige Kategoric. sondern cine Vergegenwärtigungsform des Spruches: "Damit ist ... gesagt. daß es eine cinfache Form gibt, die wir Spruch nennen, und daß sich diese einfache Form vergegenwärtigt in einem Sprichwort". (S.155) Nach seiner Definitionheißt also Spruch (und damit auch Sprichwort): "die literarische Form, die eine Erfahrung abschließt, ohne daß diese damit aufhört, Einzelheit in der Welt des Gesonderten zu sein. Sie bindet diese Welt in sich. ohne sie durch ihre Bündigkeit der Empirie zu entheben". (S.156) Bausinger kommt zu einer "vorsichtigen Definition", die das Sprichwort als eine "partiell gilltige Lebensregel analogischer Struktur" betrachtet. (S.103) Im Begrif 'Regel' treffen sich Sein und Sollen:

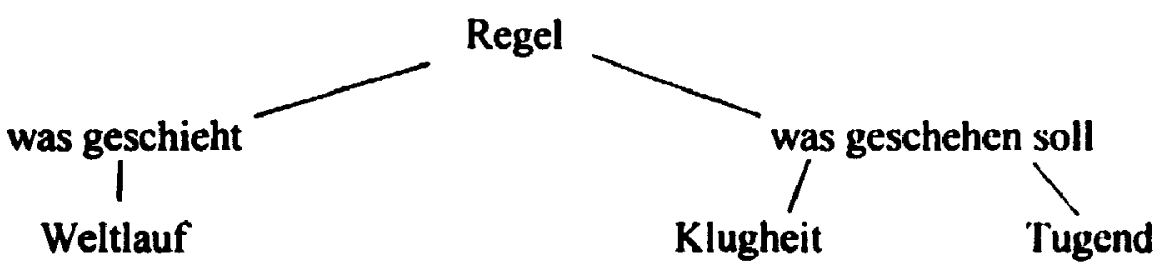

Das heißt, daß die Regel im allgemeinen nicht nur als Vorschrift formuliert ist, sondern vielmehr auch einen Vorgang kommentiert. "Richtet ein Sprichwort den Blick nach vorn, dann meistens nicht als Appell zu aktiver Gestaltung und Änderung, sondern eher als Hinweis auf eine Gesetzlichkeit, die passiv zu erdulden oder klugerweise in Rechnung zu stellen, die in religiőser oder weltmännischer Ergebenheit zu akzeptieren ist." (S.104) 
Beyer faßt in seinem Sprichwörterlexikon den Begriff des Sprichworts folgendermaßen zusammen: "Sprichwörter sind allgemein oder zumindest weithin bekannte, fest und dauerhaft geprägte Sătze, die eine prägnant formulierte Lebensregel bzw. verallgemeinerte Lebenserfahrung enthalten. In ihrer komplexen Aussage und ausgefeilten Gestalt bilden sie zugleich Miniaturtexte von manchmal großem poetischem Reiz. Prägnanz und Volkstümlichkeit nach Inhalt und Form sind unerläßliche Voraussetzungen für eine weitgehend mündliche, oft über die Jahrhunderte reichende Überlieferung." (S.6) Aber an der sogn. 'Weisheit ' der Sprichwörter zweifeln sie. Sie meinen, daß Sprichwörter keine Allgemeingültigkeit im Sinne von unumstößlichen Lebensweisheiten besitzen. (S.7) In diesem Zusammenhang zitiert er Redlich, der behauptet, daß die scheinbare Verbindlichkeit des Sprichworts für jedermann sich vornehmlich aus der jeweils herrschenden Moral ergibt. (Redlich, S.228)

\subsubsection{HERKUNFT DES SPRICHWORTS}

Bebermeyer erklärt die Herkunft des Sprichworts aus zwei Quellen - volkstümlichem Sprachgut oder 'Spruchweisheit' und Literatur. Außer einheimischen literarischen Schöpfung wird seit mittelalterlicher Zeit auch antikes wie biblisches Spruchgut in deutscher Übersetzung vermittelt, vor allem in den Schulen. (S.135) Dabei muß beachtet werden, daß die Grenzen zwischen volkstümlichen und literarischen Sprichwörtern fließend sind, denn die Literaten schöpfen aus dem Volksml.ald und dieser macht sich literarische Sprichwörter zu eigen. Was den Schöpfer des Sprichworts betrifft, so ist er so wenig wie beim volkstümlichen Lied, Märchen und der Sage das Volk als solches. 
Vielmehr machte sich stets ein Einzelner zum geschickten Former !nd Deuter volkshafter Weisheit. Die Hörer nahmen den Spruch auf, trugen ihn weiter und gaben ihm, falls nötig, eine schlagkråftige Gestalt. Röhrich/Mieder bestătigen diese Ansicht mit ihrer Behauptung, der Urheber eines jeden Sprichwortes sei immer ein Individuum. (S.26) Weiter bemerken sie, daß gewöhnlich eine monographische Studie nötig ist, um die Herkunft nur eines einzigen Sprichwortes genau zurilckzuverfolgen. Sie vermuten, daß die Entstehung eines größeren Teils der Sprichwörter in der vorliterarischen Zeit liegt. "Ihr erstes Auftauchen in antiken literarischen Quellen ist also meist bereits ein Zitat aus der mündlichen Überlieferung. Hieraus ergibt sich, daß der früheste schriftliche Beleg eines Sprichwortes nicht unbedingt der Ursprung das Sprichwortes sein muß." (ebenda) Neben der mündlichen, d.h. volkstümlicher Quelle spielt die literarische Herkunft der Sprichwörter eine große Rolle. Viele Sprichwörter sind eigentlich Sentenzen oder geflügelte Worte von Dichtern, die dann durch häufigen Gebrauch volksläufig, d.h. sprichwörtlich, geworden sind. Auch diese Sprichwörter werden für anonym gehalten, obwohl sich der eigentliche Urheber durch mühsame Forschungsarbeit nachweisen läßt. (S.26) Eine Sondergruppe von Sprichwörtern kann auf identische Sprichwörter in anderen Sprachen zurückgeführt werden und stellt die LEHNSPRICHWÖRTER dar. Viele der heute als typisch deutsch empfundenen Sprichwörter sind bei naherer Betrachtung ursprünglich nicht auf deutschsprachigem Boden entstanden. Vielmchr hat die deutsche Sprache eine große Anzahl von Sprichwörtern aus anderen Sprachen entlehnt, wie sich auch der deutsche Wortschatz durch Wortentlehnungen ständig vergı ößert hat. Der größte Anteil der deutschen Lehnsprichwörter geht auf die griechisch 
- römische Antike und auf die Bibel zurück und ist vor allem durch schriftliche Überlieferung entlehnt worden. (S.37)

\subsubsection{STILISTISCHE MERKMALE DES SPRICHWORTS}

Bebermeyer legt die FORM als auschlaggebenden Faktor beim Übergang vom geflügelten Wort zum Sprichwort fest: "Nicht durch Tiefe, Eigenheit oder Neuheit der verkündeten Weisheit wird eine Wendung zum Sprichwort, im Gegenteil : viele der gängigsten Sprichwörter sprechen Alltagsgedanken aus. Das Entscheidende ist die Eorm...". Diese 'Form' ist begründet in der Freude am Klang, am Spiel der Vokale, am Laut schlechthin...." (S.136) Einige Theoretiker berufen sich in ihren Definitionen des Sprichworts auf seine POETISCHEN QUALITÄTEN. So Maghoub: "A proverb is a piece of literature by virtue of its having the stylistic constituents of a literary utterance...it differs from other utterances by having characteristics of heightened symmetry and structure over and above the symmetry and structure inherent in all uses of language." (S.1) Röhrich/Mieder nennen die BILDHAFTIGKEIT als ein besonders wichtiges Merkmal der Sprichwörter. (S.52) ${ }^{5}$ Zur sogn. Bildhaftigkeit tragen verschiedene rhetorische Mittel bei. Röhrich/Mieder haben die folgenden hervorgehoben:

Unter Bildhaftigkeit wird in der Stilkunde die Verwendung sogn. sprachlichen Bilder verstanden. Die Ausführlichkeit eines sprachlichen Bildes reicht je nach der Funktion von Andeutungen bis zu einer eigenwertig geschlossenen Beschreibung. Neben der al!gemeinen Bildhaftigkeit dichterischer Sprache gibt es die Sonderformen der sogenannten uneigentlichen Redeweise wie Vergleich, Metapher, Symbol, Embıem. Auch die Alltagsspr.sche schmückt sich mit bildhaften Ausdrücken, z.B. Redensarten. (Duden. S.62) 
- $\quad$ Parallelismus (>Andere Städtchen, andere Mädchen<).

- die Antithese (>Lange Haare - kurzer Verstand $<$ ).

- $\quad$ das Paradox (>Einmal ist keinmal<).

- die Hyperbel (>Der Teufel scheißt immer auf den großen Haufen<), und

- die Zusammenkoppelung heterogener Dinge (>Liebe und Husten läßt sich nicht verbergen $<$ ).

Als weiteres stilistisches Merkmal der Sprichwörter wird bei Röhrich / Mieder eine Neigung zu bestimmten Stil- und Strukturformen hervorgehoben. (S.56) Sprichwörter streben nach Rhythmus und Wohlklang. Deshalb können bei ihnen markante sprachliche Verfahren systematisch beobachtet werden (S.56-63):

- $\quad$ Erstens trägt das Sprichwort oft die Merkmale des Verses. Reim und Länge betreffend, tritt am häufigsten der endreimende Zweizeiler auf ( $>$ Was ich nicht weiß, macht mich nicht heiß. $<$, $>$ Wer den Pfennig nicht ehrt, ist des Talers nicht wert. $<$ ). Ebensohäufig erscheint der Einzeiler mit Binnenreim: >Eile mit Weile $<$, >Borgen macht Sorgen<. Andere, verwandte Stilformen sind Schlagreim (>Trau - schau - wem<), Pausenreim ( $>$ Not - kennt kein Gebot<), der sogenannte Schültelrcim ( $>$ Unter den schönsten Steppdecken kann der blödste Depp stecken<) und der Ablauıreim (>Wer

Röhrich/Mieder, S.63: "Das Sprichwori geht selten über den Zweizeiler hinaus. Sog. Vielsprüche sind selten (z.B. "Ein Sct reiber ohne Feder, ein Schuster ohne Leder, ein Kaufmann ohne Geld, sind die größten Gauner auf der Welt."). Mit dem Vielspruch ist meist die Gattung des Sprichworts verlassen und der Spruch, Priamel, etc. erreicht." 
rastet, der rostet $<$ ). Den Rhythmus betreffend, kommt folgendes häufig vor:

Zweihebigkeit (>Eile mit Weile<), daktylische Formen (>Was ich nicht weiß, macht mich nicht heiß<), alternieren von betonten und unbetonten Silben (>Glück und Glas, wie leicht bricht das $<$ ). Der Wohlklang trägt auch dazu bei, daß die Sprichwörter leichter und besser im Gedächtnis der Sprecher behalten werden.

- Zweitens dient, syntaktisch gesehen, auch die kurze Form des Sprichworts zur leichteren Einprägsamkeit: "Wichtiges Stilmerkmal des Sprichworts ist seine schlagfertige Kürze und geschliffene Prägnanz." (S.56) Diese Kürze wird oft durch Auslassungen (auch Ellipsen genannt) erreicht, z.B. $>$ Ende gut, alles gut $<$. Was Satzmuster betrifft, fallen viele Sprichwörter unter die Kategorie der Relativsätze ( $>$ Wer anderen eine Grube gräbt, fallt selbst hinein<). Dem moralisierenden Ton entsprechend, greifen Sprichwörter oft zu imperativischen Formulierungen ( $>$ Eile mit Weile! $<$, $>$ Hilf dir selbst, so hilft dir Gott<). Bei Röhrich/Mieder werden bestimmte Satzmuster und syntaktische Strukturen nach dem Kriterium der Vorbildlichkeit ausgesondert. Meiner Meinung nach sollen auf dieser Liste auch die zwei oben erwähnten Satzmuster (der imperativische Satz und Relativsatz) sowie der Bedingungssatz stehen: $A$ ist $A$ (Tautologie): > Dienst ist Dienst $<$, >Schnapps ist Schnapps $<,>$ Genug ist genug $<$; A bleibt A: > Mark bleibt Mark<, >Ochs bleibt Ochs<, > Lump bleibt Lump<; $A$ ist $B$ (Identitätssatz): $>$ Zeit ist Geld $<,>$ Träume sind Schäume $<,>$ Würden sind Bürden<.

Nicht alles ist $A$, was $B$ : $>$ Nicht alles ist Gold, was glänzt<, >Es sind nicht alle Jüger, die das Horn blasen<. 
Nicht $A$ ist B: > Keine Antwort ist auch eine Antwort<.

Ohne A kein B: >Ohne Fleiß kein Preis<, > Kein Haus ohn: Maus<, >Ohne Dornen keine Rosen<;

$A$ und $B$ : $>$ Leben und leben lassen<, > Schenken und schenken lassen<.

Erst $A$, dann $B$ : > Erst denken, dann handeln<, > Erst gurten, dann spurten<.

Lieber (besser) A als B (formelhafter Komparativ): >Lieber den Spatz in der Hand, als die Taube auf dem Dach<, > Lieber eine Laus im Pott als gar kein Fleisch<;

$A$ ist größer als $B$ : >Seine Augen waren größer als der Mund<.

$A$ ist die Wurzel von $B$ : $>$ Geiz ist die Wurzel allen Übels $<,>$ Faulheit ist die Wurzel allen Fortschritts $<$.

$A$ ist die Mutter von $B:>$ Vorsicht ist die Mutter der Weisheit $<,>$ Überfluß ist die Mutter der Langeweile $<$.

$A$ ist nicht $B$ : >Aufgeschoben ist nicht aufgehoben<.

Kein A ohne B: >Keine Rose ohne Dornen<, >Kein Warum ohne Darum<.

A erkennt man an B: >Den Baum erkennt man an der Frucht $<$, > Denn Narren erkennt man am Lachen<.

Wie A, so B: >Wie der Herr, so`s Gscherr<, > Wie die Zucht, so die Frucht<.

Wo $A$, da $B$ : > ubi bene, ibi patria<.

Wo ein A, dort auch ein B: > Wo ein Wille, da ein Weg<.

Was $A$ tut, tut $B:>$ Was sich liebt, das neckt sich<, > Was du heute kannst besorgen, das verschiebe nicht auf morgen $<,>$ Wer sucht, der findet $<$.

$A$ mach $B:>$ Gut macht Mut<, > Übung macht den Meister $<$. 
A macht nicht B: > Eine Schwalbe macht noch keinen Sommer<.

Alles heilt A: > Zeit heilt Wunden<, >Musik heilt Wunden<.

Alles tut $A$ : > Geduld uberwindet alles<, > Der Tod macht alles gleich<.

Je $[\ldots] A$, desto (je) [...] $B$ (wobei das Prädikat meist entfällt: $>$ Je magrer der Hund, desto fetter die Flöhe<.

Jeder $A$ ist (tut, bewirkt) B: > Jeder ist sich selbst der Nächste $<,>$ Jeder ist seines Glückes Schmied $<$.

Wie man A, so man $B:>$ Wie man sich bettet, so liegt man $<$, > Wie man plant, so fahrt $\operatorname{man}<$.

A schüızt nicht vor $B$ : >Alter schützt vor Torheit nicht<.

Seiler weist auf eine Sonderform des Sprichworts. Es handelt sich um VIELSPRÜCHE

MIT ANKÜNDIGUNG, z.B. > Vier Dinge wachsen über Nachc: Haar, Holz, Unglück und

Pacht<. (S.226) Nach Seiler besteht ein struktureller Zusammenhang zwischen den

Vielsprüchen mit Ankündigung und der Prianel': "Man braucht ... die einleitende Formel

7

Nach dem Duden Sachlexikon der Literatur ist die Priamel ein "einstrophiger, metrisch weitgehend freier, meist paarweise gereimter Spruch. Die Priamel beginnt mit der Aufzahlung von Dingen, Handlungen oder Geschehnissen, die miteinander nicht in unmittelbarer Beziehung stehen und mündet in eine pointierte Schlußwendung, in der eine uberraschende Gemeinsamkeit aufgezeigt wird. ... [Die Priamel war besonders im Mittelalter beliebt -B.V.] - Ein spätes Beispiel aus der Barockzeit von G. Stolle: An der Hunde Hinken, An der Huren Winken. An der Narren Dünken, An der Weiber Zahren, An der Krämer Schweren, 
des Vielspruchs nur an sein Ende zu stellen und mit der bis dahin letzten Zeile durch den Reim zu verbinden, so hat man eine Priamel." (S.229) Ein Beispiel aus seinem Werk: >Ein Bube aufm Roß, eine Bubin im Schloß, eine Laus im Grind ist ein hochmütig Gesind<. (S.230)

\subsubsection{INHALTLICHE MERKMALE UND BEDEUTUNG DES SPRICHWORTS} In der Diskussion um die Definition des Sprichworts wurden Volksläufigkeit und Lehrhaftigkeit als inhaltliche Merkmale hervorgehoben und erörtert. Kanyó betont den 'Weisheitsaspekt' der Sprichwörter: "Der logisch-gnostische Charakter der Sprichwơrter wird in den meisten parömiologischen Arbeiten als ein Grundzug dieser Gattung gesehen." (S.79) Röhrich/Mieder unterscheiden bei Sprichwörtern zwei Bedeutungsebenen - die anschauliche Bedeutung und die 'eigentliche' oder intendierte/gemeinte Bedeutung (S.54). So sind im Sprichwort deutlich zwei unterschiedliche Aussageformen zu differenzieren, nämlich: die direkte und die indirekte Aussuge. In direkten Sprichwörtern decken sich Sachverhalt und Aussage; es sind unverhüllte Aussagen ( $>$ Wer wagt, der gewinnt $<$ ). In indirekten Sprichwörtern, dagegen, ist der Realbereich selten der eigentlich gemeinte, sondern häufiger ist es erst die übertragene Bedeutung. Diese Doppelseitigkeit wird besonders durch poetische Bilder erzielt, hauptsächlich durch Metaphern ( $>$ Neue Besen kehren gut<). Fleischer meint, es steckt ein zu erschließender und nicht mit der wörtlichen Bedeutung ohne weiteres 
gegebener 'tieferer Sinn' darin. Er gibt implizit zu verstehen, dieser tiefere Sinn sei durch Bildhaftigkeit zustande gekommen. (S.80)

Zoltán Kanyó erörtert auch die Zeitbezüge im Sprichwort (S.156). Nach ihm handelt es sich hier nicht um Zeitbestimmungen, die vom Zeitpunkt der Kommunikationssituation her gesehen als vergangen oder zukünftig bzw. gleichzeitig gelten, sondern um Relationen der Vor-bzw. Nachzeitigkeit, die bei der beliebigen Wahl des einen Zeitpunktes bestehen sollen.

\subsubsection{FUNKTION, GEBRAUCHSWEISE UND WIRKUNG DES SPRICHWORTS} Sprichwörter müsssen immer innerhalb einer Texteinheit vorkommen, wenn sie ein kommunikatives Ziel erfullen sollen. Sie wirken daher auf den Text, in dem sie eingebettet sind, im Sinne einer intertextuellen Übertragung. Sie kommen als eine bestimmte Textsorte in einer Vielfalt von Textsorten vor: im Dialog, im literarischen Text, in persuasiven Textsorten wie Werbeanzeigen und politischen Reden.

Lewandowski sieht die kommunikative Funktion von Sprichwörtern im Stützen oder Unterstreichen der eigenen Meinung; Argumentationen können im Sprichwort kulminieren oder durch ein Sprichwort abgeschlossen werden. (S.1044) Beyer sieht im Gebrauch von Sprichwörtern heute wie in früheren Zeiten ein Mittel zur Belebung der Rede: "Wer ein Sprichwort gebraucht, ob im Ernst oder spöttisch, ob vollständig oder nur andeutungsweise. darf darauf rechnen, seiner Aussage einen besonderen Nachdruck zu verleihen." (S.5) Röhrich/Mieder führen als Funktionsmöglichkeiten des Sprichworts eine 
Reihe von Sprechhandlungen an: Warnung. Überredung. Argument. Bestätigung. Trost. Besänftigung, Überzeugung, Mahnung. Zurechtweisung. Feststellung. Charakterisierung. Erklärung, Beschreibung, Rechtfertigung. Zusammenfassung, usw. Leider geten sic keine Beispiele. (S.81) Sie meinen. daß der Gebrauch von Sprichwörtern in hohem Maße situationsabhängig ist: erst in der Gebrauchssituation zeigt es sich als äußerst anpassungsfähiges Sprachbild, dem keine definitiven Funktionswerte zugeschrieben werden können. Sie warnen auch vor der in der Forschung gängigen Vereinfachung und Reduzierung der Funktionswerte des Sprichworts nur auf das Lehrhafte (obwohl die lehrhafte Tendenz heute noch in Textsorten wie politische Karikatur oder Werhesprache ausgeschöpft wird).

Lewandowski sieht die inhaltliche Funktion von Sprichwörtern als entweder "explizierend oder verhüllend", entweder "präzisierend oder verallgemeinernd". (S.1044) Was er wohl damit meint, ist das Verhältnis des Sprichworts zur außersprachlichen Wirklichkeit. Röhrich/Mieder betonen die Klarheit der Aussage des Sprichworts: "Sprichwörter bringen in der Regel eine klare Aussage: ...>Was der Bauer nicht kennt, das frißt er nicht<. Einfache prosaische Sätze sind hier gültig, deutlich und ohne verborgene Hinter- oder Nebengedanken formuliert." (S.52) Aber daneben gibt es auch zahlreiche bildhafte Sprichwörter, die einen Allgemeingedanken, der auch mehr oder weniger abstrakt ausdrückbar wäre, in ein plastisch-konkretes Anschauungsbild kleiden. Umgekehrt muß oft das Bild eines Sprichwortes erst wieder abstrahiert werden, wenn man den Sinn verstehen soll. Die Autoren geben das folgende Beispiel: >Stehend Wasser 
stinkt, gebrauchter Pflug blinkt<. Die Sprichwortantithese 'stehend - gebraucht' und 'stinkt - blinkt' wird nur durch die Übertragung in die Abstrakta 'Faulheit-Fleiß' greifbar. Der volkstümlichen Ausdrucksweise fällt es schwer, abstrakte Begriffe, wie z.B. Streit, Zank, Schwatzhaftigkeit, Zorn, Verleumdung metaphernlos zu umschreiben. (ebenda)

Beyer (S.5) meint, daß die Sprichwörter "so lebendig wie eh und je" sind, obwohl ihre Zahl geringer ist als in früheren Epochen und ihre Funktion anders. Heutzutage werden Sprichwörter nicht mehr als "goldene Lebensregeln oder Weisheiten" angesehen und dienen nicht mehr zur Weitergabe gesellschaftlicher Normen und moralischer Sätze an folgende Generationen. Was aber heute noch gilt, ist die "eindringliche, suggestive Kraft" des Sprichworts, die seiner prägnanten, formelhafen Gestalt entstammt. Ein neuer Zugang zu sprichwörtlichem Material zeigt sich auch in der modernen Neigung zum spielerischen Umgang mit Sprichwörtern "in dem sich ein überlegenes Verhältnis zu den überkommenen Ausdrücken zeigt." (ebenda)

Der moderne Sprichwortgebrauch unterscheidet sich von dem Sprichwortgebrauch in 'früheren Zeiten'. Damit ist die Zeit gemeint, wo die bäuerliche Kultur noch stark vertreten war oder Menschen noch in solchen Verhältnissen lebten, wo sie sehr aufeinander zugewiesen waren, z.B. in Arbeitergemeinschaften während der industriellen Revolution. Die moderne, stark individualistische Lebensweise, scheint auf dem ersten Blick für volkstümliche Formeln wenig übrig zu haben. Diese Untersuchung zeigt jedoch, daß wenigstens in der Werbung, die Sprichwörter sich einer großen Beliebtheit freuen. 
Røhrich/Mieder sehen die Arbeit 'auf dem Feld'. d.h. die Untersuchung der Sprichwörter in ihrer Gebrauchssituation (Kontext), als die einzige Möglichkeit, das heutige Wesen dieser Textsorte zu erfassen. Die Fragen, die bei einer solchen Analyse beantwortet werden müssen, sind die fogenden: "wo, wann, warum, wie, von wem und für wen wird das jeweilige Sprichwort verwendet?" (S.81) Auch Herles sieht das Volkstümliche als noch aktuell für den modernen Menschen. Die volkstümlichen Elemente sind auch dem Menschen der technischen Welt noch so vertraut, daß er sie selten als 'Traditionsgüter identifiziert, sondern sie als selbstverständlichen Besitz wertet. (S.68) Der Beweis dafür ist der häufige Einsatz solcher Elemente in der modernen Werbung. Insbesondere zeugt die Variation der Sprichwörter in Werbetexten von ihrem Leben in der technischen Welt. (S.71) In diesem Sinne sind Sprichwörtermuster noch produktiv. Ein abgewandeltes Sprichwort läßt sich einer Breite von Situationen anpassen. Auch Mieder betont die Rolle der Abwandlung im modernen Sprichwortgebrauch: "Zwar steht der moderne Mensch, wie bereits erwähnt, dem Weisheitsgehalt und dem damit verbundenen Autoritätsanspruch vieler Sprichwörter oft sehr kritisch gegenüber, was zur Folge hat, daß der ursprügliche Wortlaut des Sprichwortes variiert wird, aber die Formelhaftigkeit der sprichwörtlichen Aussage, bleibt dennoch erhalten. Damit ist die für die Moderne geltende Lebensideologie des Sprichwortes gekennzeichnet: im heutigen Sprachgebrauch lebt das Sprichwort vor allem in der Variation!" (S.70) Das Sprichwort tritt im modernen Sprachgebrauch häufig nur in der Form einer Anspielung, auf eine Schwundstufe reduziert, auf. Im Allgemeinen läßt sich beschließen, daß heutzutage die Sprichwörter vor allem in der Presse, in der Politik, und in der Werbung Einsatz finden. Die Bildlichkeit 
des Sprichworts macht jedenfalls einen Text anschaulicher und lebendiger, wobei der dem Sprichwort zugrundeliegende Anspruch auf Allgemeingültigkeit die Aussagekraft der Argumente verstärkt.

\subsubsection{SONDERTYPEN DES SPRICHWORTS}

a) Rechtssprichwort

Geschichtlich gesehen, handelt es sich bei den Rechtssprichwörtern um einstige "zusammenfassende, bündige und bindende Rechtsformeln." (Bausinger, S.105) Im Laufe der Zeit sind sie entweder vergessen worden oder in den Sprachschatz der Sprichwörter übergegangen. Beispiele der Rechtssprichwörter, die Bausinger anführt, wären $>$ Wo kein Kläger, da ist auch kein Richter $<$, oder $>$ Wer kommt zuerst, mahlt zuerst $<$.

b) Bauernregel

Die Bauemregel wird oft als eine Sondergruppe der Sprichwörter behandelt. Nach Beyer sind sie ein Beispiel dafur, wie bestimmte gesellschaftliche und wirtschaftliche Gruppen in der Form des Sprichworts die für sie wichtigen Anschauungen, Erlebnisse und Erfahrungen zum Ausdruck bringen. Als entsprechende andere Gruppen nennt er z.B. die Handwerker, die Kaufleute und die Adeligen. (S.9) Die Bauernregel kann entweder eine WETTERREGEL oder eine ARBEITSREGEL sein. Die Arbeitsregel summiert fur die Landwirtschaft wichtige Gesetzlichkeiten, z.B. >Dreimal ackern ist einmal misten<. Im Wettersprichwort werden einige vom 'Volk' beobachtete meteorologische Gesetzlichkeiten ausgedruckt, wie z.B. >Januar warm, des Gott erbarm<. Hier tritt der 
Vorschriftscharakter der Sprichwörter völlig zurück. (Bausinger, S.107) Röhrich/Mieder (S.8) stellen fest, daß viele Wetterregeln an wichtige Lostage anknüpfen, und zwar an die Heiligentage. Das setzt die Kenntnis des Heiligenkalenders voraus. Die formale Struktur dieser Gruppe von Wettersprichwörtern wäre etwa: "Wie das Wetter am Tage X, so das Wetter am Tage Y". Regeln, die das Wetter eines bestimmten Monats oder Tages mit einem spăteren in Relation bringen, nennt man Korrelationsregeln. Weitere Merkmale nach Röhrich/Mieder (S.9-10) sind der Reim (>Schaltjahr-Kaltjahr $<$, >lst der Winter warm, wird der Bauer arm<), hinter dem man den älteren Stabreim erkennen kann (>lst im Herbst das Wetter hell, bringt es Wind im Winter schnell<). Besonders belicht ist dic Personifikation der Tage des Heiligenkalenders: >Hat Martin [1 1.November] einen weißen Bart wird der Winter lang und hart $<$.

\section{c) Wellerismus}

Wellerismen, auch Sagwörter oder Beispielsprichwörter genannt, verdanken ihren Namen der Dickensschen Figur des Samuel Weller. Beyer (S.14) beschreibt diese Formen folgendermaßen:"Hier wird ein Sprichwort oder ein ähnlicher Ausspruch von jemandem 'gesagt' und gleichzeitig in eine 'Situation' gestellt, die zur Äußerung gewisscrmaßen wic die Faust aurs Auge paßt: > Was sich liebt, das neckt sich, sagte die Katze zur Maus und fraß sie,...<" Nach Beyer ist der komische Effekt, der sich durch den überraschenden Kontrast von Ausspruch und Handlung (Vorgang) einstellt, charakteristisch furr Wellerismen. "Sagwörter verstehen sich nicht als ernsthafte Lebensregeln, ironisieren diese vielmehr". (ebenda) Beyer betrachtet diese Form als heute noch produktiv. Meiner 
Meinung nach zeigen die Wellerismen, daß die Bedeutung der Sprichwörter relativ ist. Sie lassen sich Situationen anpassen, die einem Sprecher unerwartet sind, z.B. >Aller Anfang ist schwer, sagte der Dieb, und stahl zuerst den Amboß<. Diesen Verfremdungseffekt mag man komisch oder ironisch nennen. Die Beliebtheit der Sagwörter in früheren Zeiten zeigt, daß die Relativität der sprichwörtlichen Bedeutung den Sprechern schon immer bewußt war.

\subsubsection{VERHÄLTNIS DES SPRICHWORTS ZU ÄHNLICHEN FORMEN}

a) Formen, die auch volkstümlich sind: das Sprichwort als einfache Form /als Sprachformel

Der Begriff der 'einfachen Form' stammt von Jolles. Die einfachen Formen, wie er sie auffaßt, wären die Legende, die Sage, die Mythe, das Rătsel, das Märchen, der Witz, der Spruch [mit dem Sprichwort], der Kasus und das Memorabile. Sie stellen Grundformen sprachlichen Gestaltens dar, die keinem historischen Wandel unterliegen sollen. Diese außer-bzw. vorliterarischen Formen sind im Gegensatz zu literarischen Kunstformen keine individuellen Schöpfungen, sondern sind sprachliche Ereignisse in bestimmten Situationen und Lebensbereichen. (Duden Sachlexikon der Literatur S.115) Innerhalb der übergeordneten Kategorie der 'Volkspoesie' schließt Bausinger die Sprichwörter in die Gruppe der 'Sprachformel und Sprachspiele', im Gegensatz zu den 'Erzählformen' einerseits und den 'szenischen und musikalischen Formen' andererseits ein. 
Beziehung zum Spruch

Unter den Theoretikem, die ich herangezogen habe, ist eigentlich Jolles der cinzigu. der die Sprichwörter unter die Kategorie 'Spruch' subsumiert. Die Kategorie 'Spruch' ist schwer zu definieren. Kanzogs Beitrag im Reallexikon der deutschen Sprache stellt dic Lage dar (S.151). Er sieht die Schwierigkeiten, den Begriff 'Spruch' eindeutig zu definieren: "in der bisherigen Praxis der Verwendung des Wortes 'Spruch' und seiner Komposita ( wie Sinn-, Sitten-, Denk-, Mahn-, Lehr- und Wahrheitsspruch). So wird das Wort mit spezifischen literarischen Phänomenen, mit dem Apophthegma, dem Iipigramm ... der Maxime ... und dem Sprichwort ... in Verbindung gebracht; es umschreibt dancben verkürzt auch die unterschiedlichsten Erscheinungsformen der Spruchdichtung in ihren gattungstypischen Ausprägungen und ihrer eigenen Geschichtlichkeit ". Um diese Vielfalt der Bezüge auf einen Nenner zu bringen, hält es Kanzog fưr zweckmäßig. Sprache als Oberbegriff für alle spruchhaften Texte anzusehen, so daß 'Spruch' zu cinem Phänomen der Tiefenstrukturdieser Texte wird, deren Oberflächenstruktur dic Bestimmung typischer Eigenheiten des Diskurses erlaubt. Kanzog hebt als typische Sprachgebärde spruchhafter Texte das 'Kurz und Bündige' der Rede hırvor, das sich auf' einen Gedanken konzentriert, der in der Regel in einen.Satz oder in eine. Strophe cingeht. Diese Begrenzung des Textumfangs und der daraus folgende Zwang zur Prägnanz des Ausdrucks ist nicht nur eine formale Eigenschaft dieser Texte, sondern ein unverzichtbares Merkmal der tiefenstrukturellen Sprachkonzeption. (S.153) Mit dem Verhältnis von Sprichwort und Spruch beschäftigt sich auch Bausinger. Iir sicht cinen "prinzipiellen Unterschied" zwischen diesen zwei Formen - das Sprichwort ist 
situationsabhängig, aber der Spruch nicht: "Das Sprichwort gehört in den Bereich der Rede, gehört zu einer speziellen Situation." (S.112) Das Sprichwort bindet diese hesondere Situation an eine Ordnung, im Sinne einer abstrahierten Erfahrungsweisheit. Aber diese Ordnung ist nicht beständig, da die Erfahrungsweisheit des Menschen relativ ist. Z.B. gibt es diese zwei Sprichwörter, die Entgegengesetztes behaupten: > Jung gefreit hat nie gereut $<$ und $>$ Jung gefreit hat stets gereut $<$. Dies macht das Sprichwort gewichtig und leicht zugleich. Dagegen ist der Spruch "Aushängeschild eines bestimmten $\underline{\text { ordo, }}$, und dieses Schild bleibt bestehen, wird nicht abgenommen. ... " (ebenda) Der Spruch wird nicht durch eine Situation relativiert, er ist unabhängig

b) Lite.arische Formen, die inhaltlich und formell verwandt sind Beziehung zum geflügelten Wort, zur Maxime, zur Sentenz, zum Aphorismus und zum Epigramm

Das Deutsche (wie viele europàische Sprachen) kennt außer dem Sprichwort andere kurze Formen, die bestimmte Gedanken ebenso auf eine prägnante und effektvolle Weise ausdrücken. Diese Formen wären etwa das geflügelte Wort, die Maxime, der Aphorismus, die Sentenz und das Epigramm. Diese Formen ähneln den Sprichwörtern und Redensarten in mehrerer Hinsicht, wie z. B. in den stilistischen Merkmalen der gedanklichen und formalen Konzentriertheit oder in der moralisierenden Tendenz ${ }^{8}$ sowie

Sowinski (S.77) meint, die Maxime und das Epigramm seien auf Sprichwörter zurückzuführen. 
dem Allgemein'heitsanspruch. Das Kriterium, durch das sie sich unterscheiden, ist ihre Herkunft: die Maxime, der Aphorismus, die Sentenz. das Epigramm und das geflügelte Wort entstammen literarischen Quellen, und werden noch als 'literarisch' empfunden; d.h. bei ihrer Erwähnung wird noch an ihre Quelle gedacht. Obwohl auch viele Sprichwörter auf verschiedene literarische Werke zuräckzuführen sind, sind sie durch häufigen und in der sprachlichen Gemeinschaft durchgehenden Gebrauch so eingeschliffen worden, daß sie volkstümliches Sprachgut darstellen; d.h. bei ihrer Erwähnung denkt keiner an ihre einstige Quelle. Und, wie es oben ausgelegt wurde, sind die meisten Sprichwörter auch tatsächlich von unbekannten Indivic'‘len eingeführt worden. So Beyer: "Wer [ein Sprichwort] benutzt, nimmt nicht - wie beim Zitat - den Gedanken einer einzelnen, meist bedeutenden Persönlichkeit in Anspruch, sondern dic gangbare Münze kollektiver Erfahrung und Bewertung, und zwar gleichgültig, ob er sich ihr anschließt oder sie bezweifelt. Sprichwörter sind Gemeingut." Beyer meint das im zweifachen Sinne. Historisch gesehen, geben $S_{\mathfrak{r}}$. chwörter 'gültige Ansichten einer größeren Menschengruppe' wieder, die meist von Unbekannten auf eine treffende Formel gebracht wurden; pragmatisch gesehen, kann nur das als Sprichwort gelten, was unabhängig davon, ob es aus dem Volksmund, aus einer literarichen Quelle oder aus Entlehnung stammt - von breiten Volksschichten wirklich aufgenommen, benut:xt (dabei oft umgemodelt und abgeschliffen) und weitergetragen wird. (S.7) Trozdem kann man sagen (wie Lewandowski, S.1044), daß der Übergang zur Sentenz, zum geflügelten Wort, zum Epigramm usw. fließend ist. 


\section{Verhälenis zum Slogan}

Der Slogan bezeichnet einen prägnanten und einprägsamen Ausdruck, der die Anzeigen für eine bestimmte Ware immer begleitet. Er zeigt oft die gleichen stilistischen Merkmale wie das Sprichwort. Oft wird sogar im Slegan ein Sprichwort zitiert, leicht abgewandelt oder seine Form nachgeahmt. Umgekehrt kommt es auch vor, daß ein besonders gelungener Slogan sich so im Gedächtnis der Sprecher einprägt und so weitläufig wird, daß er zum Sprichwort wird (z.B. Keine Feier ohne Meyer oder im Englischen Just do it). Der Unterschied ruht aber in den Textsorten: der Slogan ist teil einer Werbeanzeige und hat eine epideiktische Funktion. Sein Autor, obwohl nicht bekannt, ist nachweisbar. Das Sprichwort ist anonym und hat keine epideiktische Absicht an sich. Es kann aber in epideiktischen, so wie anderen Textsorten eingesetzt werden, um die Argumentation zu unterstützen. Über das Verhältnis von Slogan und Sprichwort sagen Röhrich/Mieder (S.5), daß es zwischen ihnen enge Berührungspunkte gibt, denn bei beiden handelt es sich um formelhafte Ausdrücke, die häufig verwendet werden. Der Slogan an sich ist eine kurze, oft wiederholte Aussage mit einer bestimmten Richtung. Er weist oft Stilmerkmale des Sprichwortes wie Alliteration, Reim, Rhythmus, usw. auf. Der Unterschied zwischen den beiden liegt in der Zweckmäßigkeit des Slugans. So summieren die Autoren: "Im allgemeinen aber gilt, daß der Slogan vor allem sein zweckverbundenes Sonderinteresse charakterisiert, während das Sprichwort lebensnahe Erfahrungen ausdrückt." (ebenda)

c) Verhältnis zu den Redensarten

Laut Fleischer wurden Sprichwörter und die sogn. sprichwörtlichen Redensarten bis 
Wanders Veröffentlichungen meist auf einen Haufen geworfen (S.17). Allerdings haben Sprichwörter und Redensarten viele gemeinsame Züge. Als Hauptunterschied wird meist der syntaktische Bau der beiden festgelegt: Das Sprichwort stellt eine vollständige Aussage dar, die keiner Abänderung bedarf. Die Redensart muß syntaktisch in einen Satz eingebaut werden, d.h. sie bedarf einiger Änderungen. Oder mit den Worten von Fleischer stellen Sprichwörter Mikrotexte dar, während die Redensarten als lexikalische Einheiten im Lexikon c’ner Sprache gespeichert werden. (S.80) Ausführlicher gehe ich auf diese weiter unten ein, nachdem die Merkmale der Redensarten ausgearbeitet sind.

\subsection{Die Redensart}

\subsubsection{DEFINITION}

Laut Lewandowski ist eine Redensart eine "stehende bzw. feste Wortverbindung oder Redewendung, die als phraseologische Einheit zum Wortbestand einer Sprache gehört und durch ihren Bildgehalt einen anderen Sachverhalt symbolisch ausdrückt, z.B. $>$ jemandem Sand in die Augen streuen...<" (S.823-4) Redensarten sind als bildhafte Wendungen sct.wer durch Substitute zli ersetzen. Ein wichtiges Merkmal der Redensarten ist, daß sie "syntaktisch nicht vollstăndig bzw. eigenständig [sind] und ... beim Gebrauch in einen Satz eingebettet werden [müssen]." (ebenda) Wie wir oben gesehen haben. ist dies ein wichtiges Kriterium für die Unterscheidung von Redensarten und Sprichwörtern.

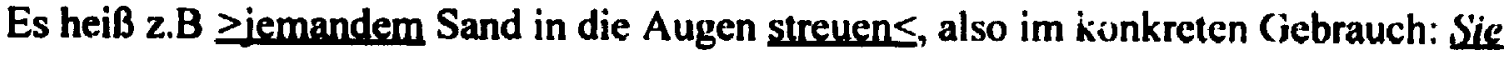
streut ihm Sand in die Augen. Im Grunde genommen braucht die Redensart einen Kontext, um überhaupt zur Geltung zu kommen. (Sowinski, S.93) 


\subsubsection{ABGRENZUNG DER REDENSART GEGENÜBER ANDEREN WENDUNGEN}

Es ist schwer, die Redensarten von anderen Wortverbindungen genau abzugrenzen. In dieser Arbeit habe ich mich an die Klassifikation von Görner (S.6-10) angelehnt. Er gradiert sechs verschiedene Typen der Wortverbindungen/Kollokationen nach Graden der Idiomatizităt:

i) Die freien (unfesten) Wortverbindungen, deren einzelne Glieder trennbar sind und mit anderen Wörtern ausgetauscht werden können. Diese 'Austauschbarkeit' unterliegt natürlich den Gesetzen der semantischen und sonstigen Verträglichkeit. Z.B.: >schlechtes Wetter $<$, > ein unerfreuliches Erlebnis $<$, >mit dem Sohn sprechen $<$.

ii) Die sogenannten losen Wortverbindungen an. In diese Gruppe gehören Wendungen, die durch besonderen Gebrauch innerhalb bestimmter Bereiche in ihrer Wortfolge bestimmt, in ihrer Gesamtheit aber nicht umgedeutet sind [d.h. die Bedeutung ist die Summe der Bedeutungen der einzelnen Wörter]. Zu ihnen sind auch mehrgliedrige Eigennamen und Titel, wie auch stehende Vergleiche zu rechnen: >eire gelbe Karte<, $>$ der Thüringer Wald $<$, > kalt wie Eis $<$.

iii) Die festen Wortverbindungen, die man gemeinhin als Redewendungen bezeichnet. Hierher gehören die einfachen phraseologischen Verbindungen, bei denen eine Komponente in ihrer Bedeutung verblaßt oder auch bis zu einem gewissen Grade umgedeutet ist. Diese Verbindungen sind in ihrer Gesmtheit immernoch aus ihren Gliedern zu erschließen. Die Austauschbarkeit der einzelnen Glieder ist bei ihnen stark eingeschränkt: >Anweisungen geben $<$, > einen Entschluß fassen $<$.

iv) Die phraseologischen Einheiten (festen Redewendungen) an, die meist nur in 
Ubertragener Bedeutung vorkommen und die dann in ihrer Gesamtbedeutung schon nicht mehr ohne weiteres erschlossen werden können. Einbezogen werden hier die phraseologischen Vergleiche: $>$ der rote Faden $<$, > Sand ins Getriebe streuen $<$, > gucken wie ein Auto<.

v) Die sogenannten Zwillingsformeln, die man eigentlich der vorigen Gruppe zurechnen könnte, die sich aber durch einige Merkmale von ihnen abheben. Sie bestehen im allgemeinen aus zwei, manchmal auch aus drei tragenden Wörtern der gleichen Wortart. In der Reihenfolge ihrer Glieder steht hăufig das wichtigere Wort vor dem als weniger wichtig angesehenen, oft auch das kürzere vor dem längeren, z.B. >nie und nimmer $<$. Zum Teil sind sie durch Stab- oder Endreim gebunden: $>$ Feuer und Flamme $<$, >weder Fleisch noch Fisch<. Aus Röhrich/Mieder kann noch hinzugefügt werden, daß oft zur Verstärkung das gleiche Wort wiederholt wird (geminatio): >Schlag auf Schlag<, $>$ Wurst wider Wurst $<$. Die rhythmische oder klangliche Bindung bewirkt eine fast unveränderbare Reihenfolge der Glieder. (S.18) Röhrich/Mieder machen die folgende interessante Beobachtung in bezug auf dem modernen Sprachgebrauch: "Selbst heutige literarische oder politische Prägungen verlaufen noch nach dem Wortpaarschema der älteren Zwillingsformeln, z.B. $>$ Soll und Haben $<$, >Schuld u.ıd Sühne $<,>$ Ost und West $<$, $>$ Frieden und Freundschaft $<$. (ebenda)

vi) Die sogenannten starren phraseologischen Wendungen (idiomatischen Wendungen, oder die sprichwörtlichen Redensarten_dar. Sie sind dadurch gekennzeichnet, daß sie in ihrer Gesamtheit voll umgedeutet sind, das heißt, daß sich ihre Gesamtbedeutung nicht aus den Bedeutungen ihrer einzelnen Bestandteile erhellt. Sie 
muß durch Paraphrasen erklärt und bewußt gelernt werden. ${ }^{9}$ Ihre Glieder sind nur ausnahmsweise mit anderen Wortern austauschbar. In ihrer Form können sie, von den für die Verwendung im Kontext notwendigen grammatischen Abwandlungen abgesehen, im allgemeinen nicht verändert oder ergänzt werden: >einen Bock schieỉen<, >durch die Lappen gehen<. Rohrich/Mieder definieren diese Kategorie der Redewendungen folgendermaßen: "Wenn eine Redewendung neben ihrem eigentlichen Sinn noch eine ubertragen-bildliche Bedeutung hat und wenn gar ihre heutige Gebrauchsfunktion sich soweit von der primären Bedeutung der Einzelu jrter entfernt hat, daß der ursprüngliche Sinn gar nicht oder kaum mehr empfunden wird, dann bezeichnen wir sie eben als sprichwörtliche Redensart." (S.20) Zu dieser Gruppe rechnet man auch bestimmte starre Verbindungen in Satzform. wie >das geht auf keine Kuhhaut<, und wie Auslassungssätze der Art >Schwamm drüber!<. Röhrich/Mieder zählen diese Formen auch nicht zu den Sprichwörtern, obwohl sie wie die Sprichwörter syntaktisch abgeschlossen sind. Sie haben im kommunikativen Sinne "keinen Eigenwert, sondern müssen sich auf etwas zuvor Gesagtes beziehen." (S.16)

Röhrich/Mieder betonen auch den Unterschied zwichen einer sprichwörtlichen Redensart und einer einfachen Redensart. (S.15,17) Dabei ist die Bildhaftigkeit das entscheidende Kriterium: "entbehrt ein redensartlicher Ausdruck des sprichwörtlichen Bildes, so spricht

Die Bedeutung einzelner lexikalischer Elemente ist of deshalb unbekannt, weil die Einheiten aus friheren Zeiten stammen, wo ihre Bedeutung völlig durchsichtig war, aber im Laufe der Geschichte verblaßt und verschwunden ist. 
man gewöhnlich nur von 'Redensarten'. ... Beides [sprichwörtliche Redensart und einfache Redensart] ist nicht das gleiche, d.h. nicht jede Redensart oder 'stehende Wendung' kann man schon als sprichwörtlich bezeichnen. 'Einfache Redensarten' oder bloß metaphorische Redewendungen sind zunächst einmal schwăcher, blässer, weniger bildhaft und farbkräftig. ... Das sind einfache Gebrauchsmetaphern." (S.15-16) Meiner Meinung nach ist ihre Definition in diesem Sinne widersprüchlich, denn Metaphern sind auch sprachliche Bilder, und Wendungen wie >alles auf einen Haufen werfen<, oder >am Gipfel des Glücks stehen<, die sie als einfache Redensarten klassifizieren, sind doch bildhaft. Was sie damit (d.h. mit dem Begriff der Bildhaftigkeit) wohl meinen, ist die 'Undurchschaubarkeit', d.h. die undurchsichtige Bedeutung der sprichwörtlichen Redensarten. Die Bedeutung der 'einfachen Redensarten' ist dagegen 'durchsichtig/transparent' - sie kann aus der Bedeutung der einzelnen Komponenten erschlossen werden. ${ }^{10}$

In seinem linguistisch orientiertem Werk Phraseologie der deutschen Gegenwartssprache zieht Fleischer drei Kriterien zur Abgrenzung der Phraseologismen [Redensarten] von freien Wortverbindungen heran: 1)Idiomatizităt, 2)semantischsyntaktische Stabilität u.:d 3)Lexikalisierung und Reproduzierbarkeit. (S.35) Unter Idiomatizităt wird die Nicht-Ableitbarkeit der Gesamtbedeutung aus der Bedeutung der Teile verstanden (vgl. Lewandowski, S.404). Die Stabilităt hängt mit der Idiomatizităt

\footnotetext{
${ }^{10}$ Damit würde ich sie zur zweiten Gruppe in der Görnerschen Klassifikation rechnen.
} 
zusammen und verhindert den Austausch, die Ablanderung, das Weglassen und das Hinzufugen von Elementen in den Phraseologismus (Fleischer, S.41). Die Lexikalisierung und Reproduzierbarkeit bedeutet, daß die Phraseologismen (Redensarten) lexikalisiert werden, d.h. als lexikalische Einheiten gespeichert werden, und dann in der Kommunikation wieder als eine Einheit reproduziert werden (S.67-8).

\subsubsection{HERKUNFT DER REDENSART}

Für die Redensarten gilt Ähnliches wie für die Sprichwörter. Ihre Herkunft ist oft unklar, der vermeintliche Urheber unbekannt. So Röhrich/Mieder: "Über den eigentlichen Gebrauchsbeginn, die Entstehung oder Geburt sozusagen einer sprichwörtlichen Redensart wissen wir so gut wie in keinem Fall Bescheid. Wenn wir von einer Wendung sagen, sie sei >sprichwörtlich<, ist sie ja bereits Kollektivgut und hat dann meist schon einen mehr oder weniger langen Gebrauch hinter sich." (S.19) Vermutlich sind aber sprichwörtliche Redensarten zunächst vielfach nur Augenblicksbildungen, die dann wegen ihrer treffenden Formulierung Anklang fanden und weiterhin gebraucht wurden. Im allgemeinen ist der Urheber einer sprichwörtlichen Redesart ebenso unbekannt wie der eines Volksliedes oder eines Märchens.

Es gibt auch viele Redensarten, die aus anderen Sprachen entlehnt worden sind. Da die Hauptquellen in der Antike und in der Bibel liegen, kommen viele eingedeutschte Redensarten aus dem Griechischen, Lateinischen, Hebräischen und anderen Sprachen des Mittelmeerraumes. So Röhrich/Mieder: " Daß biblische Zitate zu frei verfugbaren 
Redensarten geworden sind, liegt weitgehend an der bewußt volkstumlichen Art, in der Luther die Bibel eindeutschte. Biblischen Ursprungs sind z.B. >im siebten Himmel sein< - ... > Die Spreu vom Weizen sondern< -... >einem das Leben sauer machen<." (S.20) Die Bildhaftigkeit ist in vielen sprichwörtlichen Redensarten nicht erklärbar. Rø̆hrich/Mieder finden sie geradezu phantastisch, so daß sie keinen Wirklichkeitshintergrund zu haben scheinen, z. B. >das Kind mit dem Bade ausschutten<...>einen Besen fressen > ..>leben wie Gott in Frankreich<...Sie spekulieren über die bloße Freude am krăftigsurrealen Sprachbild, der Lust am Paradoxen, denen sie ihre Entstehung vermutlich zu verdanken haben. Viele Sprichwörter stammen aus einem bestimmbaren kulturgeschichtlichen Hintergrund, wie z.B. aus dem Schusterleben: >alles über einen Leisten schlagen<. Vielfach verläuft die sprachgeschichtliche Entwicklung so, daß sich eine Redensart immer mehr vom Realbereich entfernt. Daher klingen sie dem heutigen Sprecher seltsam. Deshalb halten die Autoren eine gewisse Erklärungsbedürftigkeit fur ein Kennzeichen der Gattung: " >Am Hungertuch nagen<, - >in die Tretmühle kommen< - > Maulaffen feilhalten< sind z. B. solche erklärungsbedürftigen sprichwörtlichen Redensarten, die einen durchaus nachweisbaren Realsinn gehabt haben, die aber heutzutage nur noch bildlich verstanden werden. Ja sogar der ursprungliche Sinn der Einzelwörter ist meist unverstăndlich geworden, weil er zu weit in das vortechnische Zeitalter zuruckreicht, als daß wir heute noch wüßten, was Kerbhölzer, Tretmühlen, Maulaffen, Hungertücher, und dgl. dereinst waren und bedeuteten." (ebenda) Görner betont aber, daß man nicht den Schluß ziehen soll, alle Redensarten würden geprägt in der Zeit, auf die die in ihnen vorkommenden Wörter schließen lassen. Manche sind erst später entstanden. (S.S) Dies 
stimmt mit dem uberein, was weiter unten uber die Entstehung neuer Redensarten angenommen wird, d.h. neue Redensarten werden aufgrund von alten Formeln gebildet.

\subsubsection{STILISTISCHE MERKMALE DER REDENSART}

Nach Lewandowski sind die stilistischen Merkmale von Redensarten "volkstumliche Kürze und Prägnanz, (oft derbe oder pralle) Anschaulichkeit bzw. Bildhaftigkeit, Übertreibungen, Euphemismen (z.B. >lange Finger machen<), formelhafte Ausdrïcke, Wiederholungen, veraltete Formen (z.B. >(mit) Kind und Kegel<), schließlich eine gewisse Expressivität (z.B. >eine neue Platte auflegen<)." (S.824) Röhrich/Mieder ziehen Parallelen zwischen Redensarten und Sprichwörtem, was die Bildhaftigkeit betriff: "Die lebendige Sprache bevorzugt immer den bildkräftigeren Ausdruck." (S.55) Sowinski meint, daß die Redensarten "trotz ihrer Formelhaftigkeit noch durch eine gewisse Anschaulichkeit wirken und deshalb gern im volkstümlichen Sprechen verwendet werden (z.B.> im Stich lassen<, > aus dem Stegreif vortragen<, >es ist fünf vor zwölf< usw.)" (S.259)

Im einzelnen wurden einige beliebte rhetorische Figuren oben bei der Beschreibung der verschiedenen Redensarten-Kategorien schon erwähnt, also Stabreim, Endreim, Geminatio; dazu kann man noch die Tendenz zur Verkürzung hinzufügen. Manche Redensarten sind durch Verkürzung aus sprachlich längeren Wendungen entstanden, so z.B. >eine.n eins auswischen< aus ursprünglich > einem ein Auge auswischen<. Ähnlich $>$ einem etwas anhängen< aus >einem ein Schandzeichen anhängen<. Röhrich/Mieder 
stellen fest: "Je bekannter Sprichwort und Redensart durch häufige Anwendung und vielfachen Gebrauch werden - und Sprichwort bedeutet ja dem Wortsinn nach 'vielgesprochenes Wort' -, desto mehr neigen sie zur Verkürzung, desto mehr genügt die bloße Andeutung." ( S.19)

Zum Schluß sei noch ihre Feststellung (S.18-19) erwähnt, daß neue Redensarten nach dem typischen Form-Modell ălterer Redensarten geprägt sind, und dann immer wieder abgewandelt und variiert werden. Solche Variantenbildungen sind z.T. oikotypisch, regional oder nach verschiedenen Sprachbereichen differenziert.

\subsubsection{BEDEUTUNG DER REDENSART}

Wie oben schon dargelegt wurde, bewegt sich die Bedeutung der Redensarten von relativ transparent bis zu völlig undurchschaubar. Ich würde hier eine Metapher aus der Chemie heranziehen - sprichwörtliche Redensarten sind wie chemische Verbindungen, in denen aus mehreren Elementen eine neue Materie ensteht, die andere Eigenschaften aufweist als ihre Bestandteile.

\subsubsection{FUNKTION, GEBRAUCHSWEISE UND WIRKUNG DER REDENSAR'T}

Redensarten müssen immer in einen Text 'eingebettet' werden. Da wirken sie durch ihre Merkmale auf den Text, in dem sie vorkommen. D.h. ihr Gebrauch stellt, wie bei den Sprichwörtern immer einen Fall einer intertextuellen Anleihe dar. 
In bezug auf das Medium findet Mieder, daß die Redensarten vor allem in der mündlichen Kommunikation ihre Verwendung finden, wo sie fast unbewußt die Ausdruckskraft der Mitteilung verstärken. "Ganz bewußt bedienen sich ihrer aber alle, die sich an ein breiteres Publikum wenden: Zeitungen, die Werbung, Reklame, die politische Propaganda." (S.91-2) Ihre Bildhaftigkeit kommt dem Streben nach "Allgemeinverstăndlichkeit des sprachlichen Ausdrucks" zugute. Weiterhin emotionalisieren und dynamisieren sie die Sprache. Mieder hebt den Gebrauch der Redensarten als Zeitungsschlagzeile hervor. In diesem Kontext dienen sie als "volkssprachlicher Blickfang", der den folgenden Artikel "bildlich zusammenfaßt und zum Weiterlesen auffordert." (ebenda) Für Herles sind die Redensarten "eher ornamental als funktional". Sie geben der Sprache einen "bildlichen Charakter". Sie sind noch eine produktive Kategorie: "Redensarten bilden sich siandig neu." (S.73) Außer den neuen Redensarten gibt es auch die neuen Redensartparodien, die einen komischen Effekt auslösen (Röhrich/Mieder, S.116), wie z.B. >es geht mir durch Mark und Pfennig< oder >Mit dem einen Fuß stand er im Grabe, mit dem anderen nagte er am Hungertuch<.

\subsubsection{GEMEINSAMKEITEN UND UNTERSCHIEDE ZWISCHEN SPRICHWORT}

\section{UND REDENSART}

Wie man aus der obigen Ausfuhrung schließen könnte, teilen Sprichwörter und

Redensarten viele stilistische Merkmale:

-Sie sind ahnlich konstruiert, indem sie kurz und bündig sind. 
-Sie sind formelhaft.

-Sie streben nach Rhythmus und Wohlklang.

- Sie neigen zur Bildhaftigkeit in der Sprache.

-Sie sind 'volkstümlich', d.h. sie sind den Muttersprachlern wohl vertraut.

-Sie haben eine gleiche Geschichte, d.h. sie werden als anonyme Prägungen empfunden.

Der Hauptunterschied zwischen den beiden Formen besteht in ihrem syntaktischen Verhalten. Beide sind feste Strukturen, aber das Sprichwort ist vollständig, es erscheint immer gleich, wăhrend die Redewendungen erst in einen konkreten Kontext mit allen nötigen syntaktischen und morphologischen Änderungen eingebettet werden müssen. Das kommt daher, daß auf der Textebene Sprichwörter 'Mikrotexte' darstellen, und wie Zitate in einen Text eingesetzt werden, wăhrend die Redensarten mit lexikalischen Einheiten äquivalent sind und durch alle morphologischen und syntaktischen Änderungen gehen müssen, die für eine lexikalische Einheit bei der Inkorporierung in einen Text notwendig sind (D.h. sie bekommen ein konkretes Subjekt, folglich geht das Verb in eine finite Verbform über, usw.). Dazu ist bei den Sprichwörtern eine lehrhafte und moralisierende T^ndenz zu beobachten, während die Redensarten in dieser Hinsicht neutral sind. So wird z. B. ein positiver Begriff wie 'Glück' mit einem Tier bezeichnet, das in der 'Volksmetaphorik' als ein Träger ausgesprochen negativer Werte empfunden wird - es heißt >Schwein haben<. Redensarten unterscheiden sich von Sprichwörtern dadurch, dals sie keine Lebenserfahrungen und -regeln aussprechen (und somit uber keine inhaltliche Geschlossenheit verfügen). Die sprichwörtlichen Redensarten sind völlig idiomatisiert, d.h. semantisch undurchschaubar, während der semantische Inhalt der Sprichwörter 
(wenigstens oberflăchlich) dem normalen Sprachgebrauch entspricht.

Es gibt eine Gruppe von Formen, die einen Grenzfall zwischen Redensarten und Sprichwörtern darstellen. Es handelt sich hier um Redensarten, die eine feste Form haben.

Das sind starre phraseologische Verbindungen, die zwar einen Satz für sich bilden, z.B.

$>$ Das geht auf keine Kuhhaut!<, oder $>$ Es ist höchste Eisenbahn! $<$, jedoch keinen

Eigenwert besitzen, sondern sich auf etwas zuvor Gesagtes beziehen müssen.

(Röhrich/Mieder, S.17) 


\section{Die Werbesprache}

\subsection{Werbung}

\subsubsection{DEFINITION DER WERBUNG}

Unter Werbung verstehen die Theoretiker die Tätigkeit, mit der versucht wird. potentielle Kunden dazu zu bewegen, eine bestimmte Ware oder Dienstleistung zu kaufen. Für Schlüter ist Werbung "im engeren Wortsinn die überredung zum Kauf eines Produkts. d.h. einer Ware oder einer Dienstleistung. Nicht zur Werbung gehören strenggenommen die Anzeigen, soweit in ihnen nicht überredet, sondern nur informiert wird." (61) Ruth Römer faßt es folgendermaßen zusammen: "Ziel und Zweck der M, rbung, zu dem sie die Sprache einsetzt, ist es, einen Menschen zu einem Kauf zu veranlassen, zu einem Kaul zu überreden. ... Zur Überredung werden bestimmte rhetorische Mittel benutzt." (S.173) Dic Absicht der Überredung zum Kauf ist beiden Definitionen gemeinsam und wird als Ziel der Werbung oder gar als Wesen der Werbung gesetzt.

\subsubsection{ARTEN DER WERBUNG}

Schlüter unterscheidet folgende 'Arten' der Werbung:

i) Verkaufswerbung, wo eine Ware abgesetzt wird, und Image- oder Good WillWerbung, wo eine Firma oder Branche ihr Ansehen zu erhöhen sucht;

ii) Einführungs-Werbung, wo ein neues Produkt angeboten wird, und Repräsentations-Werbung, wo ein schon bekanntes Produkt in der Erinnerung der potentiellen Käufer befestigt wird;

iii) Werbung für Investitionsgüter, wo mehr mit sachlichen Argumenten und 
Informationen geworben wird, und Werbung für Konsumgüter, wo die Kaufimpulse und die Triebe geweckt werden sollen. (S.60)

\subsubsection{VERHÄLTNIS VON BILD UND SPRACHE IN DER WERBUNG} In bezug auf das Medium wurde ich folgende Elemente einer Werbeanzeige unterscheiden: 1) das Bildliche, d.h. Fotografien, Zeichnungen, Filme, u.ä. 2) das Sprachliche, das entweder geschrieben oder gesprochen (und auch gesungen) wird, und 3) das Auditive, z.B. Musik oder begleitende Geräusche. Welche Elemente in eine konkrete Anzeige miteinbezogen werden, hängt dann offensichtlich vom Medium ab, ob die Anzeige gedruckt oder verfilmı oder für das Radio aufgenommen wird. In dieser Arbeit wurden nur Anzeigen in Zeitschriften berücksichtigt. In dieser gedruckten Form ist eine nur aus Text bestehende Werbeanzeige zwar möglich, aber selten. Am häufigsten werden Text und Bild kombiniert. Ein Bild allein als Werbeanzeige ist auch sehr unwahrscheinlich. Man würde wenigstens den Markennamen erwarten, der ja textuell sein muß, sonst wäre das Bild wahrscheinlich als Werbebotschaft unverständlich (was wird hier als Ware angeboten?). Außerdem herrscht die Meinung, daß das Wort eine stärkere Gedächtniswirkung hat als das Bild. (Schlüter S.65) Auch Römer mißt der Sprache in der Werbung große Wichtigkeit zu: "Trotz der Wichtigkeit dieser Faktoren [Bild, Farbe, Ton] kann kein Zweifel daran sein, daß die Sprache das Hauptmedium der Werbung ist." (S.24)

Das Bild und der Text stehen in enger oder loser Beziehung zueinander. In dieser Arbeit 
wird nicht auf diese Beziehung eingegangen. In der Beispielanalyse wird gelegentlich das Bild kommentiert, aber dabei geht es nur um persönliche Bemerkungen, keinesfalls um eine wissenschaftliche Erörterung.

\subsection{Der Werbetext}

\subsubsection{DEFINITION}

Lewandowski versucht, 'Werbesprache' zu definieren, indem er sowohl ihre Merkmale wie die Merkmale der Adressaten berücksichtigt: "Sprache, die neben der Information über den jeweiligen Gegenstand der Werbung inhaltliche und formale Stimulations- und Manipulationseffekte enthält, die dem Adressaten meist nicht bewußt werden." (S.1179) Mit Rucksicht auf psychologische Strukturen (Bedürfnisse, Wünsche, Prestigevorstellungen) werden inhaltlich oft vage und mehrdeutige, klanglich und rhythmisch eingängige sprachliche Formen kreiert (z.B. Werbeslogans), die ein Produkt intensional charakterisieren und, je nach Adressatengruppe, mehr oder weniger direkt au bestimmten Entscheidungen motivieren sollen. (ebenda) In der einschlägigen Literatur wird jedoch die Werbesprache an sich selten definiert. Man geht vielmehr von einer Definition der 'Werbung' aus, und setzt voraus, daß 'Werbesprache' die Textsorte bezeichnet, die zur Erfüllung der Zwecke der Werbung eingesetzt wird. Römer, z.B., bedauert die Lage in der Werbelehre, wo "sich die Werbeleute nicht dessen bewußt zu sein [scheinen], daß die Sprache ihr Hauptmittel ist, [Werbe]Wirkung zu erzielen". (S.28) Möckelman/Zander sehen in der Sprache der Werbung ein nur auf Wirkung berechnctes, nur yon seinen Funktionen her bestimmtes Kommunikationsmittel. (S.4) (Hervorhebung - 
B.V.) Ich würde die verschiedenen Meinungen (Motivierung zur Kaufentscheidung, Wirkungsorientiertheit) in der Feststellung zusammenfassen, daß der Zweck der Werbung im Überreden zum Kauf besteht. Aus dem Blickpunkt der Sprechakttheorie würde sich ergeben, daß die Illokution des Werbetextes in der Überredung liegt. Rhetorisch betrachtet, gehört der Werbetext zur anpreisenden Rede (Epideixis), die wiederum eine Unterart des Genus der Lob- und Tadelrede (genus demonstrativum) darstellt. Bei einigen Autoren findet sich aber eine Systematisierung dessen, was 'die Funktionen des Werbetextes' genannt wird. Hier handelt es sich eigentlich mehr um Schritten, mit denen der Text seine illokutive Aufgabe der Überzeugung zum Kauf erfüllt. Diese Schritte entsprechen den strukturellen Teilen des Werbetextes. Deshalb werden sie im nächsten Abschnitt bsprochen.

\subsubsection{STRUKTUR DER ANZEIGE}

Nach Plate gibt es drei 'Hauptfunktionen der Reklamesprache'"': die 'Herstellung der Kommunikation', die 'Darstellung' und die 'Auslösung'. (S.548) Ähnlich unterscheidet Dreier vier Schritte in der Werbung (nicht nur imWerbetext) : Erregung der Aufmerksamkeit, Darstellung des Angebotes, Bedarfserweckung, Herbeifuhrung von Kaufentscheidungen. (S.88-98) Nach Schlüter hat der "Text einer vollständigen Einfuhrungswerbung gewöhnlich, wie der Text jeder Rede, drei Teile. Der erste Teil, die

11

Unter 'Reklamesprache' versteht er sowohl die Sprache der Werbung als auch die Sprache der politischen Propaganda. 
Einleitung, bestehend aus 'Zuruf' oder 'Aufhănger'. hat wie in der klassischen Rhetorik die Funktion des Aufmerksam-Machens (attentum parare)." (S.65) Ruth Romer spricht in diesem Fall von der 'Schlagzeile', die meist über der Anzeige steht. (S.79) Ihre Funktion ist, die Aufmerksamkeit des Lesers auf den nachfolgenden längeren Anzeigetext zu lenken. (Möckelmann/Zander, S.7) Der Hauptteil enthält die Überleitung und das eigentliche Argument, je nachdem als sachliche Beweisfuhrung oder als Entfaltung eines Wunschzustands. Der Schluß faßt gewöhnlich die Argumentation zusammen. Da er immer auch den Namen des Produkts noch einmal wiederholt, wirkt er als eine Art Unterschrift. Die englischen Bezeichnungen dieser drei Teile heißen 'headline', 'body copy', 'signature-line'.

\section{Der Slogan}

Der Slogan verdient gesondert erwähnt zu werden, denn er steht außerhalb des Werbetextes an sich und ist von diesem unabhängig. Der Werbetext oder das Werbebild mögen sich ändern, aber der Slogan bleibt derselbe. Ruth Römer definiert den Slogan als "eine Aussage, welche die Ware entweder unverändert oder mit leichten Abwandlungen ständig begleitet, also in jeder Anzeige auftaucht und auch in der Tonwerbung mitgesprochen wird." (S.79) Der Slogan wirkt unabhängig vom restlichen Anzeigetext; deshalb muß er in sich die Funktionen des Anzeigetextes vereinigen und sie alle gleichzeitig erfullen. Aber im Verhältnis zum eigentlichen Anzeigetext weist er spezifische Merkmale auf. Vor allem muß er leicht einpragsam sein. Dadurch merken sich die Hörer die Warennamen, die ihn ständig begleiten. Möckelman/Zander finden, 
daß die stilistischen Merkmale, die zur Einprägsamkeit des Slogans dienen, eigentlich zuerst andere Funktionen erfullen und die Einprägsamkeit nur ihre Nebenwirkung darstellt. (S.27-8) Sie unterscheiden die stilistisch rhetorischen Mittel von den psychischemotional wirkenden Maßnahmen, die beide zur besseren Einprägsamkeit des Slogans führen.

i) Die stilistisch-rhetorische Mittel:

- $\quad$ repetitive Mittel, z.B. Reim, Wiederholung von Wörtern, die für die Darstellung des Angebots semantisch bedeutsam sind, Alliteration;

- rhythmischer Parallelismus;

- durchgehendes Versmaß, klangvolle Phoneme, usw;

- $\quad$ relative Kürze des Slogans;

- $\quad$ einfache Syntax (einteilige oder zweiteilige Sätze, häufig asyndetisch);

- anschauliche und emotiona! ansprechende Ausdrücke, Metaphern, Vergleiche, Lautmalerei; ${ }^{2}$

- Antithese, direkter oder indirekter Imperativ, Superlation und Superlativ, Klimax, originelle Zweideutigkeit, Parodie.

ii) Psychisch-emotional wirkende Maßnahmen:

- die verschiedenen Arten des 'Apells an das Unterbewußtsein'; appelliert ein Slogan an ein intensives emotionales Bedürfnis, dann wird die

12

Was in der Diskussion über die Sprichwơrter und Redensarten 'Bildhaftigkeit' genannt wurde. 
Aufmerksamkeit des Umworbenen in hohem Maße erregt.

Schluter sieht den Slogan als den "Kern- und Kulminationspunkt jedes Werbetextes". Er sieht ihn auch als Hauptmittel der Repräsentationswerbung: "Repräsentationswerbung besteht vor allem in der Wiederholung des Slogans." (S.6) Das kommt wohl davon, daß Warenname urd Slogan durch das stăndige Zusammensein im Gedächtnis der Hörer untrennbar gespeichert sind. Klotz findet, die Wirksamkeit des Slogans liege in seinen stilistischen Merkmalen: "Die Schlagkraft des Slogans liegt in seiner Kürze, seiner grammatischen Beweglichkeit, seinem klanglich-rhythmischen Schlupf. Sie machen ihn als Ganzes prima vista überschaubar, einprägsam und wiederholbar. Diese Eigenschaften - im Gegensatz zu einer sachlich erklärenden Prosapassage - befehlen zugleich und gestatten ihm auf dem Wege der Verdichtung und Auslassung Ambiguitäten im Wort und im Satzbau." (S.544)

\subsubsection{MERKMALE DER WERBESPRACHE}

Nach Sowinski gehört die Werbesprache zu den Textformen, die mehr Freiheit in der Wahl der sprachlichen Stilmittel ${ }^{13}$ erlauben. Im Gegensatz zu juristischen, geschăftichen, verwaltungsinternen, sachinformierenden und vorschreibenden Texten, die verhältnismäßig invariabel sind, besteht "in anderen Textbereichen ... eine größere Wahlmöglichkeit innerhalb der Stilmittel, so vor allem im Rahmen der literarischen

13

Gemeint sind wohl rhetorische Mittel. 
Textformen, in der Sprache der Werbung, im personlichen Schriftwechsel und in der mundlichen Rede." (S.67) Im Gegensatz zu lehrhafter Rede, die sich an grammatische und sonstige Regeln halten muß, gehört die Werbesprache zur rhetorischen Rede, die sich gerade durch Abweichungen von der sprachlichen Norm zur Erzielung bestimmter Effekte auszeichnet. (Schluter, S.25-6)

\subsubsection{Rhetorische Strategien}

\section{a) Wiederholung der Anzeige}

So gut der Werbetext auch verfaßt sein mag, muß er oft vor dem Publikum wiederholt werden, um einen optimalen Werbeeffekt zu erzielen. Römer beruft sich auf den Psychologen Le Bon, der die Wiederholung neben der Behauptung und der Übertragung (von Ideen) für ein ausgezeichnetes Mittel zur Führung von Massen hält "Wenn man hundert mal gelesen hat, die beste Schokolade sei Schokolade X, man bildet sich ein, er habe es häufig gehört, und glaubt schließlich, es sei wirklich so." ${ }^{14}$ (S.174) Meistens wird nur der Slogan wiederholt, da er den beständigen Begleiter der Ware darstellt. Der Rest des Textes und das begleitende Bild werden variiert, um erstens Langeweile durch das ständige Wiederholen zu vermeiden, und zweitens die Ware und den Slogan in möglichst vielen passenden Situationen einzubetten.

Der Originalzitat lautet: "Quand nous avons lu cent fois, que le meilleur chocolat est le chocolat $X$..., nous nous imaginons l'avoir entendu dire fréquemment et nous finissons par en avoir la certitude." (Le Bon, S.73) 
b) Fesseln der Aufmerksamkeit und Einprägung im Gedăhtnis des Rezipienten Ein anderes Moment der Werbesituation ist das eigentliche Desinteresse der Offentlichkeit für die Werbebotschaft. Schluter bemerkt, daß die Werbung "nur mit schweifender und fluchtiger Aufmerksamkeit rechnen kann." (S.65) Daher muß die Aufmerksamkeit der potentiellen Kăufer gefesselt werden. Dies trifft besonders bei banalen Konsumgütern zu. Aber bloß Aufmerksamkeit zu erregen genügt nicht. Die Werbebotschaft muß sich im Gedächtnis der potentiellen Käufer einprägen. So sagt Schlüter (ebenda) von der Werbung, daß "sie hauptsächlich auf Gedăchtniswirkung ausgeht und nicht auf das Erzeugen einer momentanen Stimmung". (ebenda)

Um die Aufmerksamkeit auf sich zu lenken und sich einzuprägen, greift der Werbetext eben zu bestimmten rhetorischen (stilistischen) Mitteln und psychologischen Strategien . Hier sei nur die rhetorische Figur der 'Aufrüttelung' genannt, die ihre Wirkung durch Überraschung gewinnt. Ich habe das folgende Beispiel gefunden: Bevor Sie von Ihrer Ablage erschlagen werden. (F 19/95) als Schlagzeile in einer Anzeige für einen CANON Kopierer. Mann kann sagen, daß alle rhetorische Figuren durch Abweichung vom normalen Sprachgebrauch mehr oder weniger auch zum Fesseln der Aufmerksamkeit dienen. Die für Werbetexte charakteristischen rhetorischen Figuren werden weiter unten einzeln erörtert.

c) Verbergen der Absicht zu überzeugen / Tarnung der Epideixis Klotz stellt fest, daß in Werbeanzeigen der mittlere Schritt auf dem Weg von der Ware 
zum Kăufer, d.h. der Austausch von Geld gegen Ware, übersprungen wird. Der Kaufvorgang wird absichtlich ubersehen und nur der endgulltige Zustand, d.h. der Besitz der Ware, dargestellt: "Damit wird dem Verbraucher eingeredet, er stünde nicht mehr vor der Entscheidung zum Kauf, sondern er habe sie bereits samt dem lästigen Geldopfer hinter sich." (S.539) Auch Lewandowski sieht im Verbergen der Beeinflussungsabsicht eine der Voraussetzungen der Werbewirksamkeit. (S.1179) Ähnlich bemerken Möckelmann/Zander, daß "die Aufforderung zum Kauf ... sich in den meisten Reklamen erst sekundär [ergibt]." (S.43-44)

d) Abwesenheit der rationalen Argumwntation und Scheinobjektivität Diese Werbestrategie kann man einerseits als Resultat des oben erörterten Bedürfnisses, die eigentliche überzeugende Absicht der Anzeige zu verbergen, und andererseits als Folge des Mangels an objektiver, sachlicher Information erklären (siehe unten). Anstatt vollständiger Syllogismen werden von der werbenden Argumentation Enthymemen's bevorzugt. Andere Mittel, Scheinobjektivität zu erzielen, sind die rhetorische Figur des 'Zugestăndnisses' und die damit verbundene ( selbstverständlich falsche) 'Bescheidenheit'. Als Illustration für das Erstere habe ich folgendes Beispiel gefunden: Wenn wir die Dinge manchmal etwas kritischer betrachten, dann nur zu Ihrem Vorteil. (Sp 28/95) in einer Anzeige furr eine Versicherungsfirma. Als Beispiel für das Letztere habe ich die

is

Es handelt sich um abgekürzte Syllogismen, wo ein Schritt ausgelassen wurde, weil er vom Sprecher als selbstverständlich angenommen wurde. 
folgende Schlagzeile gefunden: Würden Ihnen zwölf Reisen pro Jahr fürs erste genügen? (F 19/95) in einer Anzeige fur ein Reise- und Kulturmagazin. Mőckelmann/Zander vermerken im Einzelnen den "vorweggenommenen Einwand" und ahnlich das "Umkehren eines negativ gemeinten Einwandes in ein zu eigenen Gunsten sprechendes Argument." Schluter findet die Anwendung der rationalen Argumentation im rhetorischen Sinne nur in der Werbung für die sogenannten Investitionsgüter ${ }^{16}$. (S.61-63)

e) Das Appellieren an das Unterbewußtsein

Schlüter (ebenda) stellt fest, daß die meisten Konsumgüter (d.h. zu verbrauchende Güter) entweder aus Genußsucht gekauft werden, wie etwa Zigaretten, oder sich schon auf einem so hohen Qualitătsgrad befinden, daß unter den verschiedenen Marken in der Tat kein Unterschied besteht. In beiden Fällen muß die Werbung nicht an den Verstand appellieren, sondern eher an das Unterbewußtsein. Auch Möckelmann/Zander finden sogar in längeren Werbetexten nur wenig sachliche Information. ${ }^{17}$ Dafür "dominieren [in der Sprache der Werbung] die Appelle an das Gefuhl und das Unterbewußtsein". (S.29) Das ist hauptsăchlich Folge der "Erkentnis der Motivforschung, daß in der Reihe der Motive, die den statistisch ermittelten 'Normalverbraucher' zu Kaufentscheidungen

Was er unter 'Investitionsgütern' versteht, erklärt er nicht. Ich würde annehmen, daß er damit Gegenstände meint, die nicht verbraucht werden, sondern längere Zeit benützt werden und relativ teuer sind. Als Beispiel gibt er einen Ölbrenner. 17

Die Autoren haben zwar Slogans untersucht und in ihrem umfangreichen Korpus wenig sachliche Informationen gefunden, aber ihrer Meinung nach liegt das an der Kurze des Slogans als Form. 
bringen, rein sachliche Argumente an letzter Stelle stehen". (S.30-1) In Ahlehnung an Vance Packard (The Hidden Persuaders S.72-83) fuhren die Autoren aus, wie die Werbung bestimmte Waren mit bestimmten emotionalen Nebenbedeutungen versieht, wie z.B. Sicherheitsgefuhl, Kraftgefühl, Liebesobjekte, usw. (S.36) Sie fanden bei der Analyse ihres Korpus, daß der Appell an die emotionalen Wünsche und Bedürfnisse durch direkte verbale Verweisungen auf diese emotionalen Nebenbedeutungen der Waren geschah. Diese Verweisungen werden noch durch thetorisch-stilistische Maßnahmen unterstuzt, die auch sonst zur Hervorhebung und Einprägsamkeit dienen. ${ }^{18}$

f) Schaffen oder Erwecken der Bedürnisse

Der potentielle Konsument muß überzeugt werden, daß er das Produkt braucht. Dies trifft insbesondere bei neuen Produkten zu.

g) Anlehnung an vorgeprägte sprachliche Muster

Herles findet die "Übernahme traditioneller und volkstümlicher Elemente" nicht verwunderlich, wenn man die "Absicht der Werbenden" erkennt, "im Leser, Hörer und Zuschauer Unterbewußtes anzusprechen und Vertrautes zu wecken". Er meint, daß "die Werbung durch den Apell an Traditionsgefuhle Käufer gewinnen [will]". (S.68) In seiner

Diese Maßnahmen sind ausfuhrlicher beschrieben in den Abschnitten über die Merkmale des Slogans und der Werbesprache überhaupt 
Untersuchura, der Slogans stellt Klotz fest, daß der Slogan seine Glaub ;urdigkeit dadurch zu bekrăftigen sucht, "daß er auch klanglich, rhythmisch und syntaktisch sich anerkannten und vertrauten Spruchen und Formulierungen angleicht." (S.541) Er vergleicht die Tendenz des Slogans, sich an bekannte sprachliche Formeln anzulehnen. mit Steherrennen: "Wenn der Slogan durch Kontrafaktur oder formale Analogic sich vom Sprichwort oder äinichem ziehen läßt wie der Radler beim Steherrennen, nimnit er teil an Schlagkraft und Renommee des Vorläufers. Einem homo novus gleich dringt der Slogan in die gute Gesellschaft ein, incem er durch Imitation eines bewährten und Lauii:ionsgeprägten Standes sich mit Prestige a nzureichern sucht." Unter 'vorgeprägten sprachlichen Mustern' versteht Klotz Formen wie Redensart, Sprichwort (Rauche, staune, gute Laune aus >Trau, schau, wem<), Abzählreim (Mir und dir - Bindinghier aus >ich und du, Müllers Kuh<), Zitat (Kaba, Kaba, hält dich gesund aus >Kuckuck, kuckuck, ruft's aus dem Wald<), usw. Möckelmann/Znnder nehmen diese Ansicht von Klotz, die die Vorliebe des Slogans für 'vorgeprägte sprachliche Mustern' betont, auf, und setzen sie fort. So finden sie, daß eine formale Ähnlichkeit mit dem Sprichwort dem Umworbenen eine Allgemeingültigkeit des Slogans (wie sie das Sprichwort für viele Menschen besitzt) souffliert, die aber faktisch nicht gegeben ist, weil der Slogan immer etwas Besonderes meint. Diese Diskrepanz zwischen Allgemeingültigkeit, die durch die Form behauptet wird, und dem Besonderen, auf das der Slogan eigentlich zielt, ist nicht aufzuheben. Sic darf dem potentiellen Käufer nur nicht bewußt werden, und damit sie aber dem Umworbenen nicht auffallt, bemühen sich die Werbetexter, das Allgemeingültige besonders zu betonen. Das geschieht am stärksten durch wörtliche Übernahme des 
Sprichwortes in den Slogan. (S.77) Der Slogan, dem Muster des Sprichworts folgend, ist schcinbar abgeründet und bestätigt, und giht vermeintlich ein Fazit wieder, das aus lirfahrungen gewonnen ist, die jedermann teilt. Tatsächlich jedoch ist er nicht dem Allgemeinen hörig, vielmehr einem Sonderinteresse. Viele andere Forscher betonen auch die Vorliebe der Slogans für volkstümliche Formeln. So sagt Herles: "Das Sprichwort ist die geschlossenste volkstümliche Form, die die Texter benutzen können. Es erfüllt am leichtesten die Definition des Slogans." (S.70) Auch Röhrich/Mieder sind ählicher Meinung: "Werbetexter greifen gern auf das vorgeprägte Baumuster eines Sprrichworts zurück, da dadurch der dem Sprichwort eigene Autoritätsanspruch sowie dessen Glaubwürdigkeit auf die Werbebotschaft übertragen werden." (S.5) Was die Häufigkeit von Sprichwörtern gegenüber den Redensarten angeht, stellen Möckelmann/Zander fest, daß Redensarten viel häufiger als Sprichwörter in Slogans eingebaut sind. Den Grund dafür sehen sie in der offenen syntaktischen Form der meisten Redensarten, die sich oft schon allein durch das A..hängen eines Wara.uramens zu einem in sich geschlossenen Gebilde machen lassen. Die abgerundete und geschlossene Form der Sprichwörter muß dagegen erst aufgebrochen werden, ehe man den Produktnamen einfügen kann. Da beide dieselbe Funktion übernehmen können, nämlich 'Schrittmacher' für die Slogans zu sein, so greifen die Werbefachleute eher zu den Ridensarten. (S.83) Auch Mieder stellt fest, daß die Redensarten "sich leicht in einen Satz einbauen" lasscn, was vor allem von ihrer Konstruktion abhängt: sie sind syntaktisch nicht voliständig und können beliebige morphologische Merkmale übernehmen, um in einen Satz zu passen. (S.91) In der Werbung erzielen sie positive Effekte durch die Vertrautheit des Klanges, wie es bei den 
Sprichwörtern auch der Fall war: "Diese Verbindung von Wirtschaftserzeugnis und Redensart [bringt] mit sich, daß der Käufar dem Produkt gegenüber von vornherein positiv eingestellt ist, denn Sprichwort und Redensart sind allgemein bekannt und allgemein gültig und darum eben sehr geeignet. ein noch unbekanntes (und auch bekanntes) Fabrikat mit dem Schein der Gebräuchlichkeit zu umgeben."(ebenda. S.97) Weiter sieht Mieder die Werbewırksamkeit der redensartlichen Überschriften darin, dał sie Altes und Modernes geschickt zu vereinen wissen. (ebenda, S.98) Traditionelles Wortgut wird mit neuen Erkenntnissen und Erzeugnissen verbunden. was der Werbung einen herkömmlichen Charakter verleiht. Mit Redensarten läßt sich aber auch ein komisc ner Effekt erzielen, wenn man stat! des idiomatischen Sinns, den wörtlichen Sinn einzelner Elemente darstellt und die Redensart als eine nichtidiomatische Phrase behandelt, entweder im Bild, im Warennamen, usw.: "Solche doppelten Spielereien mit den sprichwörtlichen Redensarten lassen sich gerade in der Illustriertenwerbung finden".(ebenda, S96) Gemeint sind Wortspiele, wo die Redensart in ihre Elemente zerlegt wird und diese buchstäbliche Bedeutung dann in der Anzeige illustriert wird. Eigentlich handelt es sich in all den Beispielen, die ich gefunden habe, um diese Verfremdung der Redensartbedeutung, durch den Einsatz der wörtlichen Bedeuting. Durch das Bild unterstützt ähneln die Illustriertenanzeigen jenen Illustrationen der Sprichwörter und Redensarten aus der Renaissance ${ }^{19}$. Für Herles (S.74) steht das Bildhafte der sprichwörtlichen Redensarten an erster Stelle: "Was dic Werbung mit 
Bildern versucht, soll die Redensart ohne Bild im Text erreichen, sie soll ausschmücken, Bildvorstellungen wecken, Vertrautes evozieren. Während das Sprichwort im Slogan allein gebraucht wird und die Funktion eines Slogans erfullt. hat die Redensart im 'Text' ihre Funktion. Sie steigert dort das Niveau und kommt dem Bedürfnis der Umworbenen entgegen, da sie vom Sprachschatz der Umworbenen ausgeht."

Zum Schluß läßt sich zusammenfassen:

-Die Werbewirksamkeit der Sprichwörter besteht in: 1) ihrem Inhalt, wo sie als Argumente zum Überzeugen eingesetzt werden und wo ihr Autoritätsanspruch ihnen als Argumente mehr Gewicht gibt; 2) ihrer Form, die durch bestimmte rhetorische Mittel besonders gefällig und einprägsam gestaltet ist; und 3) ihrer Bekanntheit, die den Rezipienten der Werbebotschaft gegenüber positiv einstimmt (Denn auf vorher oft gehörte Argumente geht man eher ein.

-Die Werbewirksamkeit der Redensarten besteht in der Zerlegung ihrer Bedeutung in die Bedeutung ihrer Elemente mit dem Effekt der Verfremdung oder Komik. Der Rezipient findet solche Texte einfallsreich und clever.

\subsubsection{Rhetorische Mittel}

a) Wiederholung

Mit 'Wiederho!ung' wird hier das Wiederholen sprachlicher Elemente innerhalb des Werbetextes gemeint, und nicht das Wiederholen des Textes selbst oder seiner Teile (was natürlich für den Absatz auch günstig sein dürfte). Nach Ruth Römer ist die 
Wiederholung "der oberste Grundsatz und das am meisten angewandte rhetorische Mittel aer Werbung." (S.173) Schlüter sieht in der Wiederholungstechnik das Erfüllen der Foderung nach Eindringlichkeit und Nachdruck in der Redekunst. (S.69) Damit verbunden ist auch ihre suggestive Kraft. (Möckelmann /7ander. S.54)

\section{Wiederholung im lexikstıschen Bereich}

- $\quad$ iteratio / gemincilio und Variation: Durch Wiederholung lexikalischer lilemente werden diese Elemente hervorgehoben. Schlüter meint, daß die Werbung nur die wörtliche Wiederholung (ileratio) vermeidet, weil hier der Text langweilig zu werden droht. Aber eine Ausnahme dieser Regel ist die Wiederholung des Markennamens selbst, die im Werbetext durchaus wünschenswert ist, da sie das Einprägen fördert. Auch Sowinski macht auf Wortwiederholungen in der Werbesprache in bezug auf Warennamen aufmerksam: "Der Name der Ware oder der Firma soll hier unbedingt auffallen; er erscheint daher meistens in Bildern. Übersch riften und mehrmals im Text, oft an auffallenden Satzstellen oder im pointierten Schlußteil. Der Wortreihung als ständiger Wiederholung wird aber eine besondere Suggestivwirkung zugemutet." (S.62)

- Variation: Wiederholung mit Variation wird bevorzugt, um Langewcile zu vermeiden. In einigen Fällen dient diese Art der Wiederholung zur Verdeutlichung.

- Teilwiederholung (meistens von Teilen des Warennamens), z..13 ... TAX(IFTT macht wieder fit. (Möckelmann/Zander, S.53). Im Korpus erscheinen: EC 'IIINAC IN von MADAUS: Untersiüzt, was uns stützl: das Immunsystem. ( $\mathrm{Br} 23 / 93)$ oder Einweg. Mehrweg. Holzweg. (Br 24/93) oder Donau abwärts - Umsatz aufwärts. (Sp 49/95) 
- die Anapher: benachbarte Konstruktionen fangen mit dem gleichen Element an.

Z.B. Salat ist gesund. Salat mit Mazola ist besser. (ET 4/89) oder Mit Computern können Sie fast alles machen. Mit uns können Sie unterrichten.(Ss 3/95)

\section{Wiederholung im phonetischen Bereich}

Bei den klanglichen Wiederholungsfiguren kann man feststellen, daß sie dem Text "den Anschein von ästhetischer Abgerundetheit und Stimmigkeit verschaffen". (Möckelmann/Zander, S.54)

- $\quad$ Alliteration (Mütter mögen Milkana) (Br 18/92)

- $\quad$ Endreim (Ein cooler flotter für wenig Schotter) (J 19/95)

- Versmaß / Rhythmisierung (Blutzucker messen kein Problem II preiswert, sicher und bequem) (Bu 46/93)

Die Rolle des Endreims und Stabreims wird auch bei Sowinski hervorgehoben. (S.59) Herles stellt fest, daß während in der modernen Dichtung um den Endreim gerungen wird und seit Wagner kein Dichter mehr den Stabreim versucht hat, diese literarischen Mittel in der Werbung zu Hause sind. Vor allem der Stabreim lebt noch in der Reklame und damit in der Volkskultur. ${ }^{20}$ (S.75-6) Er rechnet diese Werbesprüche zur volkstümlichen Spruchdichtung.

Wiederholung im șntaktischen Bereich

20

Eigentlich ist hier mit 'Stabreim' nur die Alliteration gemeint. 
- die Parallelstruktur (isokolon): gern mit einer Steigerung oder mit wachsenden

Gliedern; z.B. Progressive wollen verändern. Konservative wollen bewahren. Innovotive wollen durch Veränderung bewahren. (F 19/95)

b) Figuren des lexikalischen Bereichs

- $\quad$ Neubildungen(Neologismen)

In der Werbung dienen sie zur Vertretung der umständlicheren Attributsätze. (Schlüter.

- $\quad$ Fremdwörter

In der Werbung vermitteln Fremdwörter oft den Eindruck von Wissenschaftlichkeit. "Wenn sie unverständlich genug sind, haben sie sogar eine Art magischer Aura...", sagt Schlüter. (S.30) Besonders in der Werbung für Kosmetik findet man eine Vielfalt von Fachtermini, wie "Liposome", "Alphahydroxy-Säure", usu

- $\quad$ Metapher

Am Beispiel des Slogans Renni räumt den Magen aufillustrieren Möckelmann/Zander die Funktionen der Metapher im Slogan. (S.72-3) Das metaphorische Verb räumt auf "ist anschaulicher, bildhafter und leichter verständlich als es eine sachlich-physiologische Erklärung der Wirkungsweise des Mittels wäre. Zugleich dient die Metapher der sprachlichen Ökonomie. ... Außerdem bewirkt die [metaphorische] Umschreibung eine gefuhlsmäßige Veränderung des Textes." Die direkte Nennung 'Verdauung' wird vermieden.

- Die Personifizierung wird bei Schlüter als eine Untergruppe der Metaphern 
betrachtet (S.33); ein Beispiel wäre eine Reklame für ein Auto: Er schwärmt so gerne aus wie sie. Und macht überall eine gute Figur. ( $\mathrm{Br} 23 / 93)$

- Metonymie

Diese Figur setzt den Teil für das Ganze ein. Ein Beispiel aus dem Korpus: Kluge Köpfe fordern leistungsfähige Werkzeuge. (Uo 10/94)

- Umschreibung (Paraphrase)

- Hyperbel

Diese Figur entsteht durch die Wahl bestimmter Lexeme mit übertreibender Bedeutung: Ganz wild auf 1.2.3 Kartoffelkrönchen. (Br 24/93) oder Für einen VIN ROSÉ D'ANJOU schmelz' ich einfach so dahin. (Bu 37/95)

- (Schein)paradox:

Zwischen Mensch und Boden liegt die Erde. (St 27/95)

- Wortspiel:

Siebter Himmel auf Erden. In 8 Stunden non-stop. (F 19/95)

c) Figuren des syntaktischen Bereichs

- Die Isolierung / Atomisierung

In der Werbung werden oft Satzteile abgesondert, die sonst zu einer vollständigen Satzkonstruktion gehören würden. Dies geschieht einfach durch Zeichensetzung, Z.B. Manche Formen kann man nicht verbessern. Aber perfektionieren. (Sp 49/95) oder Wer Langzeitarbeitslose einstellt, engagiert keine Newcomer. Sondern alte Hasen. (St 27/95) Dieses Verfahren soll dem getrennten Teil mehr informativen Wert verleihen. So 
Sowinski: "Die Einzelsetzung [Isolierung] gewinnt so die Wichtigkeit einer Satzaussage und findet stärkere Beachtung. Da diese Form der 'offenen Syntax' weitere Assoziationen erlaubt, wird sie in Werbetexten oft verwendet." (S.119)

- $\quad$ Rhetorische Umwandlungen / Transformationen

1) Auslassungen / Omissionen (detractio)

- $\quad$ Ellipse: Die elliptische Konstruktion erfullt auf der einen Seite das Streben der Redekunst nach Kürze (Schlüter, S.68-69); auf der anderen $\mathrm{S} \epsilon^{*} \quad$ ann sie. laut Möckelmann / Zander, zu Mehrdeutigkeit führen. (S.52) Die Autoren geben als Beispiel Sätze, wo das Verb ausgelassen wurde. In diesem Korpus finden sich entsprechende Beispiele: VENUTRON. Damit Ihre Beine mit Ihnen Schritt halten können. (NB 27/95) oder DEINHARD LILA. Rasse, Klasse, Eleganz. (ET 12/88) Schlüter nennt diese Art der Omission Verbal-Ellipse. (S.39) Sie wirkt hinweisend oder implizierend. Zur Ellipse rechnet man auch die Auslassung der redundanten Elemente. Schlüter hält dieses Art der Ellipse fur besonders beliebt in der Werbesprache.

- $\quad$ das Asyndeton: in dieser Konstruktion wird die Konjunktion ausgelassen, z..13. Liebe darf man verschenken. Wärme nicht. (Sp 11/95) oder Ideen kommen aus dem Kopf. Farbdrucke aus Cannon Kopierern. (Sp 11/95)

- das Zeugma macht die Aussage übersichtlicher, wirkt dynamisch und erweckt Vertrauen, denn es imitiert den lockeren Stil der Altagssprache.

2) Umstellungen / Permutationen (transmulatie)

- die emphatische Umstellung (anasirophe): die Vorwegnahme der Qualifizicrung 
hat einen dramatischen Effekt. Ein Beispiel aus Mőckelmann/Zander: Ein großer Cognac - ein COURVOISIER. Aus diesem Korpus hat sich folgendes Beispiel gefunden: Unsere Landwirtschaft. Wir brauchen sie zum Leben. (Bu 38/95)

- Kreuzstellung (Chiasmus); das folgende Beispiel stellt einen unvollkommenen Chiasmus dar, denn am Ende der Konstruktion steht statt "dem Menschen" der Markenname "XYLA": Der Mensch lebt mil Holz. Holz lebt mit XYLA. (St 28/95) Der Bruch im Parallelismus wirkt als eine Überraschung und dadurch prägt sich vermutlich der Warenname dem Leser ein.

3) Zufügungen / Adjunktionen (adiecto)

Diese rhetorische Figur erscheint oft, wo Sprichwörter in veränderter Form zitiert werden, z.B. Wenn schon Stau, dann wenigstens First-Class.(F 19/95)

4) Auswechselungen / Substitutionen (immutatio)

Diese Figur ist ebenfalls beliebt, wo Sprichwörter abgewandelt werden, z.B. Ein gutes Bett ist Gold wert. (F 19/95)

d) Figuren des kompositorischen Bereichs

- Zweier- bzw. Dreiergruppe und Steigerung (klimax)

Bei Schlüter sind diese beiden Figuren getrennt behandelt, wăhrend bei Möckelmann/Zander die Zweier- und Dreiergruppe als Gestaltungsform der Steigerung angesehen werden: Guter Kaffee, bester Kaffee. Kaffee aus dem Wigomat. 


\subsubsection{Stilistische Merkmale}

a) Einfache Sătze

Viele der schon erwăhnten Autoren, z.B. Sowinski (S.76), Schlüter (S.68), Römer (S. 164) sind sich darin einig, daß die Werbesprache kurze, klare, einfache Sătze bevorzugt. Möckelmann/Zander finden dieses Merkmal für die Werbung wichtig, denn es ermöglicht dem Umworbenen "den Text ohne bewußte Aufmerksamkeit oder gedankliche Mitarbeit in dem kurzen Augenblick des Hö. ens oder Lesens" aufzunehmen. (S.46) Trotzdem fanden Möckelmann/Zandig einteilige Sätze relativ selten. (S.47) Häufiger kommen zwei- oder dreiteilige Konstruktionen vor. Häufig zerlegt man vollständige Sätze in unvollständige, um komplizierte Satzfügungen zu vermeiden. Zu diesen Mittel zählen dieselben Autoren die Atomisicrung (Isolierung) und die Omission. Schluter bemerkt, daß Relativsätze, wenn möglich, durch Adjektive oder Wortverbindungen ersetzat werden, z.B. atmungsfreudig oder der-ständig-auf-100-Typ. (S.68)

b) Übertreibung

Die Übertreibung stellt selbst eine rhetorische Figur des 'Anpreisens' dar . Nach Möckelmann/Zander kann jedes Werben mit Gründen, die nicht auf realen, objektiv nachweisbaren Eigenschaften des Erzeugnisses beruhen als Anpreisen bezeichnet werden. (S.32) Sie finden, daß der werbewirksame Effekt des übertreibenden Anpreisens vor allem darin liegt, daß die von der Norm abweichende Aussage die Aufmerksamkeit des 
Lesers oder Hörers erregt. Obwohl in der einschlägigen Literatur ${ }^{21}$ vor Übertreibung gewarnt wird, meint Römer, daß Übertreibung nötigerweise zur Werbung gehöre: "Eine Werbung, die nur sachlich berichtete und ankündigte, wäre keine Werbung mehr, sondern eine Marktinformation, ...". (S.86) Sie versucht, die verschiedenen Möglichkeiten und Gebiete der Übertreibung zu systematisieren. Insbesondere interessiert es sie, wie die Eigenschaften der Ware mittels Sprache 'aufgewertet' werden. (S.85) Sie nennt diese Erscheinung 'semantische Aufwertung': "Unter semantischer Aufwertung wird hier verstanden, daß von den angebotenen Waren mit Worten gesprochen wird, die bei einem ausgewogenen Verhältnis zwischen Wort und Sache nicht gewählt würden. Die Gegenstănde werden mit der Sprache aufgewertet. ... Die Gegenstände, die benannt oder charakterisiert werden müssen, sind wohl gut und haben ihren Wert, aber sie werden mit Wortinhalten, also mit semantischen Mitteln, auf eine höhere Stufe gestellt, als ihnen zukommt. ... Die semantische Aufwertung wird durch Faktoren formaler und inhaltlicher Natur erreicht, die eng aufeinander bezogen sind ... " Es folgt eine Liste dieser Faktoren mit sehr detaillierter und ausführlicher Analyse der einzelnen Ḿittel und Beispiele. Insgesamt gibt es sechs Gruppen dieser Faktoren. Hier sind einige repräsentative Beispiele von Ruth Römer:

- $\quad$ steigernde Komposition (wie in hocharomatisch oder Super-Colgate)

- $\quad$ Entkonkretisierung (wie in Bodenpflege für Bohnerwachs)

21

In Römer, C.85-86, eine Liste der Werke, die sie in diesem Zusammenhang untersucht hat. 
aufwertende Appellative (wie in Waschpflege fur Waschpulver; der Unterschied zum vorangehenden Faktor ist mir nicht klar)

- Benennung der Waren mit Hochwertwörtern (wie Lord Extra - Zigaretten, oder Gloria spezial - Zigaretten)

- Charakterisierung durch hoch-wertende oder superlativische Adjektive (wic extramild oder ideale Pflege)

- $\quad$ Superlativ ${ }^{22}$ und Komparativ ${ }^{23}$ (wie in das strahlendste Weiß meines Lebens oder es gibt nichts Besseres)

Römer rechnet auch den Fach- und Fremdwortgebrauch zur semantischen Aufwertung. Bei Möckelmann/Zander sind als Mittel der Übertreibung noch Verben (Aspirin rellet ihren Kopf), Metaphern (Der Gipfel der Intim-Frische: LIASAN flüssig). Vergleiche (SOMAT bringt Glanz, der wie tausterd Sterne funkelt), Gleichsetzungen (Wo Fortschrilt ist, da ist ARAL) und Verallgemeinerungen (Wer es kennt, nimmt KUKIDENT) genannt. (S.62-63)

c) Mehrdeutigkeit

22

Römer sagt vom Superlativ, daß er "wohl die älteste und beständigste Form aller Wirtschaftswerbung" darstellt. Sein Einsatz wird gesetzlich eingeschränkt, um vor unbegründeten Behauptungen zu schützen. (S.106)

Der Bezugspunkt des Komparativs wird meist verschwiegen. (Römer, S. 109) Aber es wird offensichtlich auf die Konkurrenz bezug genommen. Römer (S.110) argumentiert, der Komparativ sei in der Wirkung dem Superlativ gleichzusetzen und sollte dementsprechend gesetzlich gleich behandelt werden. 
Mockelmann/Zander behandeln die Mehrdeutigkeit innerhalb der Gruppe der 'semantischen Figuren und Stilmittel', obwohl sie eigentlich keine Figur an sich darstellt, sondem selbst ein Effekt von 'Stilmitteln' darstellt ( der Omission und des Doppelsinns / Wortspiels). (S.54) Ihr Grund dafur ist, daß3 Mehrdeutigkeit in der Werbung als 'Mittel' zur Erzielung bestimmter Wirkungen eingesetzt wird. Vor allem wird damit eine gewisse Universalităt der Aussage angestrebt und auch verwirklicht.(S.55) Volker Klotz sieht in der Mehrdeutigkeit eines der bezeichnenden Merkmale des Slogans: "Gerade die Ambiguităt, die Mehrsinnigkeit und Dunkelheit der syntaktischen Verhältnisse und Sinnzusammenhänge, ist ein entscheidender Zug des Slogans." (S.542) Weiter unten fügt er hinzu, daß die Mehrdeutigkeit nicht nur eine "Anreicherung der Sinnuancen" bewirkt, sondern "zugleich eine schillernde Unverbindlichkeit" schaff. Die verschiedenen Bedeutungen surumieren sich nicht bloß, sie relativieren einander urd entschärfen den Umriß des Ganzen. (ebenda) Damit wird also einer der Strategien der Werbung gedient, der Tarnung und Entschärfung der Werbeabsicht. Der andere Effekt betrifft den Rezipienten, indem ihm durch die Mehrdeutigkeit ermöglicht wira, sich dem Text mit seinem eigenen Erwartungshorizont zu nähern. Möckelman/Zander sagen: "Außerdem kann der Umworbene sich die Bedeutungsnuance auswählen, die seiner augenblicklichen Stimmung und Einstellung am besten entspricht." (S.57)

- $\quad$ Mehrdeutigkeit als Effekt der Omission: Als Beispiel geben Möckeimann/Zander den Slogan Täglich wie neugeboren - ODOL. (S.55) Weiter oben, im Abschnitt über rhetorische Figuren, wurde dieser Fall des ausgelassenen Verbs 'Verbal-Ellipse' genannt. In diese Kategorie wird von den Autoren auch der Komparativ ohne Bezugsglied 
eingereiht (weiter oben, im Abschnitt aber die semantische Aufwertung.wird dieser Fall auch erwăhnt): TSCHIBO 'Gold Mocca' schmeckt besser.

- Mehrdeutigkeit als Effekt des Asyndetons (weiter oben wurde das Asyndeton als Art der Omission eingestuft): In Anlehnung an Klotz (S.543) geben Möckclmann/Zander als Beispiel den Slogan lieber leichter, lieber Mercedes, der sich als crgänzend, als kausal und als konditional lesen laßßt.

- $\quad$ Mehrdeutigkeit als Effekt des Doppelsinns: Volker Klotz gibt unter mehreren Beispielen das folgende, das diese Figur sehr gut veranschaulicht: Leineweher, dhos Haus das jeden anzieht. (S. 42)

d) Imperativische Sătze

Manchmal wird zur direkten Aufforderung gegriffen, um den Leser zur Kaufentscheidung zu bringen. Möckelmann / Zander halten diese Ausdrucksweise für kontraproduktiv und vermuten bei Lesern eher eine negative, bzw. abweisende Reaktion. Ein Beispiel für einen imperativischen Slogan wäre Nimm VIM. (S.44-5)

\subsection{PRAGMATIK DER WERBEANZEIGE: DER EINFLUß DES REZIPIIEN'TIN AUI:} DIE WERBEWIRKSAMKEIT

Die überzeugende Kraft des Werbetextes ist nicht rur von den Eigenschaften des Textes selbst abhängig, sondern auch von der. Merkmalen des Rezipienten, z.B. vom sozioökonomischen Status, von der Gruppenzugehörigkeit, von der Neigung, Persuasionen zu erliegen, von dem Zeitraum der Beeinflussung und ähnliches 
(Lewandowski, S.1179) In seiner Untersuchung der Slogans stellt Klotz fest, daß die meisten Slogans absichtlich semantisch offen sind, damit der Hörer sie mit Projektionen eigener Wünsche und Ërwartungen ergänzen kann. Auf diese Weise liest jeder k ipient das, was er lesen möchte. (S.545) Sehr interessant in dieser Hinsicht ist die Stellungnahme Ecos und Schlüters, daß die Rezipienten nur durch Argumente und Appelle bewogen werden, die sie schon im voraus hören wollten. (siehe unten) Aus der Analyse verschiedener Werbeanzeigen stellt Eco fest, daß die Reklamekommunikation in senr vielen Fällen eine schon vorher gesprochene Sprache spricht und gerade deshalb verstanden wird. (S.290) Da die Anzeige (in diesem Fall eine Reklame für fertige Suppe) auf vertraute Weise das sagt. was die Betrachter schon erwarteten - und sie erwarteten es auch in bezug auf andere Produkte - ist letzten Endes die grundlegende Funktion der Anzeige die phatische ${ }^{24}$, so wie es für andere verbale Ausdrücke der Kontaktaufnahme auch zutrifft. Der Ausspruch 'schöner Tag heute' dient keinesfalls dazu, eine meteorologische Beovachtung zu vermitteln (deren Falschheit oder Wahrheit völlig irrelevant ist), sondern dazu, einen Kontakt zwischen zwei Sprechern herzustellen und dem Empfänger die Anwesenheit des Senders zu bestätigen. Ebenso sagt im Falle dieser Arzeige die Herstellerfirma einfach: 'Auch ich bin da.' Alle anderen Arten von

Jakobson unterscheidet die folgenden Sprachfunktionen: die emotive, conative bzw. appellative, referentielle, metasprachliche, phatische (Kontakt herstellende) 'Hervorhebung - B.V.] und poetische Funktion der Sprache. Jakobsc. $`$ Darlegung der Sprachfunktionen findet sich in seinem Aufsatz "Linguistics and Poetics" im Sammelband Style in Language. hrsg. von Thomas A. Sebeok. Cambridge. 1960: MIT Press (350-77). 
Kommunikation zielen nur auf diese Nachricht. Im Sinne von den oben angeführten Methoden der Werbung und Funktionen der Werbesprache setzt Eco den Schwerpunkt auf den initialen Schritt des Auf-sich-aufmerksam-Machens'. Nach einer rhetorischen Untersuchung von mehreren Werbeanzeigen in italienischen Illustrierten, kommt Eco zu den folgenden Schlußfolgerungen:

1) Topoi und Tropen sind streng kodifiziert, und jede Botschaft macht nichts anderes, als das zu wiederholen, was der Benutzer schon erwartete und kannte.

2) Die Prämissen werden in der Mehrzahl der Fälle ohne Diskussion akzeptiert, auch wenn sie falsch sind.

3) Die von jeder Kommunikation [gemeint ist wohı die Kommunikation in der Werbung - B.V.] evozierte Ideologie ist die Ideologie des Konsums: "Wir fordern Sie dazu auf, das Produkt X zu konsumieren, weil es norrıal ist, daß Sie etwas konsumicren, und wir schlagen Ihnen unsere Erzeugnisse vor statt anderer, aur die typische Weise einer Persuasion, deren Mechanismen inzwischen ja allen bekannt sind."

4) die enthymematischen Fuder sin 1 manchmal so komplex, daß es kaum vorstellbar ist, daß sie jedesmal vom Empfänger aufgenommen werden, und folglich muß man annehmen, daß ... auch die Argumentationsprozesse als Siglen ihrer selbst, als konventionelles Zeichen empfangen werden. ... Die Anzeige würde nicht dic Gründe darlegen, warum man sich auf eine bestimmte Art verhalten soll, sondern sic würde cinc Fahne, ein Stemma exponieren, auf das man surch Konvention auf eine bestimmte Art reagiert. (S.290-291) 
Seine Schlußfolgerung hestătigt seine Hypothese, nämlich, "daß die Reklamekommunikation, die so sehr an die Notwendigkeit des Rückgriffs auf das schon Erworbene gebunden ist, sich wahrscheinlich größtenteils schon kodifizierter Lösungen bedient." (S.291) Eine ähnliche Sichtweise findet sich bei Schlüter. Gegen die Vorwürfe. die Rhetorik (deren Mittel eine wichtige Rolle in Werbestrategien spielen) dier.e zur Verfuhrung und Betrug des Publikums, stellt er fest, daß sich die Redekunst großenteils auf die Vorurteile und das Wunschdenken der Hörer stützt. "Im Grunde lassen sich die Leute überreden. Jedes Publikum hat die Demagogen, die es verdient." (S.60)

Dieser Gesichtspunkt ist besonders interessant im Hinblick: auf den Gebrauch der Sprichwörter und Redensarten in Werbeauzf ${ }^{*} \geq n$. Beide Formen stellen bekanntes Sprachgut dar. Sprichwörter tragen eine moralische Autorität, die das Annehmen der persuasiven Werbeargumente erleichtert. Der Rezipient denkt nicht nach, ondern merkt sich nur das, was schon Teil seines sprachkulturellen Hintergrunds ist. 


\section{BEISPIELANALYSE}

In der einführenden Diskussion über die intertextuelle Dynamik der sprichwörtlichen Textsorten in der Werbung wurde hervorgehoben, daß diese Textsorten, d.h. Sprichwort und sprichwörtliche Redensart, als volkstümliche Formeln in der Sprachgemeinschaft sehr wohl bekannt sind und vermutlich von den Rezipienten der Werbeanzeige unmittelbar wiedererkannt werden. Folglich wird dem Leser das intertextuelle Anleihen bewußt, wie es auch die Intention der Werbefachleute war. Es wurde auch dic Form der Intertextualität festgesetzt - ob es sich um Zitate oder die Übernahme des Musters handelt. Das Resultat ist eine Mischung der Textsorten, die besonders günstig auf Kaufentscheidungen wirken soll. Im Folgenden werden einigc repräsentative oder besonders interessante Beispiele analysiert. Eine vollständige Liste aller gesammelten Beispiele findet sich im Anschluß.

\section{Sprichworter}

Sprichwörter werden entweder unverändert oder abgewרndelt zitiert, oder es werden ihre Muster übernommen mit völlig neuer Füllung.

!.1 Intertextulle Anleihe der Sprichwörter in der Form des Zitats:

\subsubsection{WÖRTLICHE ÜBERNAHME DER SPRICHWÖRTER (unverändertes \%itat)}

Diese Gruppe ist nicht zahlreich, vermutlich weil sich selten ein passendes Sprichwort finden läßt. Einige erscheinen allein im Slogan, wie Zeit ist Geld! oder Die Zcilen cindern sich. Sie sind nicht in den Anzeigetext eingebettet. Sie dienen als Blickfang. Das Besserwisserische, das der Rezipient in den alleinstehenden, auch graphisch 
hervorgehobenen Satz dieser Textsorte hineinliest, weckt. Neugier darauf, was unternommen werden mußte (d.h. gekauft werden muß), um nicht in eine Lage zu geraten, vor der das Sprichwort warnt. Wenn das Interesse geweckt worden ist, geht der Leser zum weiteren Text übe,, in dem die Auflösung der Spannung erwartet wird. Andere Zitate wiederum dienen als Pointe, wie im Falle der Anzeige für crème fraîche: Mit Crème Fraiche, original aus Frankreich, ist es wie mit original Champagner. (Wenn schon, denn schon!) . In diesem Falle ist das Sprichwort nur Teil des Slogans und erscheint als gedanklicher Anhang. Erstens verdeutlicht es, was mit der Analogie gemeint ist. Zweitens illustriert es die Logik, die hinter dieser Anzeige steckt. Eigentlich gibt es keine bessere Formulierung für diese Einstellung als "Wenn schon, denn schon."

\subsubsection{ABWANDLUNG DER SPRJCHWÖRTER (geändertes Zitat)}

Da es sich um vertraute Formen handelt, erlauben Sprichwörter reichliche Abwandlungen. Die Werbeleute verlassen sich auf die Fähigkeit der Leser, die Beziehung zum ursprünglichen Sprichwort wieder herzustellen. Dieses Verfahren ist besonders beliebt in der Werbung, was die Zahl der Beispiele zeigt. Möckelmann/Zander halten die Vertrautheit des Klanges für wichtig bei der Anlehnung der Slogans an die Sprichwörter. (S.83) Eigentlich kommt es in vielen Fällen gar nicht darauf an, daß die ursprüngliche sprachliche Form und der Sinn erhalten bleiben. Häufig geu.innt der Slogan gerade seinen Witz und damit einen Teil seiner Schlagkraft aus dem gewollten Mißverstehen (bzw. Umdeuten) des Sinnes. Es handelt sich hier sozusagen um eine 'doppelte Intertextualität', oder 'Intertextualitát in der Intertextualität': auf der ersten Ebene, der Ebene des 
Abwandelns, alludiert der abgewandelte Text auf einen Prătext; die intertextuelle Dynamik entsteht innerhalb einer Textsorte. Auf der zweiten Ebene, der Ebene des Zitierens, wird der Text in einen anderen eingebettet, der zu einer anderen Textsorte gehört. Die intertextuelle Dynamik entsteht auf dieser Ebene durch das Mischen von Textsorten, wie bei anderen der direkten Übernahme des Zitats.

a) minimale Abänderung

In diesem Fall wird wenig verändert, damit die Assoziation zum ursprünglichen Sprichwort erhalten bleibt. Das Sprichwort wird sofort im Gedächtnis abgerufen. Die abgeänderten Sprichwörter kommen in der Werbung häufiger vor als direkte Zitate. Dies mag daran liegen, daß sich die Sprichwörter durch Abwandlung an jede Situation anpassen lassen. Darüber hinaus lösen die Abwandlungen beim Rezipienten bestimmte Effekte aus. Bei allen solchen Änderungen tritt beim Leser Verfremdung ein, die dann weiter entweder zu Neugier, Komik, intellektuellem Vergnügen oder Ähnlichem fuhrt. Die Werbefachleute können ihrer Sache sicher sein, denn die Änderungen werden als solche erkannt. Im Sinne Pletts (siehe oben) können intertextuelle Zitate durch die vier rhetorischen Transformationen gehen.

- Substitution: Man ist so jung wie man sich fühlt. (nach >Man ist so alt wie man sich fuhlt $<$ ); dieses Ileispiel aus einer Anzeige für ein Fieilmittel behält die apodiktische Qualität des Sprichworts, aber durch die Substitution des Wortes "jung" fur "alt" werden positive Assoziationen geweckt. Lieses Beispiel dient zur Verdeutlichung der Bedeutung 
des ursprunglichen Sprichworts, A.h. "Man ist so alt, wie man sich fühlt" will sagen, daß man trotz großer Zahl der Jahre sich jung fühlen kann.

- Adjunktion: Bei manchen Sprichwörtern wird die Weisheit in Frage gestellt, wie bei Haarlack ist Haarlack? Nicht unbedingt. Dieser Abschnitt erscheini als Anfang des eigentlichen Werbetextes und nicht des Slogans. Er stellt die gewöhnliche Argumentation gleichgültiger Käufer in Frage. Hier wird die Volksweisheit im Sinne von " $>X$ ist $X<$ und deshalb ist jedes $\mathrm{X}$ gleich" dem Leser unterstellt. Die Werbefachfrau, die es besser weiß, faihrt fort, dem Leser ihre These zu beweisen. Der Textabschnitt erinnert an eine Erwiderung im Gespräch, denn die Frage "Haarlack ist Haarlack?" scheint wie eine Wiederaufnahme des schon gesagten. Es wird angenommen, der Käufer hätte vermutlich "Haarlack ist Haarlack" gesagt und wird danach zurechtgewiesen.

Eine Verneinung des ursprünglichen Sprichworts, wie z.B. Der Schein trügt nicht oder Wer wagt, der gewinnt nicht immer stellt die Volksweisheit in Frage. Diese beiden Beispiele stehen als Slogans, und dienen daher als Blickfang. Die Anmaßung, solche eingeschliffene Forn:eln wie $>$ Der " hein trügt $<$ und $>$ Wer wagt, gewinnt $<$ in Frage zu stellen, sollte die Leserin neugierig darauf machen, was die Gegenthese eigentlich ist.

- Omission: Die Umkehrung des Sinnes laßß sich auch durch Auslassungen erreichen, z.B. wenn das Sprichwort eine verneinte Aussage enthält. So: Wer fuihlen will, muß hören. Dieses Beispiel enthält aber auch eine Permutation der Verben, denn es heißt 
im Sprichwort $>$ Wer nicht hören will, muß fühlen $<$. Das führt uns über zu der năchsten rhetorischen Transformation.

- Permutation: das einzige Beispiel. das sich für diese Kategorie qualifizieren könnte, ist Was das Leben Dir nimmı, gibt die Natur Dir zurück! (nach: Was das Leben gibt, nimmt der Tod), wobei "nehmen " und "geben" ausgetauscht wurden und für "der Tod " wiederum "die Natur" substituiert wurde. Hier wird unter dem Blickpunkt des modemen Menschen das Leben als etwas Feindliches gesehen, das einem die Kraft raubt. dem die Natur als menschenfreundliche Instanz, von der man Hilfe erlangt. entgegengesetzt wird.

b) Starke Abänderung

Dieser Fall kann als Untergruppe des vorigen angesehen werden - das Sprichwort wird stärker geändert, die Anspielung auf den Prätext wird nicht so offensichtlich. Der neuc Text erinnert vage an das ursprüngliche Sprichwort. Es kann nicht mit Sicherheit behauptet werden, daß die Asso 2 , ion dem Leser bewußt wird. Vermutlich operiert dic persuasive Kraft des ursprünglichen Sprichworts eher durch die Bekanntheit des Musters, oder sie wirkt gar auf unbewußter Ebene.Hier sind einige Beispiele:Der Mensch leht mit Holz. (>Der Mensch lebt nicht von Brot allein<, oder >Der Mensch lebt vom Menschen<); Manche Rosen brauchen Dosen. (>Keine Rose ohne Dornen<); Wenn einem Gutes widerfährt... (> Was einem widerfăhnt, das kann auch dem anderen begegnen.<); Das schönste auf der Welt ist ein eigenes Zuhause. (>lïgenes Herd 
ist goldes wert<); Eine für alles. (>Eines schickt sich nicht für alle<); ${ }^{25}$

1.2 Übernahme oder Nachahmung sprichwörtlicher Strukturen:

Viele Slogans ahmen einzelne sprichwörtliche Satzmuster nach. Dadurch aber, daß sie sich an keine konkreten Sprichwörter anlehnen, wirken sie eher wie Sentenzen oder Maxime (aber da sie keinem literarischen Werk entstammen, fallen sie auch nicht in diese Gruppe). Hier gilt auch, daß die Vertrautheit des Klanges auf den Rezipienten positiv wirkt. Vermutlich erkennt sie/er hier das sprichwörtliche Muster; wenigstens verlassen sich die Werbefachleute darauf. Freilich ist es sehr schwer, eine Grenze zu ziehen zwischen einem stark abgeänderten Sprichwort und nur einem Sprichwortmuster. Eine Gruppe solcher 'Quasi-Sprichwörter' bilden banale apodiktische Feststellungen, wie: Es gibt Dinge, die kann man nicht verbessern. Auch Füße haben Gefühle. Erfolg erfordert vollen Einsatz, usw.

Eine weitere Gruppe bilden Quasi-Sprichwörter, die nach Mustern bebildet sind, z.B. mit Anfangswort Wer? oder Lieber..., mit den Verben machen oder sein, usw. Beispiele: Wer hisher zuviel getankt hat, wird sein blaues Wunder erleben; Wer Langzeitarbeitslose cinstcllt, kriegt keine halben Sachen. Sondern ganze Leistungen; Lieber angenehm als unbequem: Lieber ein Fußbad als ein stilles Wasser; Thymus macht die Abwehr stark;

25

Dieser Slogan (Eine für alles) könnte auch auf die Redewendung > ein Mädchen für alles $<$ oder auch auf das geflügelte Wort > un pour tous, tous pour un < zurückgeführt werden. 
Erfolg ist keine Frage des Alters.

Auch ein interessantes Beipiel ist der folgende: Schmücke deine Füße. so kannst Du Spuren hinterlassen. Hier handelt es sich um ein Quasi-Indianersprichwort, das in einer Reklame für Schuhe erscheint. Im Bild steht eine offensichtlich europäische Frau die sich als Indianerin verkleidet hat. Der Slogan spielt auf die Beliebtheit der Indianerkultur im deutschsprachigen Raum. Die angebliche kulturelle Herkunft dieses Quasi-Sprichworts verleit dem Slogan ein besonderes Gewis ht.

\section{Redensarten}

Beim Sammeln der Beispiele für diese Untersuchung habe ich nicht nur die sprichwörtlichen Redensarten im strengeren Sinne, sondern auch die 'schlichten' festen Redewendungen, die Zwillirgsformeln und die phraseologischen Verbindungen, wie sic Görner definiert hat, beachtet. Der Grund dafür war die Tatsache, daß die sogn. Bildlichkeit in gewissem, obwohl geringerem, Grade auch in diese.ı phrascologischen Einheiten präsent ist. Außerdem sind sie in dem gleichen Grade den Sprechern vertraut und ihre Wiedererkennbarkeit gleicht den sprichwörtlichen Redensarten. Folglich crzielen sie den gleichen günstigen Effekt durch die Vertrautheit des Klanges.

Mán könnte die sprichwörtlichen Redensart und die festen Redewendung wie eine chemische Verbindung betrachten. Wird sie zerlegt, so trennen sich die einzelnen Elemente, die völlig andere Merkmale aufweisen als die ursprungliche Verbindung. Auf 
diesem Phănomen beruht die Werbewirksamkeit der Redensarten, denn durch das Gegenüberstellen der wörtlichen und übertragenen Bedeutung entstehen Effekte der Verfremdung, der Komik und des intellektuellen Vergnügens. Der Prozeß der Intertextualităt fuhrt den Leser wechselweise von einer Bedeutung zur anderen. Man könnte sagen, es ginge hier auch um Intermedialităt, wo ein Medium (lexikalische Einheit, bzw. Text) in ein anderes (Bild) übertragen wird. Hier sind einige Beispiele: Heute waschen wir Ihnen so richtig den Kopf. Es geht hier um eine Reklame für Haarpflegeprodukte. Der witzige E. fekt entsteht durch die Spannung zwischen der buchstäblichen Bedeutung der Aussage, wo der Vorgang des Haarwaschens gemeint ist, und der idiomatischen Bedeutung, wo dem Leser sozusagen "der Kopf gewaschen wird"[= er getadelt wird], weil er angeblich den Unterschied zwischen guten und wenig guten Haarpflegeprodukten nicht kennt.

Zwei Ledernacken, die für Sie den Kopf hinhalten. Eine Reklame für ein Auto, dessen Sitze sehr gute Kopfstützen haben sollen. Sie "halten" buchstäblich "den Kopf" des Passagiers. Der verfremdende und witzige Effekt entsteht durch die unerwartete buchstäbliche Bedeutung, da im Sprachbewußtsein des Lesers die Redensart in ihrer üblichen. idiomatischen Bedeutung gespeichert wird, die etwa "für etwas die Verantwortung übernehmen" heißt.

Wird auch höchste Eisenbahn! In dieser Reklame spricht ein Kind, das möchte, daß seine Eltern ihm endlich einen elektrischen Zug (eines bestimmten Herstellers) kaufen. Es 
benutzt dafur die Redensart in ihrer idiomatischen Bedeutung, die heißt "es ist höchste Zeit". Da es sich dabei um die Anschaffung eines Zuges handelt, wird auch auf die buchstäbliche Bedeutung des Wortes "Eisenbahn" angespielt.

Wer uns jetzt nicht einplant, verpaßt den Anschluß. Dies ist eine Reklame für eine Türsprechanlage. Der Text will sagen, daß bei dem Bau eines Gebäudes diese Anlage sofort eingeplant werden muß, sonst kann sie nicht angeschlossen werden. Somit ist wieder die buchstäbliche Bedeutung des Wortes "Anschluß" herangezogen. Die Redensart "den Anschluß verpassen" bedeutet jedoch "keinen Ehemann finden". Durch den Gegensatz dieser zwei Bedeutungen entsteht der witzige Effekt, der die Aufmerksamkeit fesseln und den Leser günstig zum Kauf stimmen soll. Hier, wic in anderen Beispielen, dient diese Technik der Gegenüberstellung zweier Bedeutungen der besseren Einprägsamkeit des Slogans.

Sehen Sie Schwarz! Dieser Satz erscheint isoliert auf einer schwarz gemalten Seite in der Zeitschrift. Beim ersten Blick versteht man diesen Satz (durch das Ausrufezeichen) als Aufforderung die schwarze Farbe der Seitezu sehen. Aber gleichzeitig wird auch auf dic idiomatische Bedeutung "Dunkles oder Schlimmes für die Zukunft voraussehen" gespielt. Die Redensart hat eigentlich nichts mit Farbe zu tun. Erst wenn man umblättert, sicht man die Fortsetzung und die Bedeutung wird klar. Es ist eine Reklame für cine Fernsehsendung, in der ein Schauspieler Namens Schwarz die Hauptrolle spielt. "Schwerz sehen" heißt soviel wie "Herrn Schwarz sehen". Der isolierte Satii erweckt 
Erwartungen, die dann auf witzig uberraschender Weise wieder aufgelöst werden. Es gibt jedcch einen Hinweis auf den Namen, da "schwarz" großgeschrieben wird. Dieser Fall ist interessant, denn der idiomatischen Bedeutung der Redensart werden zwei unterschiedliche buchstabliche Bedeutungen entgegengesetzt, einmal die Farbe "schwarz" und einmal der Name "Schwarz".

Der Kopierer ist ins Netz gegangen. Mit "Netz" wird hier ein Computernetz gemeint, in den der Computer "gehen" kann, d.h. an den er angeschlossen werden kann. Damit wird die buchstäbliche Bedeutung des Ausdrucks in Anspruch genommen. Der lustige Effekt wird durch die Assoziation an die idiomatische Bedeutung der Redensart erzielt eigentlich heißt "ins Netz gehen" so etwas wie "in eine Falle geraten".

Oben wurde bereits erklärt, daß Redensarten semantisch als idiomatisierte lexikalische Einheiten betrachtet werden. Daher werden sie größtenteils authentisch zitiert. In diesem Korpus befinden sich nur zwei Beispiele der veränderten Zitate. Der aufmerksamkeitserregende Effekt entsteht aus dem Gegensatz zwishcen der ursprïnglichen Redensart und dem realen Sachverhalt der Werbeanzeige. Im Beispiel Sie brauchen nur Köpfchen. [vgl. "Köpfchen muß man haben"], geht es um eine Zahnbürste bei der nur der Bürstenkopf gewechselt wird und nicht die ganze Bürste neu gekauft werden muß. Dies soll in jeder Hinsicht (Sparsamkeit, Umweltfreundlichkeit, usw.) eine sehr kluge Entscheidung sein; deshalb wird die Redensart herangezogen, cienn "Köpfchen haben" heißt ja "klug sein"; dazu geht es auch um falßbare, tatsăchliche Köpfchen. Das zweite Beispiel heißt 
Empfindliche Haut tritt aus dem Schatten. [vgl. "in den Schatten stellen" oder "im Schatten leben"]. Hier geht es um eine Sonnenkreme, die empfindliche Haut besonders erfolgreich vor Sonnenbrand schützt. Diejenigen, die empfindliche Haut haben, müssen sich im Schatten halten, d.h. buchstäblich "im Schatten leben" oder sie wurden "in den Schatten gestellt". Der witzige Werbeeffekt entsteht hier auch im Gegensatz zwischen diesem buchstäblichen Gebrauch der Redensart und ihrer eigentlichen idiomatischen Bedeutung. Die armen Betroffenen können jetzt "aus dem Schatten treten".

In einigen Anzeigen wurden Redensarten kombiniert, z.B. Der Siehte Mimmel auf Erden. [aus "im siebten Himmel sein" und "Himmel auf Erden"]. Dadurch entsteht ein Wortspiel, das sich im Slogan fortsetzt - das Ganze lautet eigentlich Der Siehte Himmel auf Erden. In 8 Stunden non-stop. In dieser Reklame wird ein beliebtes Reiseziel, Bermuda, metaphorisch mit dem siebten Himmel und mit dem Himmel auf Erden verglichen, und dann als in 8 Stunden erreichbar präsentiert. Ausnahmsweise gibt ess in diesem Fall keinen Geyensatz awischen der konkreten und idiomatischen Bedeutung. I ic Redensarten werden in ihren üblichen, idic.natischen $\mathrm{E}$ : deutungen gebraucht. Der günstige Werbeeffek: er.tsteht durch das witzige Wortspiel.

Bei den sogenannten phraseol gischen Verbindungen ist die Bedeutung relativ transparent, d.h. sie kann aus den einzelnen Elementen erschlossen werden. Obwohl bei ihnen die Werbewirksamkeit nicht auf der Diskrepanz z'vischen der wörtlichen und ubertragenen Bedeutung beruht, wurden sie hier auch berücksıchtigt, da sie dennoch 


$$
2 \text { oflde } 2
$$


Bildlichkeit im Sinne der sprichwörtlichen Redensarten in den Werbetext bringen. Hinzı kommt auch die Vertrautheit dieser Gefüge. die die überzeugende Krafi des Werbetextes verstärkt. Hier sind einige Beispiele:

Jetzt hat Sicherheit ein neues Gesicht. In dieser Anzeige wird ein neues Modell eines Wagens angepriesen. Beim Wagen wird seine Fahrsicherheit hervorgehoben. indem er als Symbol für Sicherheit auftritt. Da es um ein neues Modell geht, heißt es in der Anzeige. daß Sicherheit ein neues Gesicht habe. Der Wagen wird personifizien (Gesicht) und als Symbol für Sicherheit gesetzt.

Bringen Sie ihren Nachbarn zum Schweigen. Diese Reklame soll Wände mit guter Schallisolierung anpreisen. Der witzige Effekt entsteht durch die unerwartete Interpretation der Redensart. Der Nachbar braucht überhaupt nicht zu schweigen, man hört ihn trotzdem nicht. Es ist, als ob er schwiege.

Manche verständigen sich im Ausland mit Händen und Füßen. Andere machen ess sich leichter. Die Bildlichkeit der Redensart "sich mit Händen und Füßen verständigen" stellt den Zustand der mangelnden Sprachkenntnisse besonders erfolgreich dar. Diesem Zustand werden als einzige vernunftige Alternative die Wörterbücher von LANGENSCHEIDT entgegengesetzt.

NATREEN macht das süße Leben leichler. In dieser Reklame für ein Kunstsüßmittcl wird der aufmerksamkeiterregende Werbeeffekt im Sinne der sprichwörtlichen Redensarten 
durch den Gegensatz von übertragener und buchstäblicher Bedeutung zustande gebracht. Hier ist "süls" buchstäblich gemeint, denn es handelt sich um ein Süßmittel. Der Leser, aber, kennt den Ausdruck in seiner idiomatischen Verwendung, die etwa "das mit Vergnügungen erfüllte Leben" heißt. Der Effekt sollte witzig sein. Hinzu hat der Schöpfer oder Schöpferin dieses Slogans noch eine Wendung miteinbezogen, nämlich "X macht das Adjektiv positv Y Adjektiv komparativ", wobei das Adjektiv dasgleiche bleibt. Daher hätte man erwartet, daß der Slogan "NATREEN macht das süße Leben süßer" heißen würde. Der Ersatz des erwarteten Komparativs durch das Wot "leichter" sollte beim Leser einen Verfremdungseffekt hervorrufen.

\section{SchluBbemerkung}

In dieser Untersuchung wurde eine Breite von Zeitschriften in Anspruch genommen. Die Interessengebiete reichten von Computerzeitschriften (Chip, PC Go, usw.), über sogn. "Frauenzeitschriften" (Brigitte, Frau im Spiegel, usw.), Trivialzeitschriften (Bild, Stern), Zeitschriften für spezielle Interessen (Essen und Trinken), bis zu den 'klassischen' Zeitschriften für Politik. Wirtschaft und Kuiıur (Spiegel, Focus). Dabei habe ich mein Augenmerk auf die intertextuelle Symbiose von zwei Textsorten - Werbeanzeige und Redensart, bzw. Sprichwort -gerichtet. Die soziolinguistische Analyse, die wahrscheinlich zu sehr interessanten Schlüßen über die Häufigkeit verschiedener Formen im Verhälnis zum Thema der bestimmten Illustrierte oder zur dessen Leserschaft, ist wegen des begrenzten Umfangs dieser Arbeit ausbleiben. 
Von Sprichwörtem kann zusammenfassend gesagt werden. daß sie selten unverändert in der Werbeanzeige zitiert werden. während Sprichwortabwandlungen und Sprichwortmuster viel häufiger vorkommen. Der Grund dafür ist vermutlich die Tatsache. daß für eine bestimmte Situation in der Werbeanzeige sich selten ein echtes Sprichwort finden läßt und daher das Sprichwort geändert und den spezifischeı Forderungen der Anzeige angepaßt wird. Die minimalen Abänderungen können nach den vier rhetorischen Transformationen, nämlich nach der Substitution, der Adjunktion, der Omission und der Permutation, kategorisiert werden. Die stark abgeänderten Formen crinnern nur noch vage an das ursprüngliche Sprichwort. Die Sprichwortmuster sind die häufigste Form der Anleihe, da sie beliebig ausgefüllt werden können.

Die Redensarten werden überwiegend getreu zitiert, denn bei ihnen ist das sprachliche Bild das wichtige Element, auf dem die Werbewirksmkeit beruht. Die 'bildhafte' oder übertragene Bedeutung wird in der Werbeanzeige mit der buchstäblichen Bedeutung der Komponenten kontrastiert.

Das Zitieren der Sprichwörter und Redensarten, sowie das Anleihen der Sprichwortmuster grschieht immer unmarkiert, da die Werbung sich bemüht, dic fremden Elemente nahtlus zu inkorporieren. Jede Anleihe muß getarnt werden, denn sic könnte dic Aufmerksamkeit des Rezipier ' n auf den epideiktischen Charakter des Texts lenken, und das will die Werbung vermeiden. 
Aus den gesammelten Beispielen ist zu schließen, daß Redensarten und Sprichwörter in der Werbung bemerkbar präsent sind. In bezug auf den modemen Gebrauch dieser 'volkstümlichen' Formeln kann man daraus schließen, daß sie den heutigen Sprechern wohl bekannt sind; wenigstens die Verfasser dieser Anzeigen rechnen sehr oft mit ihrem hohen Wiedererkennbarkeitsgrad und verlassen sich auf ihre günstige Wirkung auf die Rezipienten der Werbebotschaft. 


\section{E. ANHANG}

\section{Korpus}

1.1 Abkürzungen für die Zeitschriften

$\mathrm{Br} \quad \mathrm{Br}$ 'gitte

Bu Bunte

Ch Chip

ET Essen und Trinken

F Focus

FS Frau im Spiegel

GB Das goldene Blatt

HH Highscreen Highlights

J Journal für die Frau

NB Das neue Blatt

NP Die neue Post

PB Pablo

$\mathrm{Pg} \quad \mathrm{PC}$ go

PP PC Praxis

Sp Spiegel

Ss Spiegel spezial

St Stern

Uo Unix open 
1.2 Beispiele von Sprichwörtem in der Werbung

\subsubsection{UNVERÄNDERTE ÜBERNAHME VON SPRICHWÖRTERN}

Mit Crème Fraiche, original aus Frankreich, ist es wie mit original Champagner: (Wenn schon, denn schon!) (ET 7/87)

Die Zeiten ündern sich. (Uo)

Zeit ist Geld. (Pr 4/95)

- DIREKTE ÜBERSETZUNGEN

Weniger ist mehr! Ist doch klar! $(\operatorname{Pr} 4 / 95)^{26}$

Wo ich das Leben genieße, bin ich zu Hause.Mein Zuhause hat ein Dach von BRAAS. (St. $28 / 95)^{27}$

\subsubsection{ABGEWANDELTE SPRICHWÖRTER}

DOORNKAAT. Denn ein Genuß kommt selten allein. (ET 12/88) [vgl. > Ein Unglück

kommt selten allein< $]$

Eine für alles. (J 19/95) [vgl. > Eines schickt sich nicht für alle<]

Kinder brauchen Würme. (J 19/95) [vgl. >Kinder brauchen strenge Zucht]

Gut pflegen bringt Segen. (St 27/95) [vgl. >Sich regen bringt Segen<]

26

Weniger ist mehr kann entweder als eine direkte Übersetzung des englischen Sprichworts $>$ Less is more $<$ angesehen werden, oder aber als Abwandlung des deutschen. freilich weniger gebräuchlichen Sprichworts $>$ Weniger wäre mehr $<$. 27

Wo ich das Leben genieße ist mein Zuhause ist eine mehr oder weniger genaue Übersetzung des lateinischen Sprichworts > Ubi bene, ibi patria<. 
Manche Rosen brauchen Dosen. (ET 12/88) [vgl. >Keine Rose ohne Domen<]

Die Feste ändern sich. HENCKEL TROC KEN bleibt. (ET 12/88) |vgl. >Dic \%eiten

ändern sich $<$ ]

Der Schein trügt nicht. (Sp 49/95) [vgl. >Der Schein trügt $<$ ]

Anerkennung verpflichtet. (SS 3/95) [vgl. >Adel verpflichtet< oder >Ade! verpflichtet< ]

Geschmack verbi idet. (ET 8/87) [vgl. >Adel verpflichtet< oder >Adel verptlichtet<]

Haarlack ist Haarlack? Nicht unbedingt... (B 24/93) [A IST A Muster]

Reduktion ist Gewinn. (Sp 49/95) [vgl. > Less is more $<$ ]

Prozessorzeit ist kostbar. (UO 10/94) [vgl. > Zeit ist Geld<]

Ein gutes Bett ist Gold wert. (F 19/95) [vgl. > Eigener Herd ist Gold wer $<$ ]

Das schönste auf der Welt ist ein eigenes Zuhause. Günstig finanziert ist es noch mal so schön. (J 19/95) [vgl. > Eigener Herd ist Gold wert< $]^{28}$

Wissen macht Appetit. (St 27/95) [vgl. >Wissen macht frei<]

Was das Leben dir nimmt, gibı die Natur dir zurück. (NB 27/95) | vgl. > Was das I.chen gibt, nimmt der Tod<]

Wer hören will, muß fühlen. (Sp 49/95) [vgl. > Wer nicht hören will, muß fühlen $<$ ]

Wer wagt, der gewinnt nicht immer. (Ch 4/95) [ Wer wagt, gewinnt<]

Wer zu spät kommt, den bestraft die Zeit. (Pr 4/95) [vgl. >Wer zuerst kommt, mahlt

Der zweite Satz - Günstig finanziert ist es nochmal so schoin.- kann als cine Ühernahme des IST Musters angesehen werden, nach dem Vorbild von >Frisch gewagt ist halb gewonnen<. 
zuerst $<]^{20}$

Wenn schon Silau, dann wenigtens First-Class. (F 19/95) [vgl. >Wenn schon. denn schon $<1$

Nivea UV-Pflege. Denn wo Licht ist, ist UV. (B 18/92) [vgl. >Wo Rauch ist, muß auch Fever sein< $]$

Man ist so jung, wie man sich fiuhlt. (Bu 38/95) und (NP 37/95) [vgl. >Man ist so alt, wie man sich fühlt< $]$

Fitness beginnt im Kopf. (Bu 38/95) [vgl. >Charity begins at home $<$ ]

Der Mensch lebt mil Holz. Holz lebt mit XYLA. (St 28/95) [vgl. >Der Mensch lebt ...< Muster]

\subsubsection{FORMELLE SPRICHWÖRTI.ICHE MUSTER}

Kräuterkapsel macht die Bronchien frei. (Bu 38/95) [MACHEN Muster]

Thymus macht die Abwehr stark. (Bu 38/95) [MACHEN Muster]

Wasser raus macht viel aus. (NB 38/95) [MACHEN Muster]

Reflection macht es richtig. (UO 8/94) [MACHEN Muster]

Lieher ein Fußbad als ein stilles Wasser. (B 18/92) [LIEBER Muster]

Lieher interaktiv als Dativ! (J Nr.19/95) [LIEBER Muster]

Prof. Dr. Regine Rosenthal hat mich darauf aufmerksam gemacht, daß diese Formel (Wer zu spät kommt. den bestraft die Zeit) im deutschsprachigen Raum zu einem neuen politischen Sprichwort geworden ist. Sie ist eine Übersetzung eines angeblichen Gorbatschow-Zitats: "Wer zu spät kommt, den bestraft das Leben", das wiederum vermutlich auf ein russisches Sprichwort zuruckzuführen ist. 
Lieber angenehm als unbequem. (ET 7/87) [LIEBER Muster]

Lieber gleich richrig. (Bu 46/93) [LIEBER Muster]

Wer Langzeitarbeitslose einstellt. engagiert keine Newcomer. Sondern altc' i.as'n. (Si

27/95) [WER Muster]

Wer Langzeitarbeitslose einstellt, kriegt keine halben Sachen. Sondern ganze Leistunge'n. (St 28/95) [WER Muster]

Wer Langzeitarbeitslose einstellt, hat keine ausgefallene Idee. Sondern gesunden Menschenverstand. (F 19/95) [WER Muster]

Wer zuviel getankt hat, wird sein blaues Wunder erlehen. (St 28/95) [WER Muster]

Wer uns jetzt nicht einplant, verpaßt den Anschluß. (Sp 1 1/95) [WER Muster]

Wer das Abenteuer sucht, muß bis nach der Landung warten. (Sp 11/95) |WI:R Muster|

Wer weiß, wo es langgeht, kommt entspannter ans Ziel! (Sp 49/95) [WER Muster]

Wer mich bei seiner Diätkost richtig würzt. wird auch auf Entenhraten fliegen. (1:1 4/89)

[WER Muster]

Wer richtig würzt, hat mehr von der Ente. (ET 7/87) [WER Muster]

Wer richtig kocht, hat mehr vom Weihnachtsschmaus: (ET 12/88) [WER Muster]

Wenn einem Gutes widerfährt...... (ET 7/87) [WENN Muster]

Individuell reisen ist wie essen à la carte. Sie suchen sich cinfach nur die l.eckerhisxen aus. (Sp 11/95) [IST Muster]

Leistungsfähigkeit ist keine Frage des Alters. (Bu 38/95) [IST Muster]

Hautpflege ist mehr als Kosmetik (B 23/93) [IST Muster]

Schick, fit, ETA. (St 27/95) [vgl. Trau, schai, wem!] 
DEINHARD LILA. Rasse, Klasse, Eleganz. (ET 12/88) [vgl. Trau, schau. wem!]

\subsubsection{INHALTLICHE SPRICHWÖRTLICHE MUSTER (sentenzenhafte Aussagen)}

Die hesten Ideen gewinnen. (Pr 10/94)

Der erste Eindruck entscheidet. (Pr 4/95)

Qualität hat keinen Preis. (Pb 4/95)

Qualität muß nicht teuer sein. (UO 8/94)

Fragen kostet nichts. (ET 4/89)

Auch Füße haben Gefühle. (J 19/95)

Erfolg erfordert vollen Einsatz. (Bu 46/93)

Gahunat Kapseln stärken Haare und Nägel. (J 19/95)

Granufunk stärkt die Blasenfunktion. (Bu 46/93)

Oft sind große Dinge ganz einfach. (Ch 4/95)

Es gibt Dinge, die kann man nicht verbessern. Aber perfektionieren. (J 19/95)

Alles Guse kommt von ALPA Franzbranntwein. (Bu 46/93)

Könner brauchen Gönner. (Bu 38/95)

Schmücke deine Füße und du kannst Spuren hinterlassen. (J 19/95)

1.3 Beispiele von sprichwörtlichen Redensarten und anderen phraseologischen

Verbindungen in der Werbung

\subsubsection{SPRICHWÖRTLICHE REDENSARTEN}

Wer uns jetzt nicht einplant, verpaßit den Anschlup. (Sp 11/95) 
Einem MIELE Herd mit Clean Emuil können Sie jetzt leicht eins uuswischen. (Br 18/92)

Diese Erüchtchen sollten Sie mal zur Brust nehmen. (ET 7/87)

Mit frischem Rahm istalles in Butter. (ET :2/88)

"Erst meckert er. ich nähe zuviel. Lind dann gibt er mit mir an." Gerti Leitner. die bei ihm genau weiß. wie sie was einfödeln muß. (J 19/95)

Bosch hat das Eis gebrochen. (ET 7/87)

Wird auch höchste Eisenbahn. $(\mathrm{Br} 24 / 93)$

Wie ein extra trockener Wein-Aperitif aus Frankreich bei der Speisemerfeinerung richtigg unter die Haut geht. (ET 7/87)

Zwei Ledernacken, die für Sie den Kopf hinhalten. (Br 18/92)

Heute waschen wir lhnen so richtig mal den Kopf. (Sp 28/95)

Das sind die Leute, mit denen man Großaufträge an Land zicht. (Sp 49/95)

Der Kopierer ist ins Netz gegengen. (SS 3/95)

Sicherheit, die aus dem Rahmen fällt. Im neuen BLAZER. (Sp 28/95)

Ich finde Kunst sollte im Rahmen bleiben. (Sp 49/95)

Schneller als eine gesengte Sau. (CH 10/94)

Sehen Sie Schwarz! (St 27/95)

Kann man für seine Kunden die Sterne vom Himmel holen? (Sp 28/95)

Was den Meisterköchen hilft, nach den Sternen zu greifen. (ET 12/88)

Greifen Sie nach den Sternen. (CH 4/95)

Bringen Sie ihr CD-Rom Laufwerk aufTouren. (Pr 10/94)

Unsere Binde sollte möglichst trocken und sauber sein. Da kumen wir aufden Trichter. 
(Br 18/92)

Das kommL gar nichs in die Türe. (ET 4/89)

\subsubsection{KONTAMINATION VON ZWEI REDENSARTEN}

Der siebte Himmel auf Erden. In 8 Stunden non-stop. (F 19/95) [aus >im siebten Himmel sein $<$ und $>$ Himmel auf Erden $<$ ]

\subsubsection{REDENSARTVARIATIUN}

Sie brauchen nur Köpfchen. (J 19/95) [vgl. >Köpfchen muß man haben<]

Empfindliche Haut tritt aus dem Schatten. (Br 18/92) [vgl. >in den Schatten stellen< oder $>$ im Schatten leben<]

\subsubsection{ZWILLINGSFORMEN}

Wer hilft dem Gast mit Rat und Tat und gibt ihm die Schlüssel zur Stadt? (F 19/95)

Öffnet nicht nur Tür und Tor. (CH 10/94)

\subsubsection{NACHAHMUNG DER ZWILLINGSFORMEN}

Gabunat Kapseln stärken Haare und Nägel.(J 19/95)

Schwedenpollen stärken Blase und Prostata. (FS 36/95)

\subsubsection{NEUTRALE REDENSARTEN}

Sehen.Sie MERCEDES mitanderen Augen (St 27/95) 
Lassen Sie Ihre Ohren mal Augen machen. (CH 4/95)

Er verrät nicht alles quf den ersten Blick, (Sp 11/95)

Er schwärmt so gerne aus wie sie. Und macht iaberall sinc gute fïuur. ( $\mathrm{Br} 23 / 9.3)$

Wer vergleicht, fliegt auf die deutsche BA. (Sp 11/95)

Wer mich bei seiner Diätkost richtig würzt, wird auch gufEntenbraten fliegen. (4/89)

TWINHEAD SLIMNOTE 5. Auf ihn zeigen alle mit dem Finger. (CH 4/95)

Der Sekt ist aufden Geschmack gekommen. (ET 12/88)

Kommen sie auf den Geschmack! (NB 27/95)

Jetzt hat Sicherheit ein neues Gesicht. (Bu 46/93)

So haben Sie ihre Software im Griff (Pr 10/94)

Drei Viertel aller Erwachsenen sollten jetzl das Heft in die Hand nehmen. (Sp 49/95) Manche verständigen sich im Ausland mit Händen und Füßßen. Andere machen sic'h's leichter. (F 19/95)

Schauen Sie wer hinter uns steht. (Pr 10/94)

Ein Haftmittel, das alles aufden Kopf stellt. (NP 37/95)

Lassen Sie sich nicht den Kopf verdrehen.(CH 10/94)

Bei guten Kopierern geht einer leer aus. (Sp 11/95)

Wenn Milchprodukte auf den Magen schlagen: LALUK. (Bu 27/95)

Schneller auf den Punke(Bu 46/93)

Präzision guf den Punkt gebrachı. (CH 4/95)

"Du kommst mir gerade rescht", sagten die beiden und kooperierten. [sic!] (Sp 28/95)

Hier entsteht ein unübertroffener Sekt. Darangibles nichls zu rülleln. (ET 12/88) 
Woraufih, PC scharfist. (CH 10/94)

VENORUTON. Damil ihre Beine mit Ihnen Schrill halten können. (NB 27/95)

Bringen. Sie Ihren Nachbarn zum Schweigen. (F 19/95)

Den HP Laserjets können Sie ruhig die Sporen geben. (CH 4/95)

Bringen Sie ihre alle auf Trab. (Pr 4/95)

Ganz wild auf 1.2.3. Karloffelkrönchen. $(\mathrm{Br} 24 / 93)$

Wer bisher zuviel getankt hat, wird sein blaues Wunder erleben. (St 28/95)

\subsubsection{PHRASEOLOGISCHE VERBVERBINDUNGEN}

Bereiten Sie Ihren Kunden einen freundlichen Empfang? (Sp 49/95)

Mit C'OREL FLOW kommen Sie ins Geschäft. (CH 4/95)

Wann verselzl Graphikbeschleunigung Sie derart in Begeisterung? (Pr 4/95)

\subsubsection{REDEWENDUNGEN}

Ereic Eahrt für den BROTHER HL-630. ( 'r 10/94)

.Jetzt auch für grauc Mäuse. (F 19/95)

Dic Zeit ist reif! (Br. 24/93)

Manche Spiele werden schon mil dem ersten Zug entschieden. (Sp 49/95)

Wer Langzeitarbeitslose einstellt, hat keine ausgefallene Idee, sondern gesunden

Menschenversland. (F 19/95)

Natreen macht das süße Leben leichter. (ET 7/87)

"Seine MAYOGURT. sagte Herr Appel, sei eine Spezialitat, mit der nicht nur junges 
Gemüse eine gute Figur macht." (ET 4/89)

Frischer Wind in der GUI und Datenbankentwicklung. (II) 11/94)

Xvision powert Sie über alle Hürden. (UO 11/94)

\subsubsection{ANSPIELUNG AUF EINE REDEWENDUNG}

Seiten, die die Welt bedeuten. (PC 3/95) [vgl. > Bretter, die die Welt bedeuten $<$ ]

\section{Listen}

2.1 Liste der Sprichwörter nach dem Stichwort und der Numerierung von Wilhelm Wander:

\section{GELD}

631 Geld regiert die Welt.

HERD

10 Eigen Herdt ist Goldes werth, ist er gleich arm, so ist er doch warm. [sic!]

11 Eigener Herd ist Geltes wert. [sic!]

HÖREN

78 Wer nicht hören will, muß fühlen.

KIND

403 Kinder brauchen strenge Zucht

\section{LEBEN}

199 Was das Leben gibt, nimmt der Tod.

200 Was das Leben uns geschenkt, das raubt der Tod alles wieder. 


\section{RAUCH}

103 Wo Rauch ist, muß auch Feuer sein.

108 Wo's Rauch gibt, da ist's Feuer nicht weit.

ROSE

46 Keine Rose ohne Dornen.

SCHEIN

4 Der Schein trügt

TRAUEN

27,28 Trau, schau. wem!

UNGLÜCK

85 Ein Unglück kommt selten allein.

WAGEN

67 Wer wagt, gewinnt

WENIGER

2 Weniger wäre mehr.

WENN

17 Wenn schon, denn schon.

WISSEN

390 Wissen macht bescheiden

391 Wissen macht frei

ZEIT

241 Die Zeiten ändern sich. 
701 Zeit ist Geld.

2.2 Liste der Sprichwörter nach Mustern (mit Stichwort und Nummer in Wanders Lexikoni)

WIE Muster

Wie man's treibt, so geht's. (TREIBEN. 30)

Wie du dein Bett machst, so magst du darauf schlafen. (BETT, 66)

WENN Muster

Wenn die Katze aus dem Haus ist, dann tanzen die Mäuse.

Wenn dem Esel zu wohl ist, geht er aufs Eis tanzen.

WO Muster

Wo gehobelt wird, da fallen Späne (HOBELN, 2)

Wo Rauch ist, muß auch Feuer sein. (RAUCH, 103)

IST Muster

Sicher ist sicher (SICHER, 6)

Gut gekaut ist halb verdaut (KAUEN, 5)

MACHEN Muster

Gelegenheit macht Diebe (GELEGENHEIT, 14)

Die Zeit macht gescheit. (ZEIT, 187)

LIEBER Muster

Lieber eine Laus im Kohl als gar kein Fleisch.

Lieber gutlos als ehrlos. 
MENSCH Muster

180 Der Mensch lebt nicht vom Brot allein

183 Der Mensch lebt nur einmal

184 Der Mensch lebt vom Menschen

2.3 Liste der Sprichwörter nach dem Sprichwörterlexikon von Beyer

Eines schickt sich nicht für alle. [nach Goethe, Beherzigung]

Man ist so alt, wie man sich fühlt.

Sich regen bringt Segen.

Wer zuerst kommt, mahlt zuerst.

2.4 Liste der englischen Sprichwörter (nach The Concise Oxford Dictionary of Proverbs) Less is more.

Charity begins at home.

2.5 Liste der sprichwörtlichen Redensarten

den ANSCHLUB verpassen

etwas auf TOUREN bringen

jemandem eins AUSWISCHEN

etwas zur BRUST nehmen

es ist alles in BUTTER

das EIS brechen 
es wird höchste EISENBAHN!

(bei) jemandem etwas EINFÄDELN

unter die HAUT gehen

HIMMEL auf Erden

im siebten HIMMEL sein

für jemanden den KOPF hinhalten

jemandem den KOPF waschen

etwas an LAND ziehen

ins NETZ gehen

aus dem RAHMEN fallen

im RAHMEN bleiben

schneller als eine gesengte SAU

SCHWARZ sehen

die STERNE vom Himmel holen

nach den STERNEN greifen

auf TOUREN bringen

auf den TRICHTER kommen

das kommt gar nicht in die TÜTE

sein blaues WUNDER erleben

2.6 Liste der Zwillingformen

mit RAT und TAT 
TÜR und TOR öffnen

2.7 Liste der neutralen Redensarten:

AUGEN machen

etwas mit anderen AUGEN sehen

auf den ersten BLICK

jemand kann EINPACKEN

eine gute FIGUR machen

auf iemanden mit dem FINGER zeigen

auf etwas FLIEGEN

auf den GESCHMACK kommen

eine neues GESICHT haben

etwas im GRIFF haben

etwas in die HAND nehmen

sich mit HÄNDEN UND FÜSSEN verständigen

HINTER jemaıdem stehen

auf den KOPF stellen

jemandem den KOPF verdrehen

KÖPFCHEN muß man haben

LEER AUSGEHEN

auf den MAGEN schlagen 


\author{
auf den PUNKT (bringen) $)^{30}$ \\ jemandem RECHT KOMMEN \\ an etwas gibt es nichts zu RÜTTELN \\ SCHARF auf etwas sein \\ in den SCHATTEN stellen \\ im SCHATTEN leben \\ mit etwas SCHRITT halten \\ jemandem die SPOREN geben \\ auf TRAB bringen \\ WILD auf etwas sein
}

2.8 Liste der phraseologischen Verbverbindungen (mit sinnentleertem Verb):

in BEGEISTERUNG versetzen

einen (freundlichen) EMPFANG bereiten

ins GESCHÄFT kommen

zum SCHWEIGEN bringen

2.9 Liste der Redewendungen

Die Zeit ist reif?

30

Diese Redensart ist vermutlich eine Übersetzung aus dem Englischen: >to (bring to) the point<. 
Jetzt wird's aber Zeit!

Nach mir / uns die Sintflut!

ein Spiel mit dem ersten Zug entscheiden

gesunder Menschenverstand

das süße Leben

graue Maus

junges Gemüse

frischer Wind

über alle Hürden

das Früchtchen

Bretter, die die Welt bedeuten 


\section{F. SCHRIFTENVERZEICHNIS}

Bausinger, Hermann. Formen der 'Volkspoesie'. Berlin, 1980: Schmidt.

Bebermeyer, Gustav. "Sprichwort". In: Reailexikon der deutschen Literaturgesschichte. Bd. IV. [Hrsg.] Klaus Kanzog und Achim Masser. Berlin/New York, 1984: Walter de Gruyter.

Beyer, Horst und Annelies. Sprichwörter und sprichwörtliche Sammlungen von I6./h. his zur Gegenwart. München, 1985: Beck.

Broich, Ulrich. "Formen der Markierung von Intertextualität". In: Interlextualität. Formen, Funktionen, anglistische Fallstudien. [Hrsg.] Broich, Ulrich und Manfred Pfister. Tübingen, 1985: Niemeyer.

Broich, Ulrich und Manfred Pfister [Hrsg.]. Intertextualität. Formen. Funktionen. anglistische Fallstudien. Tübingen, 1985: Niemeyer.

Büchman, Georg. Geflügelte Worte. München/Zürich, 1959: Droemer-Knaur. 
Linguistics. London and New York 1981: Longman.

Dreier, Wilhelm. Funktion und Ethos der Konsumwerbung. Münster, 1965: Verlag Regensberg.

Duden. Die Literatur. Mannheim, Wien, Zürich, 1980: Bibliographisches Institut.

Eco, Umberto. Einfuihrung in die Semiotik. München, 1972: Fink.

Evans, Katharine A. The portrayal of Women in German Advertising: Sociolinguistic and Didactic Perspectives. [Thesis M.A.] Ottawa, 1991: Carleton University.

Flader, Dieter. Strategien der Werbung. Kronberg/Taunus, 1976: Scriptor Verlag.

Fleischer, Wolfgang. Phraseologie der deutschen Gegenwartssprache. Leipzig, 1982: VEB Bibliographisches Institut.

Gömer, Herbert. Redensarten. Leipzig, 1986: VEB Bibliographisches Institut.

Hain, Mathilde. Sprichwort und Volkssprache. Eine volkstümlich-soziologische Dorfuntersuchung. Gießen, 1951: Wilhelm Schmitz Verlag. 
Hebel, Udo J. "Towards a Descriptive Poetics of Allusion". In: Intertextmalit!: [Ed.] Heinrich F. Plett . Berlin, New York, 1991: de Gruyter. 135-164.

Herles, Helmut. "Sprichwort und Mărchenmotiv in der Werbung". In: Zeitschrifi für Volkskunde. 62 (1966): 67-80.

Hoesterey, Ingeborg und Ulrich Weisstein [Hrsg.]. Intertextuality: Gicrman Literature and Visual Art from the Renaissance to the Twentieth Century. Columbia. S.C.. USA. 1993: Camden House.

Jakobson, Roman. "Linguistics and Poetics". In: Style in Language. [Ed.] Thomas A. Sebeok. Cambridge, 1960: MIT Press. 350-77.

Jolles, Andre. Einfache Formen. Darmstadt, 1958: Wissenschaftliche Buchgesellschaft.

Kanyó, Zoltán. Sprichwörter. Analyse einer einfachen Form. The Hague, Paris, New York, 1981: Mouton.

Kanzog, Klaus. "Spruch". In: Reallexikon der deutschen Literalurgeschichte. Bd. IV. [Hrsg.] Klaus Kanzog und Achim Masser. Berlin/New York, 1984: Walter de Gruyter.

Karrer, Wolfgang. "Titles and Mottoes as Intertextual Devices". In: Intertextuality. [Ed.]. 
Heinrich F. Plett. Berlin, New York, 1991: de Gruyter. 122-134.

Klotz, Volker. "Slogans". In: Sprache im technischen Zeitalt?r. 7 (1963): 538-546.

Kristeva. Julia. "Bakhtine, le mot, le dialogue et le roman". In: Critique. 23 (1967): 438465.

Le Bon, Gustave. Psychologie des Foules. Paris, 1963: Presses universitaires de France.

Lewandowski, Theodor. Linguistisches Wörterbuch. Heidelberg, 1984: Quelle und Meyer.

Lindner, Monika. "Integrationsformen der Intertextualität". In: Intertextualität. Formen, Funktionen, anglistische Fallstudien. [Hrsg.] Broich, Ulrich und Manfred Pfister. Tübingen, 1985: Niemeyer.

Maghoub, Fatma M. A Linguistic Study of Cairene Proverbs. Bloomington, 1968: Indiana University Press.

Mai, Hans-Peter. "Bypassing Intertextuality. Hermeneutics Textual Practice, Hypertext.". In: Plett, Heinrich, F[Ed.]. Intertextuality. Berlin, New York, 1991 : de Cruyter. 30-59. 
Mieder, Wolfgang. "Sprichwörter im modernen Sprachgebrauch". In: Mutrersprucche'. 85 (1975) 65-88.

Mieder, Wolfgang. Deutsche Sprichwörter in Literatur. Politik. Presse und W'erhung. Hamburg, 1983: Helmut Buske.

Mieder. Wolfgang. Sprichwort. Redensart, Zitat. Bern/ Frankfurt am Main/New York. 1985: Peter Lang.

Mieder, Wolfgang. Sprichwort - Wahrwort!? Frankfurt am Main/ Berlin/ New York/ Paris/ Wien, 1992: Peter Lang.

Morawski, Stefan. "The Basic Functions of Quotation". In: Sign, Language, ( 'ulture.

[Ed.] A.J. Greimas. The Hague, 1970: Mouton

Möckelmann, Jochen und Sönke Zander. Form und Funktion der Werheslogans.

Göppingen, 1970: Verlag Alfred Kümmerle.

Müller, Wolfgang. "Interfigurality. A Study on the Interdependence of Literary Figures". In: Intertextuality. [EN.] Heinrich F. Plett. Berlin, New York, 1991: de Ciruyter. 101-121.

Packard, Vance. The Hidden Persuaders. New York, 1957: David McKay 
Peukes, Gerhard. Untersuchungen zum Sprichwort im Deutschen. Berlin, 1977: Erich Sichmidt.

Pfister, Manfred. "Konzepte der Intertextualităt". In: Broich, Ulrich und Manfred Pfister [Hrsg.] Intertextwalität. Formen, Funktionen, anglistische Fallstudien. Tübingen, 1985: Niemeyer. 1-30.

Phillips, Gary A. "Sign/ Text/ Différance. The Contribution of Intertextual Theory to Biblical Criticism". In: Intertextuality.[Ed.]. Heinrich F. Plett. Berlin, New York, 1991: de Gruyter. 78-97.

Plate, Hermann. "Werbung oder Information?" In: Sprache im techrischen Zeitalter. 7 (1963): 547-557.

Plett. Heinrich F. Textwissenschaft und Textanalyse. Heidelberg, 1975: Quelle und Meyer.

Plett, Heinrich F. [Ed.]. Intertextuality. Berlin, New York, 1991: de Gruyter.

Plett. Heinrich F. "Intertextualities". In: Intertextuality. [Ed.]. Heinrich F. Plett. Berlin, New York. 1991: de Gruyter. 3-29. 
Popescu, Codruta. Anglizismen im deutschen Fachwortschatz, dargestellt an Beispiele'n aus der Computerwerbung. [Research Essay] Ottawa. 1995: Carleton University.

Redlich, Friedrich. "Sprichwort". In: Deutsche Volksdichtung. Eine Einfiuhrung. Leipzig 1987: Phillip Reclam.

Röhrich, Lutz. Lexikon der sprichwörtlichen Redensarten. Bd. 1. 1976.

Röhrich, Lutz und Wolfgang Mieder. Sprichwort. Stuttgart, 1977: Metzler.

Römer, Ruth. Die Sprache der Anzeigenwerbung. Düsseldorf, 1968: Schwann.

Ruprecht, Hans-Georg. "The Reconstruction of Intertextuality". In: Interlex/uality. [Ed.|.

Heinrich F. Plett. Berlin, New York, 1991: de Gruyter. 60-77.

Sandig, Barbara. Stilistik der deuschen Sprache. Berlin/ New York, 1986: de Gruyter.

Schlüter, Hermann. Grundkurs der Rhelorik. München, 1974: Deutscher Taschenbuchverlag.

Seiler, Friedrich. Deutsche Sprichwörterkunde. München, 1922: C.H. Beck'sche 
Verlagsbuchhandlung.

Simpson, John [Sammler]. The Concise Oxford Dictionary of Proverbs. Mitarbeit von Jennifer Speake. Oxford University Press, 1992: Oxford.

Sowinski, Bernhard. Deutsche Stilistik. Frankfurt am Main, 1972: Fischer.

Wander, Wilhelm: Deutsches Sprichwörter-Lexikon. 5 Bände. Darmstadt, 1964:

Wissenschaftliche Buchgesellschaft. 


$$
\begin{aligned}
& \underset{21 \cdot 11.96}{\text { END }} \\
& \text { FIN }
\end{aligned}
$$

